\title{
State-of-the-art report: GCL shear strength and its measurement - ten-year update
}

\author{
P. J. Fox ${ }^{1}$ and T. D. Stark $^{2}$ \\ ${ }^{1}$ Professor, Department of Structural Engineering, University of California-San Diego, La Jolla, \\ California, 92093, USA, Telephone: +1 858822 0431, Telefax: +1858822 2260,E-mail: pjfox@ucsd.edu \\ ${ }^{2}$ Professor, Department of Civil and Environmental Engineering, University of Illinois at \\ Urbana-Champaign, Urbana, Illinois, 61801, USA, Telephone: +12173337394, \\ Telefax: +1 217333 9464,E-mail: tstark@illinois.edu
}

Received 11 November 2014, revised 21 November 2014, accepted 21 November 2014

\begin{abstract}
This paper presents an invited update to our 2004 state-of-the-art report and provides a comprehensive source of information on the shear strength and shear strength testing of geosynthetic clay liners (GCLs). Essential concepts of shear stress-displacement behavior and shear strength are presented, followed by detailed discussions on the laboratory measurement of the shear strength of GCLs and GCL interfaces. The paper also provides recommendations for the selection of design strength envelopes for stability analyses and checklists to assist users in the specification of GCL shear testing programs. North American practice is emphasized and discussions are focused primarily within the context of landfill bottom liner and cover systems. Conclusions and recommendations are provided with regard to GCL shear strength behavior and current GCL strength testing practice, improvements for GCL strength testing are suggested, and future research needs are identified.
\end{abstract}

KEYWORDS: Geosynthetics, Geosynthetic clay liner, Bentonite, Shear strength, Durability, Shear test, Stability analysis, Landfill

REFERENCE: Fox, P. J. \& Stark, T. D. (2015). State-of-the-art report: GCL shear strength and its measurement - ten-year update. Geosynthetics International, 22, No. 1, 3-47.

[http://dx.doi.org/10.1680/gein.14.00030]

\section{INTRODUCTION}

Internal and interface shear strengths of geosynthetic clay liners (GCLs) are needed for static and seismic stability analyses in the design of waste containment facilities and other facilities that incorporate these materials as hydraulic barriers. These strengths warrant particular attention because bentonite, the essential component of a GCL, is a weak material after hydration and thus can provide a potential surface for instability. Reported values of GCL internal and interface shear strengths show significant variability due to variability in component materials and manufacturing processes, differences in testing equipment and procedures, and changes in the design, manufacture, and application of GCLs over time. As a result, it has long been recognized that design shear strength parameters for GCLs and other geosynthetics must be measured using project-specific materials tested under conditions closely matching those expected in the field (Koerner et al. 1986; Bove 1990; Eith et al. 1991; Koerner and Daniel 1993; Gilbert et al. 1997; Stark et al. 1998). Shear strengths of GCLs and GCL interfaces are routinely measured using laboratory shear tests and depend on many factors. Current understanding of the effect and importance of these factors has evolved over the last 10 years and significant new information on several issues has become available (e.g. dynamic shear strength, progressive failure effects, GCL conditioning, design strength envelopes and long-term shear strength). At present, there is no single source that summarizes this information with commentary.

This paper presents an invited update to our original state-of-the-art (SOA) report on the shear strength and shear strength testing of GCLs (Fox and Stark 2004). Essential concepts of shear stress-displacement and strength behavior are presented, followed by detailed discussions on laboratory measurement of the shear strength of GCLs and GCL interfaces. The latter section addresses assessment of shear test quality, specimen size, shear devices, specimen gripping surfaces, specimen selection and trimming, gap setting and multi-interface tests, normal stress selection and number of tests, conditioning stage, shearing stage, and final specimen inspection and water contents. The paper also provides recommendations 
for the selection of design strength envelopes for stability analyses and checklists to assist users in the specification of GCL shear testing programs. Natural sodium bentonite GCLs and North American practice are emphasized and discussions are focused primarily within the context of landfill bottom liner and cover systems. Conclusions and recommendations are provided with regard to GCL shear strength behavior and current GCL strength testing practice, improvements for GCL strength testing are suggested, and future research needs are identified. This paper also contains some changes in notion that the authors consider preferable to notation presented in the original SOA report.

\section{GCL PRODUCTS}

GCLs are manufactured hydraulic barriers consisting of bentonite clay bonded to a layer, or layers, of geosynthetic material. The first such products were developed in the early 1980s and consisted of sodium bentonite held between two woven geotextiles. The variety of GCL products has since greatly increased as manufacturers have attempted to improve performance and address specific applications. Nonetheless, all GCLs can be divided into unreinforced and reinforced products. Unreinforced GCLs contain no geosynthetic reinforcement across the bentonite layer and, as such, have shear strength equal to that of the bentonite. The bentonite layer for these products may contain adhesive and/or added moisture to minimize bentonite loss during transportation and installation. Unreinforced GCLs can be geotextile (GT)-supported in which case the bentonite is contained by woven (W) and/ or nonwoven (NW) geotextiles. Unreinforced GCLs can also be geomembrane (GM)-supported in which case the bentonite is glued to one side of a smooth geomembrane (GMS) or a textured geomembrane (GMX). Encapsulated GCLs are constructed by placing a second GM over an unreinforced GM-supported GCL.

Reinforced GCLs are GT-supported and can be stitchbonded (SB) or needle-punched (NP). SB GCLs contain parallel lines of stitching that run in the machine direction of the product and transmit shear stress across the geotextiles to resist shearing through the bentonite layer. NP GCLs contain fibers that extend from a NW cover GT, pass through the bentonite, and are anchored in a $\mathrm{W}$ or NW carrier GT, forming a W/NW or NW/NW product, respectively. Some NP GCLs are subjected to a heat treatment process that melts the reinforcing fibers adjacent to the anchoring geotextile. Reinforced GCLs can also be encapsulated between two textured geomembranes, which is becoming a more frequent choice for waste containment design. In this way, the bentonite is at least partially protected from hydration and will have higher average shear strength than in the fully hydrated condition. High bentonite strength, and in particular high residual strength, is important for applications in which large internal shear displacements are a realistic possibility for the GCL (e.g. seismic design).

Other types of GCLs have been developed, including a GCL with an internal structure similar to a geonet (GN) that reinforces the bentonite, reduces lateral bentonite migration due to normal stress concentrations, and provides higher tensile and internal shear strengths (Stark 1997, 1998), and a heat-treated W/NW NP GCL with a polypropylene coating applied to the woven side (Lucas 2002). Both unreinforced GT-supported and NP GCL products have been developed with a flexible membrane liner, ranging from a thin geofilm to a $0.5 \mathrm{~mm}$-thick (or thicker) GMX, laminated to one side. These products, called composite laminate GCLs, are self-contained composite liners and can be used for a variety of applications, including pond liners. More information on GCL product types can be found in Qian et al. (2002), Koerner (2012), commercial literature and websites of the various manufacturers, and the Specifier's Guide published annually by Geosynthetics magazine.

Polymer-amended bentonites have been developed for cases where ion exchange results in much higher hydraulic conductivity for natural bentonite GCLs (Trauger and Darlington 2000; Ashmawy et al. 2002; Di Emidio et al. 2011; Benson et al. 2014; Scalia et al. 2014). Ion exchange has been shown to occur for GCLs in the laboratory and field, and is generally more problematic for conditions involving low confining stress, lack of prehydration with clean water, wet/dry cycling, and ambient solutions with high ionic strength, multivalent cations, or extremes in $\mathrm{pH}$ (Shackelford et al. 2000; Kolstad et al. 2004; Meer and Benson 2007; Benson and Meer 2009; Scalia and Benson 2011). Several forms of commercial GCLs are available with different amounts and types of polymer additives, including both unreinforced and reinforced products. Polymer-amended bentonites have been shown to maintain low hydraulic conductivity for a wide range of solution concentrations known to adversely affect natural bentonite, including hyperacid and hyperalkaline solutions, and may be useful for containment of concentrated leachates that cannot be contained effectively by natural bentonite GCLs (Scalia et al. 2014). Amended bentonites are also more costly that natural bentonite and, although data is limited, may yield lower interface shear strength if the polymer extrudes into the interface.

\section{SHEAR STRESS-DISPLACEMENT BEHAVIOR}

\subsection{Shear stress-displacement relationships}

Static shear strength behavior is measured for relatively slow loading conditions and corresponds to all data in this report unless otherwise indicated. Shear stress-displacement relationships for GCLs and GCL interfaces, as obtained from short-term static shear tests, are used to determine shear strength parameters and to conduct stability analyses that yield estimates of displacement. Shear stress-displacement relationships can also provide an important indication of test data quality (Section 8.2). Figure 1 illustrates a typical relationship between shear stress $(\tau)$ and shear displacement $(\delta)$ as obtained from a laboratory direct shear test conducted on a hydrated GCL at constant shearing normal stress $\left(\sigma_{\mathrm{n}, \mathrm{s}}\right)$ and constant shear displacement rate $(R)$. Shear stress 


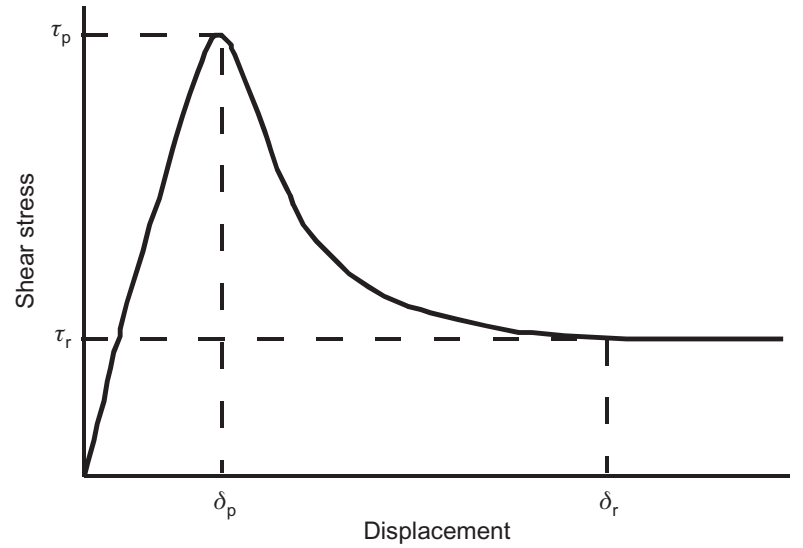

Figure 1. Typical shear stress-displacement relationship for internal shear of a hydrated GCL

increases rapidly to a peak shear strength $\left(\tau_{\mathrm{p}}\right)$ at the beginning of the test. The corresponding displacement at peak $\left(\delta_{\mathrm{p}}\right)$ is usually less than $50 \mathrm{~mm}$. In general, values of $\delta_{\mathrm{p}}$ are smallest for unreinforced GCLs, intermediate for NP GCLs, and largest for SB GCLs. GCL interfaces, such as GMX/GCL, typically yield small to intermediate values of $\delta_{\mathrm{p}}$. As displacement continues, most GCLs and GCL interfaces experience post-peak strength reduction, in which measured shear stress decreases and ultimately reaches a residual (i.e. constant minimum) shear strength $\left(\tau_{\mathrm{r}}\right)$ after which no further strength reduction occurs. The displacement associated with residual strength $\left(\delta_{\mathrm{r}}\right)$ may be as large as 0.1 to $0.5 \mathrm{~m}$ or more, depending on the material(s) and normal stress level. In cases where $\tau_{\mathrm{r}}$ is not measured in a laboratory shear device, a large displacement shear strength $\left(\tau_{\mathrm{ld}}\right)$ is often reported along with the corresponding displacement (e.g. a common notation is $\tau_{75}$ for the shear strength at $\delta=75 \mathrm{~mm})$.

Post-peak strength reduction can result from several mechanisms, including failure of GCL reinforcement or supporting geotextiles, failure of adhesive used to contain the bentonite, clay particle reorientation at the failure surface, volumetric expansion of material within the shear zone (e.g. soil), and loss of roughness for interface geosynthetic materials (e.g. GMX). Internal shear failure of NP GCLs occurs if the reinforcing fibers rupture or pull out of the geotextiles, whereas SB GCLs fail if the reinforcing stitches rupture or tear out of the geotextiles. Fiber pullout may be reduced if heat treatment or GM lamination is applied to the carrier (i.e. anchoring) GT of a NP GCL. The residual strength ratio $\left(\tau_{\mathrm{r}} / \tau_{\mathrm{p}}\right)$ for internal shear of GCLs varies widely, with reported values ranging from 0.04 to 1.0 , depending on the product type and test procedure. In general, values of $\tau_{\mathrm{r}} / \tau_{\mathrm{p}}$ increase in the following order: hydrated NP GCL $<$ hydrated SB GCL $<$ hydrated unreinforced GCL $<$ dry unreinforced GMS-supported GCL < dry unreinforced GMX-supported GCL (Fox et al. 1998a; Chiu and Fox 2004). The terms 'dry' and 'unhydrated' denote a GCL specimen tested in the as-received moisture condition. Values of $\tau_{\mathrm{r}} / \tau_{\mathrm{p}}$ for GCL interfaces are generally larger than for internal shear of hydrated reinforced GCLs.

\subsection{Unreinforced GCLs}

Two examples of shear stress-displacement $(\tau-\delta)$ relationships for internal shear of unreinforced GCLs, as obtained from direct shear tests, are shown in Figure 2a. The dry unreinforced GCL was encapsulated between two highdensity polyethylene (HDPE) GMXs with the bentonite glued to the lower GMX (specimen size $=300 \mathrm{~mm} \times$ $\left.300 \mathrm{~mm}, \sigma_{\mathrm{n}, \mathrm{s}}=96 \mathrm{kPa}, R=1 \mathrm{~mm} / \mathrm{min}\right)$. The second relationship was obtained for an unreinforced W/W GCL sheared in the fully hydrated condition (specimen size $=406 \mathrm{~mm} \times 1067 \mathrm{~mm}, \quad \sigma_{\mathrm{n}, \mathrm{s}}=72 \mathrm{kPa}$, $R=0.1 \mathrm{~mm} / \mathrm{min}$ ). The hydrated GCL has low peak shear strength and $\tau_{\mathrm{r}} / \tau_{\mathrm{p}}=0.40$. Hydrated unreinforced GCLs can sustain only small shear stresses without failure and are not appropriate for applications on slopes or applications on flat ground where shear stresses are transferred from nearby slopes (Stark et al. 1998). The dry encapsulated GCL has much higher peak and residual shear strengths and a large displacement strength ratio $\tau_{60} / \tau_{\mathrm{p}}=0.81$, indicating that significantly less post-peak strength reduction occurs in the dry condition due to the stiff consistency and resulting granular texture of the bentonite. The high residual shear strength of dry GCLs is advantageous for designs in which the GCL may be sheared beyond the peak (Section 7). Values of $\delta_{\mathrm{p}}$ are relatively small $(<10 \mathrm{~mm})$ for both unreinforced GCLs in Figure 2a.

\subsection{Reinforced GCLs}

Needle-punched or stitched reinforcement is used to transmit shear stress across the weak bentonite layer of a GCL, with the needle-punched variety being the more common choice in North America. The additional confinement provided by needle-punched fibers also decreases the water content of the hydrated bentonite and the potential for bentonite migration (i.e. squeezing), although significant migration has been observed for NP GCLs under severe loading conditions in the laboratory and field (Koerner and Narejo 1995; Fox et al. 1996; Stark 1998; Fox et al. 1998b, 2000; Shan and Chen 2003; Stark et al. 2004). The peel strength test (ASTM D 6496) is routinely used as a quality control index test in the manufacturing of NP GCLs to assess the relative strength and density of reinforcement.

Figure $2 \mathrm{~b}$ shows examples of $\tau-\delta$ relationships for internal shear of a hydrated W/NW NP GCL and hydrated $\mathrm{W} / \mathrm{W}$ SB GCL (specimen size $=406 \mathrm{~mm} \times 1067 \mathrm{~mm}$, $\left.\sigma_{\mathrm{n}, \mathrm{s}}=72 \mathrm{kPa}, R=0.1 \mathrm{~mm} / \mathrm{min}\right)$. These relationships display higher peak shear strengths than the hydrated unreinforced GCL in Figure 2(a) due to additional shear resistance provided by the geosynthetic reinforcement and lower residual strength ratios $\left(\tau_{\mathrm{r}} / \tau_{\mathrm{p}}=0.06\right.$ and 0.11 for $\mathrm{NP}$ and SB, respectively) due to failure of the reinforcement. At this normal stress, peak strength of the SB GCL is approximately one-half that of the NP GCL. The reported values of $\tau_{\mathrm{r}} / \tau_{\mathrm{p}}$ for internal strength of hydrated NP GCLs are as low as 0.04 (Fox et al. 1998a; Fox and Ross 2011), indicating that reinforced GCLs can experience very large strength reduction if the peak strength is 


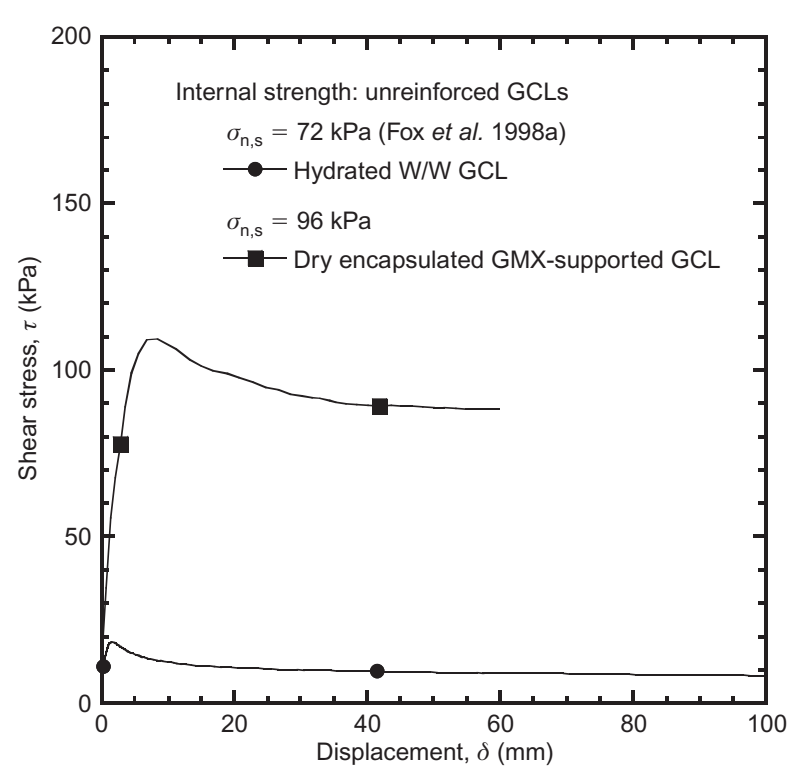

(a)

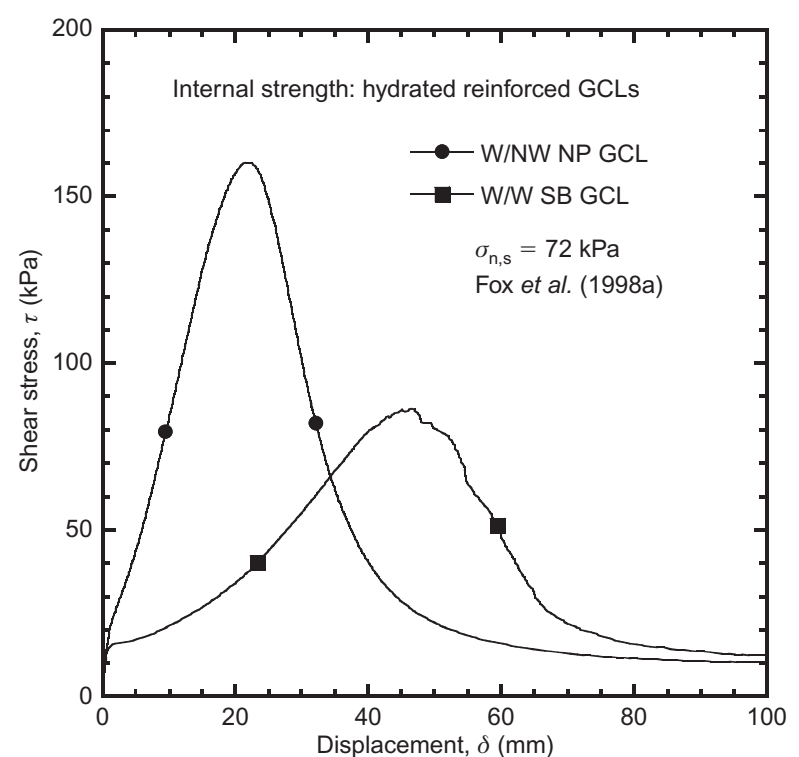

(b)

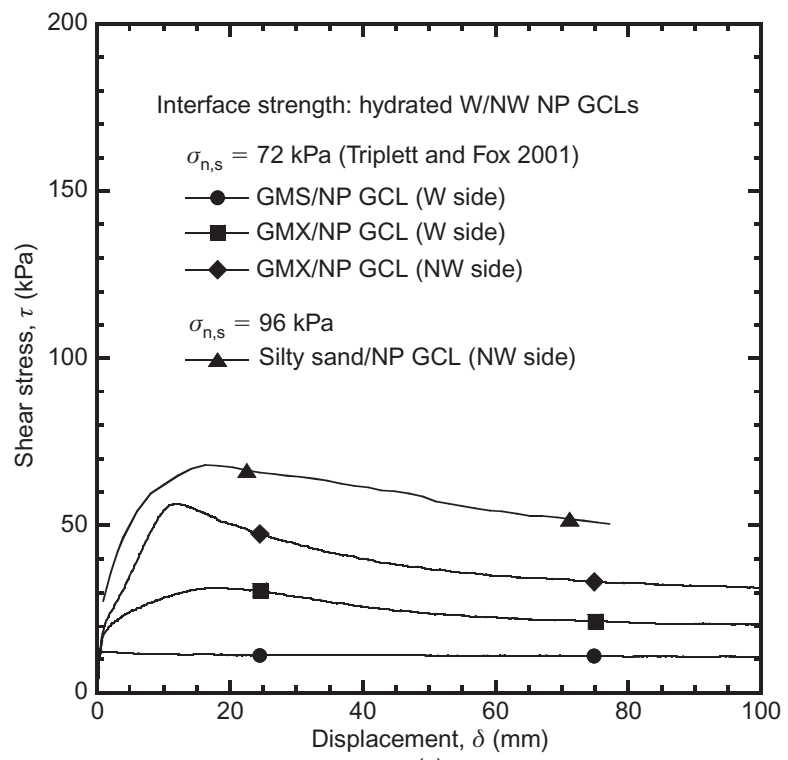

(c)

Figure 2. Shear stress-displacement relationships for:

(a) unreinforced GCLs; (b) hydrated reinforced GCLs; and (c) hydrated NP GCL interfaces exceeded. Dry NP GCLs can also experience large strength reduction at low normal stress (Feki et al. 1997; Chiu and Fox 2004). In Figure 2b, displacement at peak for the SB GCL is approximately twice that for the NP GCL. This is due to the ability of supporting geotextiles to stretch around the lines of stitching prior to tearing at the stitching (see Fuller (1995) for photograph of this effect). The essentially uniform reinforcement density for NP GCLs prevents this type of deformation, resulting in lower $\delta_{\mathrm{p}}$ values.

Based on analysis of a large database of test results, Zornberg et al. (2005) reported several findings for the internal shear strength of GCLs: (1) peak shear strengths displayed high variability, (2) NP GCLs had higher peak strengths than SB GCLs, (3) NP GCLs with NW carrier GTs had higher peak strengths than NP GCLs with W carrier GTs, and (4) heat-treated NP GCLs had slightly lower $(7 \%)$ peak strengths at low normal stress $\left(\sigma_{\mathrm{n}, \mathrm{s}}=50 \mathrm{kPa}\right)$ and slightly higher $(9 \%)$ peak strengths at high normal stress $\left(\sigma_{\mathrm{n}, \mathrm{s}}=300 \mathrm{kPa}\right)$ than NP GCLs with no heat treatment. This latter finding suggests that heat treatment of reinforcing fibers may be more effective for high normal stress conditions.

\subsection{Reinforced GCL interfaces}

Shear stress-displacement relationships for four NP GCL interfaces are shown in Figure 2c. Three tests were performed with HDPE geomembranes $\left(\sigma_{\mathrm{n}, \mathrm{s}}=72 \mathrm{kPa}\right)$ and one was performed with silty sand $\left(\sigma_{\mathrm{n}, \mathrm{s}}=96 \mathrm{kPa}\right)$. Interface peak strengths are smaller and interface large displacement strengths are larger than corresponding values for internal shear of reinforced GCLs in Figure $2 b$. The relationship for the GMS/NP GCL interface has the lowest peak strength, the highest residual strength ratio $\left(\tau_{\mathrm{r}} / \tau_{\mathrm{p}}=0.82\right)$, and is nearly independent of whether shear occurs against the W or NW side of the NP GCL (Triplett and Fox 2001). As shown in Figure 2c, this independence does not hold for GMX/NP GCL interfaces. Peak and large displacement interface shear strengths are generally higher for a GMX sheared against the NW side of a NP GCL than for the W side (Daniel et al. 1998; Triplett and Fox 2001; Chiu and Fox 2004; McCartney et al. 2009). von Maubeuge and Eberle (1998) found that GMX/NP GCL (NW side) interfaces had higher shear strengths when the NP GCL was manufactured using a thicker NW GT. Differences in GM texturing process (e.g. laminated versus coextruded) have a relatively minor effect on GMX/NP GCL interface shear strength (Chiu and Fox 2004; McCartney et al. 2005). McCartney et al. (2005) also found that geomembrane asperity height was a good indicator of peak shear strength for an unhydrated GMX/ NP GCL (NW side) interface. McCartney et al. (2009) reported that GMX/GCL interface strengths are sensitive to GM flexibility with flexible GMXs (e.g. very lowdensity polyethylene) yielding higher strengths than stiffer GMXs (e.g. HDPE). A similar effect was reported by Fox et al. (2011) for linear low-density polyethylene and HDPE GMSs sheared over gravelly sand.

The $\tau-\delta$ relationships in Figure 2c indicate lower large displacement strength ratios for the GMX interfaces 
than the GMS interface, which results from higher levels of damage during shear and is consistent with the findings of Triplett and Fox (2001) and McCartney et al. (2009). Large displacement strength ratios for the GMX interfaces are higher for the $\mathrm{W}$ side $\left(\tau_{200} / \tau_{\mathrm{p}}=0.57\right)$ than the $\mathrm{NW}$ side $\left(\tau_{200} / \tau_{\mathrm{p}}=0.47\right)$. Although less published data are available, peak strengths for soil/NP GCL interfaces show significant variability depending on soil type and preparation method (Chiu and Fox 2004). The silty sand/NP GCL relationship in Figure $2 \mathrm{c}$ displays moderate post-peak strength reduction $\left(\tau_{77} / \tau_{\mathrm{p}}=0.74\right)$. Moderate to no postpeak strength reduction has been reported for shear tests conducted on dry sand/NP GCL interfaces (Garcin et al. 1995), moist silty sand/SB GCL interfaces (Feki et al. 1997), and a variety of other soil/NP GCL interfaces (Chiu and Fox 2004). The NP GCL interfaces in Figure 2c indicate $\delta_{\mathrm{p}}<20 \mathrm{~mm}$. Values of $\delta_{\mathrm{p}}$ for NP GCL interfaces can vary over a wide range and, with the exception of soil interfaces, are often lower than those for internal shear of hydrated NP GCLs (Chiu and Fox 2004).

\section{STATIC SHEAR STRENGTH}

\subsection{Total versus effective normal stress}

As with natural soils, shear strengths for GCLs and GCL interfaces are a function of the effective normal stress on the failure surface. GCLs are generally considered to be drained for static stability analyses because, although measurements have never been reported, excess pore pressures are assumed to be small in the field. There is good justification for this assumption. Encapsulated GCLs remain essentially dry after installation except where GM defects, seam defects, or panel overlaps lead to local hydration (Section 7.4). Hydrated GCLs and GCL interfaces are also unlikely to develop significant excess pore pressures after installation because: (1) GCLs are thin and are usually drained on at least one side and, (2) loading rates are typically slow relative to the rate of GCL consolidation (Gilbert et al. 1997). Possible exceptions include hydrated GCLs that are encapsulated, installed between a GM and a compacted clay liner, or under seismic loading.

Shear strengths from laboratory tests are expressed in terms of total normal stress on the failure surface. Thus, the nature of pore pressure development during shear is a critical consideration. Internal shear of hydrated NP GCLs has been consistently observed to occur at a GT/bentonite interface (Gilbert et al. 1996a; Fox et al. 1998a; Eid et al. 1999; Fox and Ross 2011). Whether or not shear-induced excess pore pressures exist on the failure surface is currently unknown as efforts to measure such pressures for W/NW NP GCLs have been largely unsuccessful (Fox et al. 1998a; Eid et al. 1999). Fox et al. (1998a) suggested that failure at the $\mathrm{W}$ GT/bentonite interface would be drained, whereas Eid et al. (1999) suggested that migration of bentonite into the W GT might reduce hydraulic conductivity and allow excess pore pressures to develop. Based on volume change and shear strength data over a wide range of normal stress levels and displacement rates,
Fox et al. (2015) and Ross and Fox (2015) concluded that excess pore pressures on the failure surface for GCL internal shear and GMX/NP GCL interface shear tests increased with increasing normal stress and displacement rate. In addition, Triplett and Fox (2001) measured small positive pore pressures for GM/NP GCL interfaces at peak shear strength. Although these inferred and measured pore pressures only provide an indication of qualitative trends, available information suggests that shear-induced excess pore pressures are non-negative at peak strength and small at large displacements. As such, the current practice of characterizing GCL shear strength parameters in terms of total normal stress and then using these parameters for drained effective stress stability analyses appears to be either appropriate or conservative.

\subsection{Shear strength envelopes}

Shear strength envelopes are prepared by conducting shear tests at different normal stress levels and plotting shear strength versus total shearing normal stress. As an example, Figure 3a shows $\tau-\delta$ relationships obtained from four internal direct shear tests of a hydrated W/NW NP GCL. The relationships are smooth and similar in shape and indicate that both $\tau_{\mathrm{p}}$ and $\tau_{\mathrm{r}}$ increase with increasing $\sigma_{\mathrm{n}, \mathrm{s}}$. Peak and residual strength envelopes, shown in Figure $3 \mathrm{~b}$, are slightly nonlinear (i.e. curved) with stress-dependent tangent friction angles that decrease with increasing $\sigma_{\mathrm{n}, \mathrm{s}}$. In general, strength envelopes for GCLs and GCL interfaces display more variety than for natural soils due to the composite nature of these materials and the potential for failure of geosynthetic components. GCL internal and interface peak strength envelopes can be linear, multilinear (e.g. bilinear), or nonlinear. Multi-linear or nonlinear relationships are often observed over a large normal stress range (Olsta and Swan 2001; Chiu and Fox 2004; Fox and Ross 2011). Residual strength envelopes for GCLs and GCL interfaces may be nearly linear (Fox et al. 1998a; Chiu and Fox 2004); however, changing failure mode for multi-interface specimens with increasing normal stress or increasing displacement rate can introduce nonlinearity and possible discontinuities (Eid and Stark 1997; Eid 2011; Fox and Ross 2011; Ross and Fox 2015).

Figure 4 shows several common relationships that can be used to characterize shear strength envelopes for GCLs and GCL interfaces. The normal stress range over which tests are conducted often dictates the degree of nonlinearity in the resulting data and the appropriate relationship that should be used. Linear envelopes are the simplest relationships and can have zero or non-zero intercepts. A multi-linear envelope, consisting of two or more line segments, gives an abrupt change in friction angle at the intersection point(s) and may reflect true shear strength behavior in some cases (e.g. Fox and Ross 2011). Nonlinear envelopes show a gradual change in tangent friction angle as shearing normal stress increases and may pass through the origin. Strength envelopes that pass through the origin (i.e. zero cohesion intercept) are typical of GCL interface shear strengths and internal shear strengths of unreinforced GCLs. It is often unclear if peak strength envelopes for reinforced GCLs actually have a non-zero 


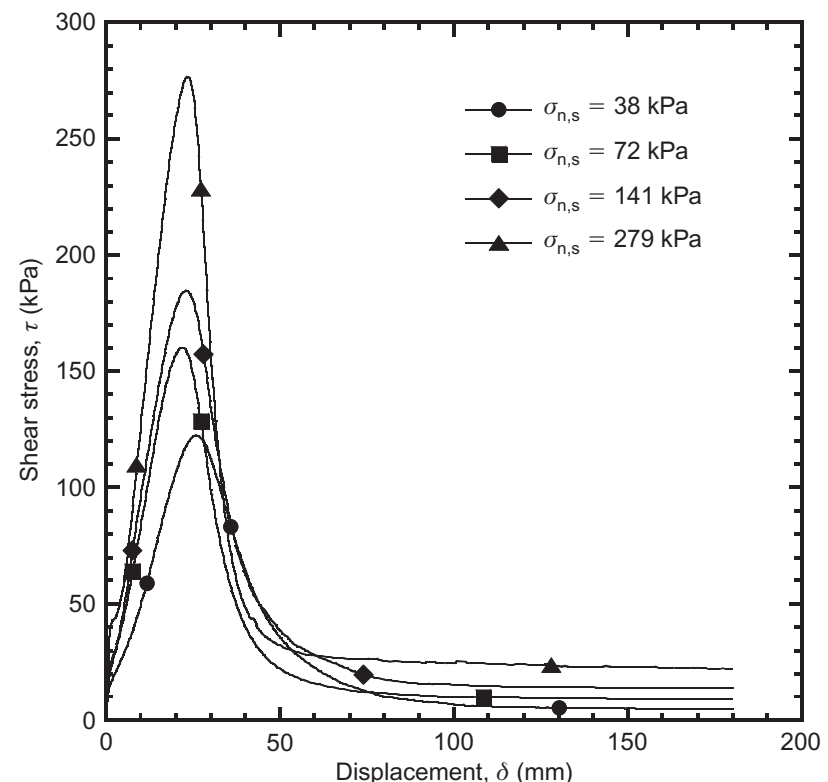

(a)

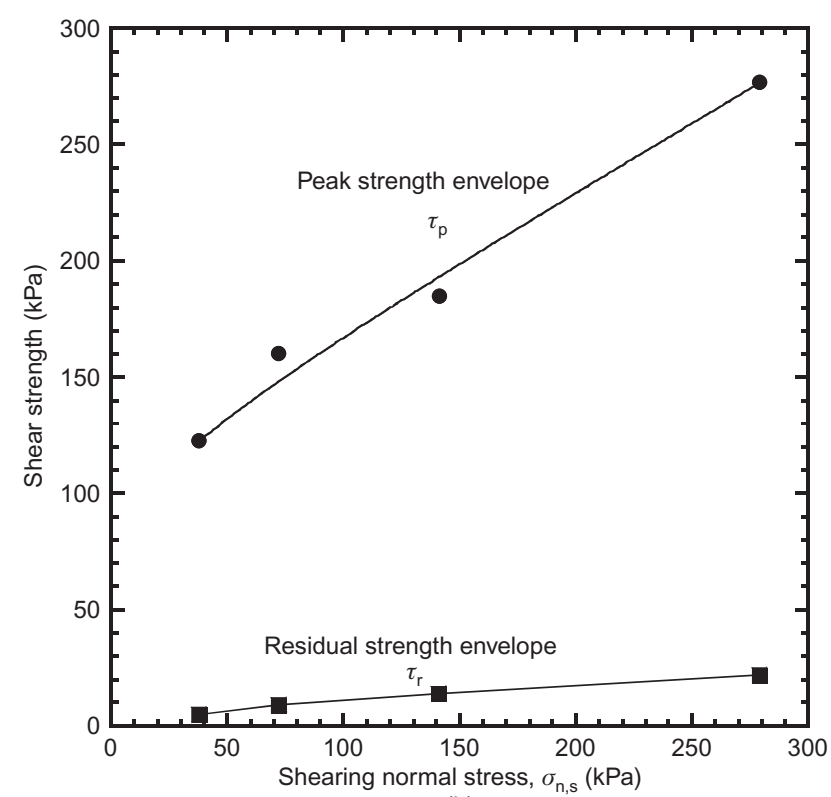

(b)

Figure 3. Internal direct shear tests of a hydrated W/NW NP GCL: (a) shear stress-displacement relationships; (b) peak and residual shear strength envelopes (Fox et al. 1998a)

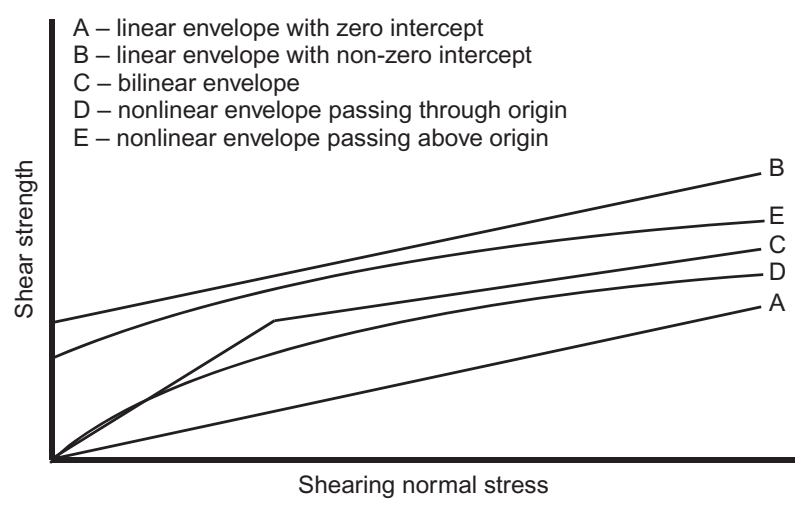

Figure 4. Common relationships used to characterize shear strength envelopes for GCLs and GCL interfaces cohesion intercept because of difficulties with adequate specimen gripping surfaces at low normal stress (Section 8.6). Interestingly, Chiu and Fox (2004) found that the nonlinear regression envelope for a large database of internal peak strengths for NP GCLs had a zero cohesion intercept. This supports the concept that entanglement of needle-punched fibers in the carrier GT is essentially a frictional mechanism (Gilbert et al. 1996a; Fox et al. 1998a). On the other hand, the reinforcement connection for SB GCLs is not frictional and thus these products would be expected to have strength envelopes with a nonzero cohesion intercept.

The familiar Mohr-Coulomb relationship is used to characterize linear and multi-linear strength envelopes. For internal shear strength, these relationships can be written as

$\tau_{\mathrm{p}}=c_{\mathrm{p}}+\sigma_{\mathrm{n}, \mathrm{s}} \tan \phi_{\mathrm{p}}$

internal peak strength envelope

$\tau_{\mathrm{ld}}=c_{\mathrm{ld}}+\sigma_{\mathrm{n}, \mathrm{s}} \tan \phi_{\mathrm{ld}}$

internal large displacement strength envelope

$\tau_{\mathrm{r}}=c_{\mathrm{r}}+\sigma_{\mathrm{n}, \mathrm{s}} \tan \phi_{\mathrm{r}}$

internal residual strength envelope

where $c_{\mathrm{p}}, c_{\mathrm{ld}}$ and $c_{\mathrm{r}}$ are the peak, large displacement, and residual cohesion intercepts and $\phi_{\mathrm{p}}, \phi_{\mathrm{ld}}$ and $\phi_{\mathrm{r}}$ are the peak, large displacement, and residual internal friction angles, respectively, for each linear segment. Corresponding relationships for interface shear strength are mathematically identical, but are written using different notation for clarity

$\tau_{\mathrm{p}}=c_{\mathrm{i}, \mathrm{p}}+\sigma_{\mathrm{n}, \mathrm{s}} \tan \phi_{\mathrm{i}, \mathrm{p}}$

interface peak strength envelope

$\tau_{\mathrm{ld}}=c_{\mathrm{i}, \mathrm{ld}}+\sigma_{\mathrm{n}, \mathrm{s}} \tan \phi_{\mathrm{i}, \mathrm{ld}}$

interface large displacement strength envelope

$\tau_{\mathrm{r}}=c_{\mathrm{i}, \mathrm{r}}+\sigma_{\mathrm{n}, \mathrm{s}} \tan \phi_{\mathrm{i}, \mathrm{r}}$

interface residual strength envelope

where the additional subscript $i$ indicates interface shear conditions. The notation in Equations 4 to 6 has been modified and, along with the use of $\delta$ instead of $\Delta$ for shear displacement, is considered preferable to notation presented in the original SOA report (Fox and Stark 2004).

Although many GCL strength envelopes are nonlinear, linear or multi-linear equations are commonly used to characterize these relationships for simplicity. In this case, $c$ and $\phi$ (or $c_{\mathrm{i}}$ and $\phi_{\mathrm{i}}$ ) are fitted to different sections of the data and thus vary with normal stress. Figure 5 illustrates several possibilities. Assume the nonlinear strength envelope (A) extending from point 1 to point 3 represents actual material strength and that the shear strength at $\sigma_{2}$ is needed for analysis. A tangent linear strength envelope (B) is drawn at point 2 with friction angle $\phi_{\tan }$ and intercept $c_{\text {tan }}$. For all normal stresses except $\sigma_{2}$, envelope B 


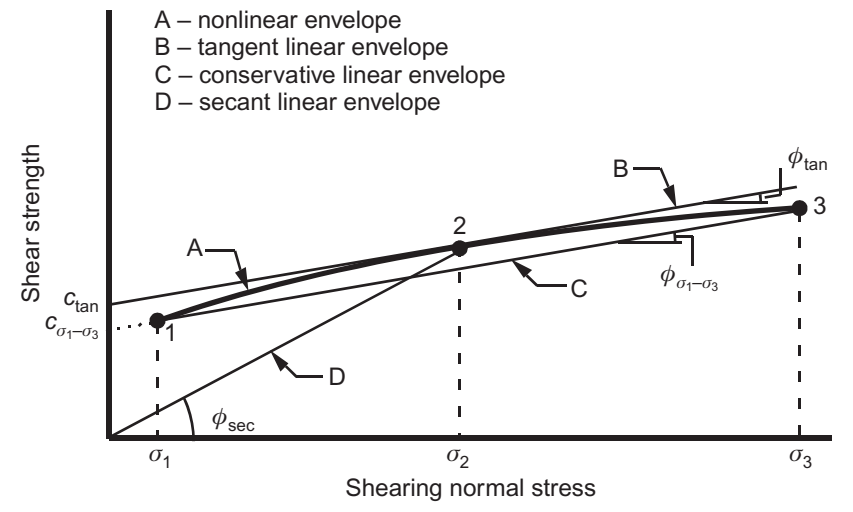

Figure 5. Linear characterization of a nonlinear shear strength envelope

overestimates the actual shear strength and is unconservative. Linear envelope $\mathrm{C}$ is drawn between endpoints 1 and 3 and has friction angle $\phi_{\sigma_{1}-\sigma_{3}}$ and intercept $c_{\sigma_{1}-\sigma_{3}}$. Envelope $\mathrm{C}$ underestimates the shear strength at $\sigma_{2}$ and represents a conservative fit to envelope $\mathrm{A}$ for the normal stress range $\sigma_{1}$ to $\sigma_{3}$. If, however, envelope $\mathrm{C}$ is extrapolated outside of this normal stress range, shear strengths will likely be overestimated. Another possibility is to define a secant friction angle $\phi_{\text {sec }}$ from the origin to point 2. The value of $\phi_{\mathrm{sec}}$ bears no resemblance to the actual material friction angle and can be used only with the normal stress for which it is defined $\left(\sigma_{2}\right)$. Finally, a bilinear envelope (not shown) can be fitted between points 1, 2, and 3, which will provide a good, yet slightly conservative, approximation to the data. Caution should always be exercised when linear equations are used to characterize nonlinear shear strength data to avoid overestimating the actual shear strength. In an attempt to limit the misuse of GCL shear strength parameters in practice, Stark (1997) suggested that subscripts be added to reflect both the level of shear displacement and the applicable range of normal stress. Examples of this notation for friction angles corresponding to peak, $\delta=50 \mathrm{~mm}$, and residual conditions and $\sigma_{\mathrm{n}, \mathrm{s}}=100$ to $300 \mathrm{kPa}$ would be $\phi_{p, 100-300 \mathrm{kPa}}, \quad \phi_{50 \mathrm{~mm}, 100-300 \mathrm{kPa}}$ and $\phi_{r, 100-300 \mathrm{kPa}}$, respectively.

Nonlinear equations can also be used to characterize nonlinear strength envelopes and thus avoid errors associated with fitting linear equations. Gilbert et al. (1996a) used the following relationship, based on the Duncan and Chang (1970) hyperbolic model, to characterize internal and GM interface shear strengths for a NP GCL

$$
\tau_{\mathrm{p}}=\sigma_{\mathrm{n}, \mathrm{s}} \tan \left[\phi_{\mathrm{o}}+\Delta \phi \log \left(\frac{\sigma_{\mathrm{n}, \mathrm{s}}}{p_{\mathrm{a}}}\right)\right]
$$

where $\phi_{0}$ and $\Delta \phi$ are constants determined from regression analysis and $p_{\mathrm{a}}$ is atmospheric pressure. Although undefined at the origin $\left(\sigma_{\mathrm{n}, \mathrm{s}}=0\right)$, Equation 7 can provide a satisfactory fit at low $\sigma_{\mathrm{n}, \mathrm{s}}$ values. Fox et al. (1998a) and Thiel et al. (2001) used the following relationship for a $p$-order hyperbola with non-orthogonal asymptotes proposed by Giroud et al. (1993)

$$
\tau_{\mathrm{p}}=a_{\infty}+\sigma_{\mathrm{n}, \mathrm{s}} \tan \delta_{\infty}-\frac{a_{\infty}-a_{\mathrm{o}}}{\left(1+\frac{\sigma_{\mathrm{n}, \mathrm{s}}}{\sigma_{\mathrm{o}}}\right)^{p}}
$$

where $a_{\infty}, \delta_{\infty}, a_{0}, \sigma_{\mathrm{o}}$ and $p$ are constants. Although Equation 8 provides more general characterization for nonlinear strength envelopes, a larger number of data points are needed to use this relationship. Nonlinear models may provide better characterization of shear strength than linear models for certain GCLs and GCL interfaces. However, extrapolation of a nonlinear model outside of the stress range for which it was developed is likewise not recommended. Such attempts may result in an overestimate or underestimate of actual strength. Shear strength parameters for both linear and nonlinear equations can be determined through regression analysis. For this to be accurate, the reliability of each data point should be approximately the same (i.e. no erroneous data included). More conservatively, an equation can be fitted as a lower bound to the data points.

An alternative to all the above equations and fitting methods is to simply use the strength envelope described by the test data directly for stability analysis (Stark et al. 2000). Many slope stability software programs allow a user to enter combinations of normal and shear stress to describe a strength envelope. The programs then linearly interpolate between data points to determine the shear resistance for normal stresses encountered along the failure surface. If the shear strength data points display a smooth trend, they can be entered directly and the method is straightforward. More difficulty is encountered if the data points display significant variability. For example, some variability is indicated for the peak strength envelope in Figure $3 \mathrm{~b}$ and is likely due to differences in needlepunched fiber density for these specimens. In such cases, direct interpolation between data points will produce a strength envelope with undulations that are not representative of average material behavior and may introduce unwanted irregularities for stability analysis. Thus, a smooth fit through the data points is needed in some cases. Stress coordinates representing the smooth envelope can then be entered into a software program instead of the actual data points.

\subsection{Unreinforced GCLs}

The drained shear strength of hydrated sodium bentonite is the lowest of any natural soil (Mesri and Olson 1970). Shan and Daniel (1991) conducted direct shear tests on a hydrated unreinforced W/W GCL and reported peak shear strength parameters of $c_{\mathrm{p}}=4 \mathrm{kPa}$ and $\phi_{\mathrm{p}}=9^{\circ}$. Subsequent studies have reported similarly low strength parameters for unreinforced GCLs in the hydrated condition. Peak and residual strength envelopes obtained from torsional ring shear tests on a GMS-supported GCL are shown in Figure 6 and yield secant friction angles of 8 and $5^{\circ}$, respectively, for $\sigma_{\mathrm{n}, \mathrm{s}}=200 \mathrm{kPa}$ (Stark et al. 1998). Using direct shear tests, Fox et al. (1998a) measured $\phi_{\mathrm{p}}=10.2^{\circ}$ and $\phi_{\mathrm{r}}=4.7^{\circ}$ for an unreinforced $\mathrm{W} / \mathrm{W} \mathrm{GCL}$ (Figure 7). These residual friction angles are in close agreement with the value of $4.0^{\circ}$ measured from torsional 


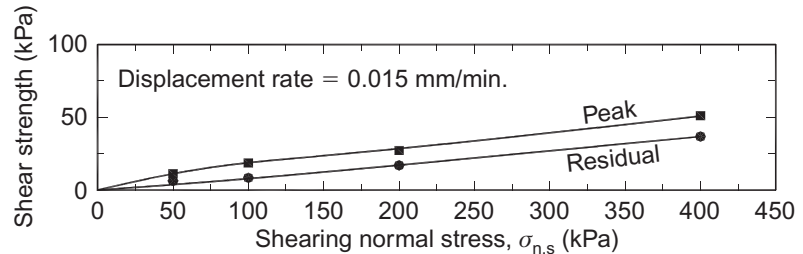

Figure 6. Peak and residual shear strength envelopes for a hydrated unreinforced GM-supported GCL (Stark et al. 1998)

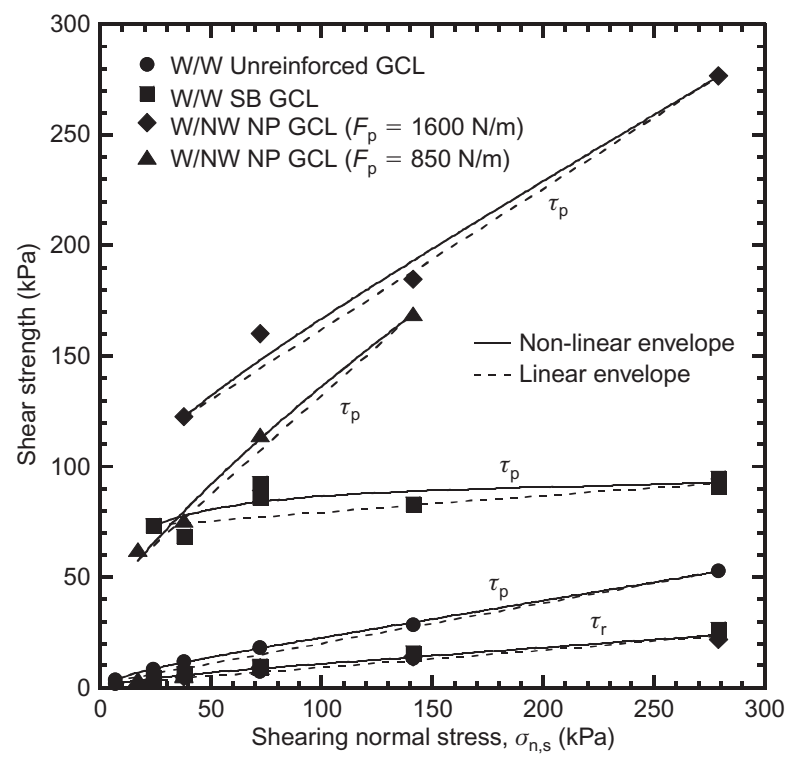

Figure 7. Peak and residual shear strength envelopes for hydrated unreinforced, SB, and NP GCLs (Fox et al. 1998a)

ring shear tests on hydrated sodium montmorillonite (Müller-Vonmoos and Løken 1989) and the lower-bound strength envelope for GCLs $\left(\phi_{\mathrm{r}}=5^{\circ}\right)$ defined by Gilbert et al. (2004).

Encapsulating unreinforced bentonite between two geomembranes will significantly reduce the amount of bentonite hydration and produce higher shear strength and lower susceptibility for bentonite migration (Stark 1998; Thiel et al. 2001). Chiu and Fox (2004) showed that dry unreinforced GMX-supported GCLs generally have slightly lower internal peak strengths and much higher residual strengths than hydrated NP GCLs. The main design issue for unreinforced encapsulated GCLs thus becomes the amount of bentonite hydration that is expected, on average, over the life of a facility. Once established, stability analyses can be conducted using prorated peak and residual strength envelopes based on the estimated ratio of dry and hydrated areas for the encapsulated GCL (Section 7.4).

\subsection{Reinforced GCLs}

Geosynthetic reinforcement greatly increases the peak shear strength of hydrated GCLs. Figure 7 shows peak and residual strength envelopes for a W/W SB GCL and two W/NW NP GCLs (Fox et al. 1998a). The NP GCL specimens were taken from two rolls of the same commercial product having peel strengths $\left(F_{\mathrm{p}}\right)$ of 850 and $1600 \mathrm{~N} / \mathrm{m}$. Corresponding strength envelopes for an un- reinforced W/W GCL are also shown for comparison. All GCL specimens were hydrated under the shearing normal stress using the two-stage accelerated conditioning procedure (Section 8.10.5). Each data set was fitted with a nonlinear strength envelope using Equation 8 and a linear strength envelope between the endpoints of the nonlinear envelope. The nonlinear envelopes are slightly curved (concave down), and thus the linear envelopes are conservative over the indicated normal stress range.

The unreinforced GCL has the lowest peak shear strength at any normal stress and the corresponding linear envelope is defined by $c_{\mathrm{p}}=2.4 \mathrm{kPa}$ and $\phi_{\mathrm{p}}=10.2^{\circ}$. Peak strength for the SB GCL increases slightly with increasing normal stress for $\sigma_{\mathrm{n}, \mathrm{s}}<72 \mathrm{kPa}$ and is nearly constant at approximately $90 \mathrm{kPa}$ for $\sigma_{\mathrm{n}, \mathrm{s}}>72 \mathrm{kPa}$. When peak strength of the hydrated bentonite was subtracted from that of the SB GCL, the contribution of stitched reinforcement to peak strength was found to be essentially independent of normal stress and solely dependent on tearing strength of the woven geotextiles (Fox et al. 1998a). Thus, the increase of peak strength with normal stress for the SB GCL in Figure 7 resulted from increased shear strength of the W GT/bentonite interface. Peak shear strength for the NP GCL increases sharply with increasing normal stress and shows good correlation with peel strength. Shear strength parameters (linear envelope) for $F_{\mathrm{p}}=850 \mathrm{~N} / \mathrm{m}$ are $c_{\mathrm{p}}=42.3 \mathrm{kPa}$ and $\phi_{\mathrm{p}}=41.9^{\circ}$, and values for $F_{\mathrm{p}}=1600 \mathrm{~N} / \mathrm{m}$ are $c_{\mathrm{p}}=98.2 \mathrm{kPa}$ and $\phi_{\mathrm{p}}=32.6^{\circ}$. This lends further support to the concept that needle-punched fiber connections are frictional in nature (Section 4.2) and is consistent with the findings of Heerten et al. (1995), Richardson (1997), von Maubeuge and Eberle (1998), von Maubeuge and Lucas (2002) and Rouncivell and Scheele (2008). Athanassopoulos and Yuan (2011) also reported that peak shear strength of a W/NW NP GCL was closely correlated with peel strength and that the relationship could be described using a power law equation. Other investigations have not reported a similar close correlation (Zornberg et al. 2005; Zornberg and McCartney 2009), which has served as a topic of discussion in the literature (Fox 2006; Koerner 2006; Zornberg et al. 2006). The bonding strength measured from a shear tensile test has likewise been investigated as a possible index test for internal shear strength of NP GCLs (Eichenauer and Reither 2002), although von Maubeuge and Ehrenberg (2000) reported inconsistent results with the method. Bacas et al. (2013) found good correlation between bonding strength and cohesion intercept for a W/NW NP GCL under dry conditions.

The residual strength envelope for each GCL in Figure 7 is independent of reinforcement type and equal to that of hydrated bentonite $\left(c_{\mathrm{r}}=1.0 \mathrm{kPa}, \phi_{\mathrm{r}}=4.7^{\circ}\right)$. Thus, the residual shear strength of hydrated GCLs can only be improved by increasing the residual shear strength of the hydrated bentonite. One possibility might be to incorporate a granular admixture (e.g. sand) into the bentonite layer. Fox (1998) reported that the residual strength of a hydrated unreinforced W/W GCL increased 260\% when the bentonite was mixed with 20/30 Ottawa sand (25\% bentonite $/ 75 \%$ sand by dry weight). In a related study, 
Schmitt et al. (1997) found that the peak shear strength $(\delta \leqslant 10 \mathrm{~mm})$ of sodium bentonite can be increased by mixing it with granular expanded shale. The practicality of maintaining a sufficiently uniform mixing process on a production scale, such that GCL hydraulic conductivity remains uniformly low, is uncertain. An NP GCL containing a granular soil/bentonite admixture may also encounter difficulties during the needle-punching process.

\subsection{Multi-interface GCL specimens}

A multi-interface GCL specimen is a layered test specimen consisting of a GCL and one or more additional materials, such as GMX or soil, which is sheared simultaneously (i.e. a multi-interface test) and fails along the weakest interface. Depending on the materials involved, the failure mode of a multi-interface GCL specimen for static loading conditions can change as the shearing normal stress increases. Dynamic shear tests have indicated that failure mode can also change with increasing displacement rate at constant normal stress (Section 5.4). The resulting peak strength envelope is typically multilinear or nonlinear and the residual strength envelope may contain one or more discontinuities.

The location of the failure surface within a multiinterface GCL specimen is controlled by internal peak strength of the GCL and interface peak strengths between the GCL and adjacent materials. GMs are commonly placed in contact with GCLs and, in such cases, interface sliding is more likely to occur at low normal stress as indicated by failures of the Cincinnati test plots (Daniel et al. 1998) and results from static shear tests (e.g. Triplett and Fox 2001; McCartney et al. 2009). As normal stress increases, GCL internal strength may become limiting and cause the failure surface to move into the GCL. Byrne (1994) and Gilbert et al. (1996a) reported that failure of GMX/NP GCL (W side) specimens changed from interface to internal as normal stress increased, with failure mode transition occurring at approximately 96 and $15 \mathrm{kPa}$, respectively, for the two investigations. Using similar materials, however, Triplett and Fox (2001) found no such failure mode transition for normal stresses up to $279 \mathrm{kPa}$. Recent tests on GMX/NP GCL composite liners indicated failure mode transition at a higher normal stress range of 692 to $2071 \mathrm{kPa}$ (Fox and Ross 2011). However, Lin et al. (2014) reported no internal failures of dry NP GCLs within composite liner specimens for normal stresses up to $1300 \mathrm{kPa}$. Thus, static shear tests have indicated: (1) contemporary NP GCLs have larger peak strengths than GMX/NP GCL interfaces in most cases, (2) GMX/NP GCL composite liners can experience GCL internal failure if the normal stress is sufficiently high, and (3) the normal stress at failure mode transition can vary widely, depending on materials and test conditions.

The data of Fox and Ross (2011) are worthy of closer examination. Large-scale direct shear tests were conducted on composite liner specimens consisting of a structured HDPE GMX over a hydrated NW/NW NP GCL. Stressdisplacement relationships are presented in Figure 8a and display similar behavior to the internal shear relationships in Figure 3a. The relationships do not show the same degree of self-similarity, however, because the GMX/GCL specimens experienced different failure modes depending on normal stress level. Failure of the GMX/GCL specimens occurred at the interface for $\sigma_{\mathrm{n}, \mathrm{s}}=71.9,348$ and $692 \mathrm{kPa}$. These relationships have similar shapes and strength reduction occurred as a result of damage to the GMX and the top geotextile of the GCL. For $\sigma_{\mathrm{n}, \mathrm{s}}=1382 \mathrm{kPa}$, failure occurred partially at the interface $(80 \%)$ and partially internal to the GCL (20\%), as determined by visual inspection. The more complicated failure mode for this specimen produced an unusual $\tau-\delta$ relationship in which shear stress shows some undulation and is clearly still decreasing at $\delta=200 \mathrm{~mm}$. Failure was completely internal to the GCL for $\sigma_{\mathrm{n}, \mathrm{s}}=2071 \mathrm{kPa}$. In this case, post-peak strength reduction occurred due to rupture/pullout of the needle-punched reinforcement and the large displacement strength represents a residual shear condition. Interestingly, the large displacement strength for $\sigma_{\mathrm{n}, \mathrm{s}}=1382 \mathrm{kPa}$ exceeds that for $\sigma_{\mathrm{n}, \mathrm{s}}=2071 \mathrm{kPa}$, which reflects the difference in failure mode.

Peak and large displacement strength envelopes are shown in Figure $8 \mathrm{~b}$ along with corresponding envelopes from internal shear tests of the same NW/NW NP GCL. Solid lines were obtained using regression and indicate consistent failure mode, whereas dashed lines indicate changing failure mode between points. The GCL specimens yielded higher peak shear strengths than the GMX/ GCL specimens at all normal stress levels. Peak strength envelopes for both test series are nonlinear and indicate friction angles that decrease with increasing normal stress. The peak strength envelope for GCL internal shear is well described as bi-linear using the following regression equations

$$
\begin{gathered}
\tau_{\mathrm{p}}=83.7 \mathrm{kPa}+\sigma_{\mathrm{n}, \mathrm{s}} \tan 23.7^{\circ} \quad\left(71.9 \leqslant \sigma_{\mathrm{n}, \mathrm{s}} \leqslant 692 \mathrm{kPa}\right) \\
\tau_{\mathrm{p}}=261.2 \mathrm{kPa}+\sigma_{\mathrm{n}, \mathrm{s}} \tan 9.9^{\circ} \quad\left(692 \leqslant \sigma_{\mathrm{n}, \mathrm{s}} \leqslant 2071 \mathrm{kPa}\right)
\end{gathered}
$$

The initial linear section of the GMX/GCL peak strength envelope corresponds to interface failure and is described by

$$
\tau_{\mathrm{p}}=8.2 \mathrm{kPa}+\sigma_{\mathrm{n}, \mathrm{s}} \tan 18.4^{\circ} \quad\left(71.9 \leqslant \sigma_{\mathrm{n}, \mathrm{s}} \leqslant 692 \mathrm{kPa}\right)
$$

At higher normal stress, the GMX/GCL failure mode transitions to GCL internal shear and the peak strength envelope becomes nonlinear.

The residual strength envelope for the GCL internal shear tests is linear over the entire stress range and essentially passes through the origin. The regression equation is

$$
\tau_{\mathrm{r}}=1.3 \mathrm{kPa}+\sigma_{\mathrm{n}, \mathrm{s}} \tan 4.8^{\circ} \quad\left(71.9 \leqslant \sigma_{\mathrm{n}, \mathrm{s}} \leqslant 2071 \mathrm{kPa}\right)
$$

where $\phi_{\mathrm{r}}=4.8^{\circ}$ is consistent with corresponding values measured for other hydrated GCLs (Sections 4.3, 4.4). At low normal stress, the GMX/GCL specimens failed at the interface and yielded higher large displacement strengths 


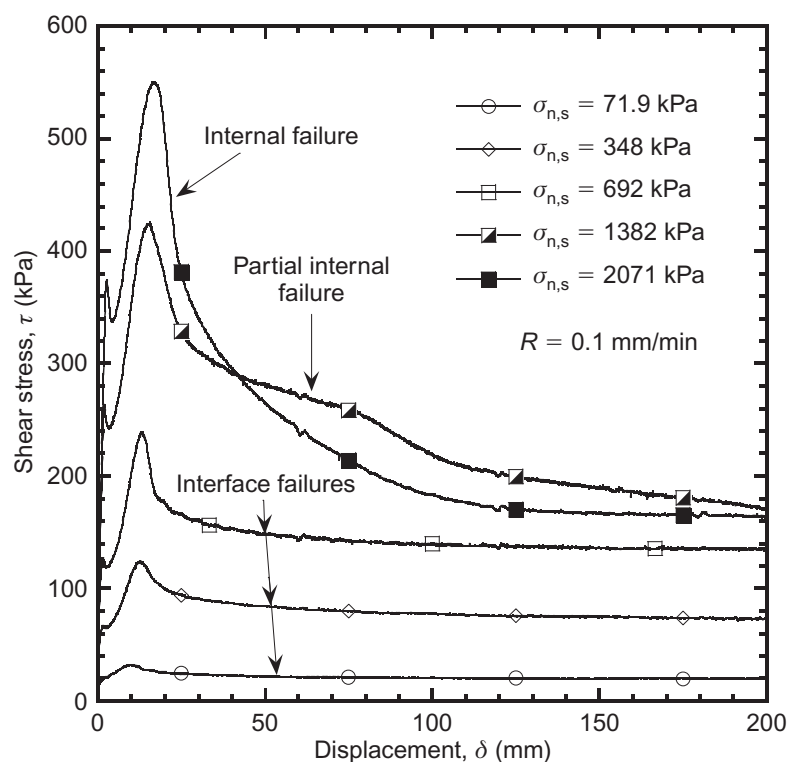

(a)

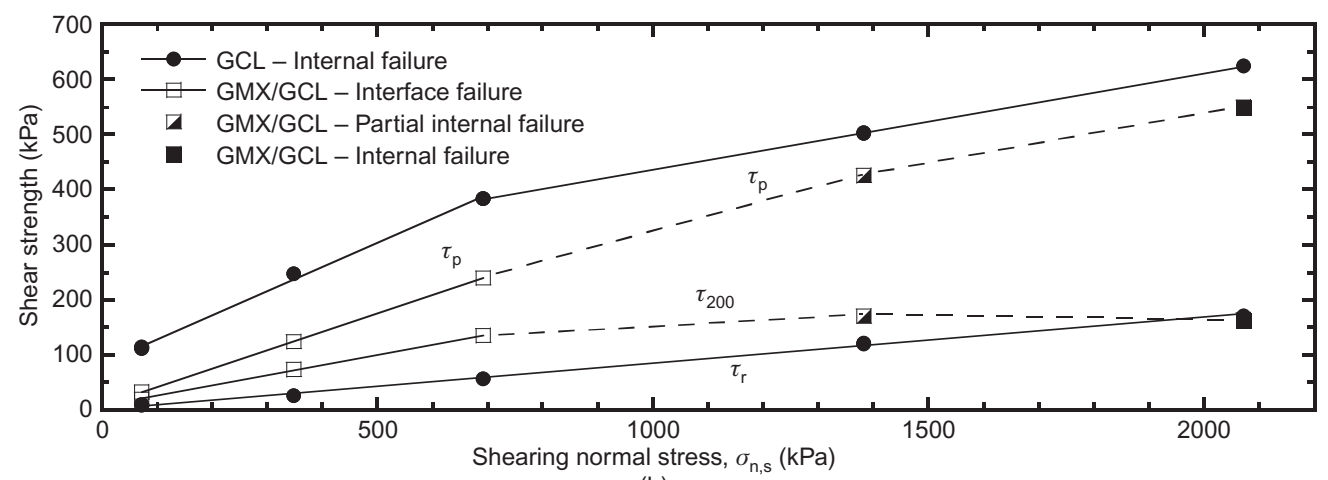

(b)

Figure 8. Multi-interface direct shear tests of a hydrated GMX/NP GCL composite liner: (a) shear stress-displacement relationships; (b) shear strength envelopes (Fox and Ross 2011)

than the GCL specimens. The corresponding linear envelope is described by

$$
\tau_{200}=7.3 \mathrm{kPa}+\sigma_{\mathrm{n}, \mathrm{s}} \tan 10.5^{\circ}\left(71.9 \leqslant \sigma_{\mathrm{n}, \mathrm{s}} \leqslant 692 \mathrm{kPa}\right)
$$

As normal stress increased, the GMX/GCL failure mode transitioned to GCL internal shear and the $\tau_{200}$ strength envelope becomes nonlinear, actually sloping downward slightly to merge with the GCL $\tau_{\mathrm{r}}$ envelope at $\sigma_{\mathrm{n}, \mathrm{s}}=2071 \mathrm{kPa}$. Considering available information, Fox and Ross (2011) concluded that hydrated HDPE GM/NP GCL interfaces generally yield higher large displacement shear strengths than hydrated NP GCLs. Based on the data of Triplett and Fox (2001), the secant large displacement friction angle for GMS/GCL interfaces is at least $7^{\circ}\left(9^{\circ}\right.$ in the McCartney et al. (2009) database) and GMX/GCL interfaces (W or NW side) will have still higher values ( $11^{\circ}$ to $15^{\circ}$ in the Fox and Ross (2011) study).

Another example illustrating the effect of failure mode transition on peak and residual strength envelopes for multi-interface GCL specimens is presented in Figure 9. Torsional ring shear tests were conducted on a dry encapsulated GCL consisting of bentonite glued to an underlying GMS and covered by a GMX (Eid and Stark 1997).

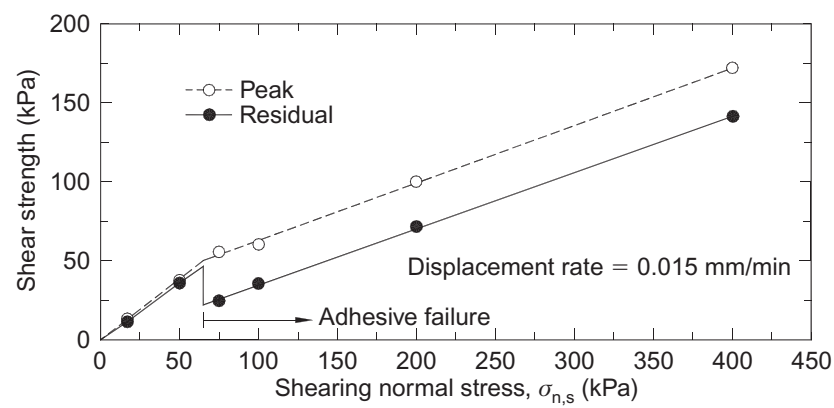

Figure 9. Peak and residual shear strength envelopes from torsional ring shear multi-interface tests of a dry encapsulated GMX/GMS-supported GCL (Eid and Stark 1997)

Failure transitioned from the GMX/bentonite interface to the bentonite/GMS interface (i.e. adhesive failure) between $\sigma_{n, s}=50$ and $75 \mathrm{kPa}$. As a result, the peak strength envelope is bilinear and the residual strength envelope displays an abrupt strength reduction corresponding the to lower shear resistance of the GMS interface. Similar failure mode transitions and strength envelopes were reported for dry encapsulated GMX/GMX-supported and faille polyvinyl chloride (PVC) GM/GMS-supported GCLs 
(Hillman and Stark 2001). Eid (2011) conducted multiinterface torsional ring shear tests on hydrated specimens of compacted silty clay overlain by an NP GCL and a GMX. For $\sigma_{\mathrm{n}, \mathrm{s}}=17$ to $400 \mathrm{kPa}$, shear strength of the composite liner system was controlled by three failure modes: GCL/soil at low $\sigma_{\mathrm{n}, \mathrm{s}}, \mathrm{GMX} / \mathrm{GCL}$ at intermediate $\sigma_{\mathrm{n}, \mathrm{s}}$, and internal GCL at high $\sigma_{\mathrm{n}, \mathrm{s}}$. The resulting peak strength envelope is trilinear and the residual strength envelope displays a strength reduction discontinuity at each failure mode transition.

Multi-interface GCL specimens can also yield higher shear strength when coarse (i.e. gravelly) soils are in close proximity to the failure surface and cause local out-ofplane deformations. Athanassopoulos et al. (2012) and Thielmann et al. (2013) measured shear strengths for composite liner specimens consisting of a coextruded HDPE GMX over a hydrated NW/NW NP GCL $\left(F_{\mathrm{p}}=2224 \mathrm{~N} / \mathrm{m}\right)$ for a wide range of normal stress, including very high stress conditions up to $4144 \mathrm{kPa}$. Two sets of direct shear tests were conducted: (1) GMX/GCL composite liners with the materials placed between rigid backing plates, and (2) GMX/GCL composite liners with the materials placed between a lower layer of compacted sand and an upper layer of coarse gravel to better replicate typical field conditions. For the first test series, interface peak secant friction angles decreased from $21.6^{\circ}$ at $\sigma_{\mathrm{n}, \mathrm{s}}=348 \mathrm{kPa}$ to $13.4^{\circ}$ at $\sigma_{\mathrm{n}, \mathrm{s}}=4144 \mathrm{kPa}$, and corresponding interface large displacement secant friction angles decreased from $7.1^{\circ}$ to $3.5^{\circ}$. Internal GCL failures were observed for $\sigma_{\mathrm{n}, \mathrm{s}} \geqslant 2072 \mathrm{kPa}$. Figure 10 presents the percentage increase for peak and large displacement shear strengths for the second test series relative to the first test series. The GMX/GCL composite liner specimens placed between soil layers produced modest increases in peak strength and large increases in large displacement strength. These strength increases occurred as a result of local out-

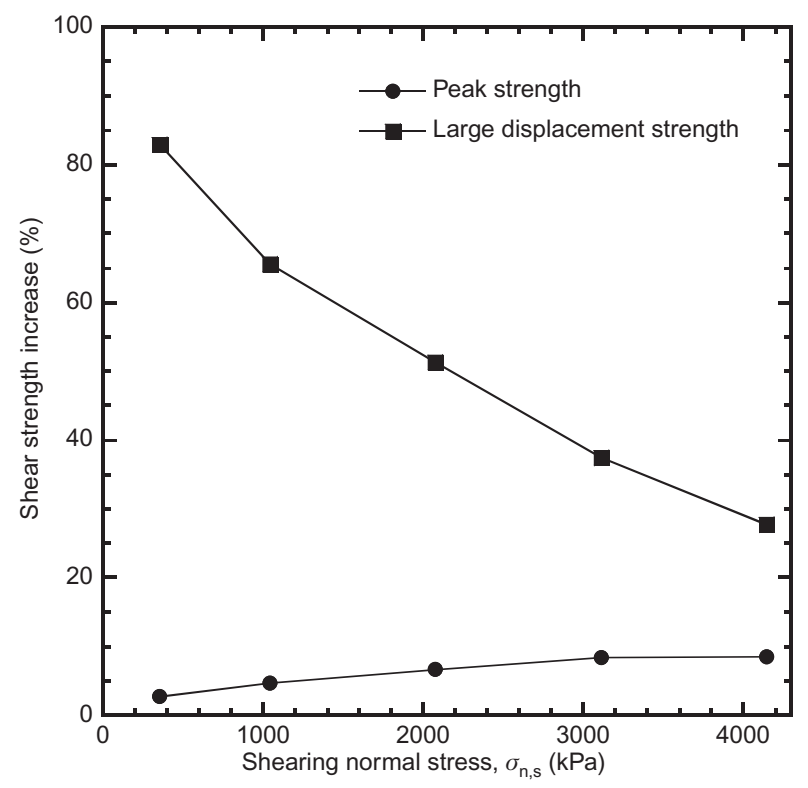

Figure 10. Increase in peak and large displacement shear strengths for a hydrated GMX/NP GCL composite liner due to local out-of-plane deformations under a gravel layer (Thielmann et al. 2013) of-plane deformation, or 'dimpling', of the liner components under the gravel particles, similar to effects reported by Breitenbach and Swan (1999) and Parra et al. (2010). The results suggest that the common practice of performing direct shear tests using rigid backing plates is conservative with regard to shear strength of GMX/GCL composite liners in contact with coarse soils.

\subsection{Strength anisotropy}

Like other geosynthetic products, the shear strength of a GCL or GCL interface may be different in the machine and transverse directions (i.e. rotated $90^{\circ}$ ). This difference has no practical significance for simple, two-dimensional slope conditions because GCLs are installed with the machine direction aligned to the slope direction. However, it may be necessary to measure transverse shear strengths for cross-seams at the base of a slope, three-dimensional failure analyses, or seismic loading that mobilizes strength in this direction. Although no information has been published for GCLs or GCL interfaces, Jones and Dixon (1998) found significant differences in $\tau-\delta$ relationships for a HDPE GMX sheared against a polypropylene GT in the machine and transverse directions. In-plane anisotropy is expected to be relatively small for internal strength of unreinforced GT-supported GCLs and NP GCLs. Internal shear strengths for encapsulated GMX-supported GCLs may show directional effects due to anisotropy of the GMX texturing.

A GCL or GCL interface may also have different peak shear strengths when sheared in opposite machine directions (i.e. rotated $180^{\circ}$ ). A particularly dramatic example of this effect is shown in Figure 11 for a SB GCL with a 101 single-thread chain stitch (Fox et al. 1998a). In this case, peak strengths differ by a factor of 1.8 for specimens sheared in opposite machine directions. Triplett and Fox (2001) found that the shear strength of GMX/NP GCL interfaces varied, on average, by $12 \%$ for specimens sheared in opposite machine directions. These results suggest that it is necessary to first determine the weakest machine direction, if one exists, for a given GCL or GCL interface. Once determined, remaining tests should be conducted in this direction since it may be difficult to ensure that GCL panels are consistently installed in the strong direction on all slopes (Smith and Criley 1995).

\subsection{Temperature effects}

Landfills typically generate heat due to aerobic and anaerobic biodegradation, exothermic chemical reactions (e.g. hydration of combustion ash, aluminum production waste, metallic wastes, and lime), and possible smoldering combustion (Martin et al. 2013). Field measurements indicate that, depending on waste type, waste density, climate, and operational conditions, landfill temperatures can typically reach as high as $60^{\circ} \mathrm{C}$ (Rowe 2005; Hanson et al. 2010; Bouazza et al. 2011). Stark et al. (2012) and Jafari et al. (2014) reported significantly higher temperatures (e.g. $120^{\circ} \mathrm{C}$ ) for aluminum production wastes that react with liquid or moisture within a landfill. In addition, Jafari et al. (2014) found that a composite liner, including a GCL component, is experiencing elevated temperatures 

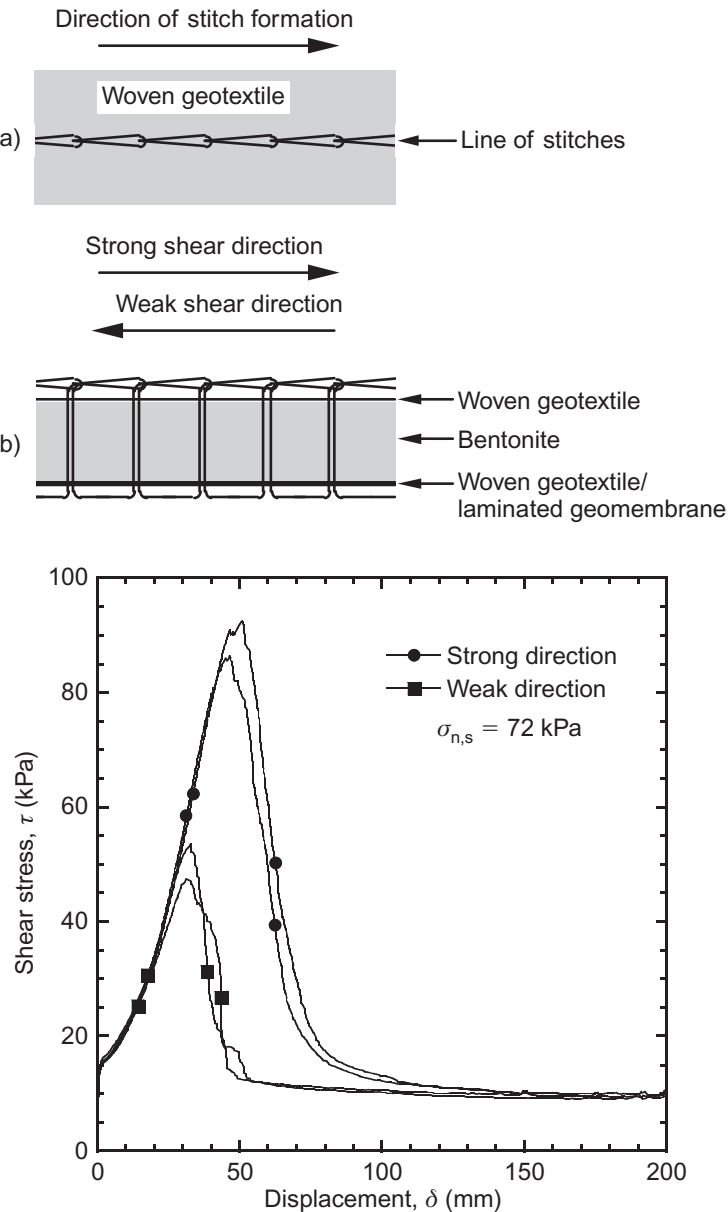

(c)

Figure 11. Shear strength anisotropy for a hydrated SB GCL: (a) plan view of stitching; (b) profile view of stitching; and c) shear stress-displacement relationships for specimens sheared in opposite machine directions (Fox et al. 1998a)

of about $85^{\circ} \mathrm{C}$. Thus, in comparison to laboratory temperatures at which shear tests are conducted, GCLs are likely to experience elevated temperatures as components of landfill bottom liner and cover systems. Although data are not available for GCLs and GCL interfaces, Akpinar and Benson (2005) investigated the effect of temperature on interface shear strength for a NW polypropylene GT sheared against a HDPE GMS and HDPE GMX using a double-interface shear device. Increasing the temperature from 0 to $33^{\circ} \mathrm{C}$ yielded an increase in peak friction angle of $2.9^{\circ}$ for the GMS/GT interface and $2.3^{\circ}$ for the GMX/ GT interface, regardless of displacement rate. Similar changes were observed for post-peak friction angles. The effect of temperature on shear strength of a GM/NP GCL (NW side) interface would be expected to follow similar trends and, if so, shear tests conducted at laboratory temperatures would yield conservative strengths. The lack of data with regard to temperature effects for shear strength of GCLs and GCL interfaces highlights the need for research on this issue.

\subsection{Strength variability}

Shear strengths of GCLs and GCL interfaces display significant variability depending on component materials and manufacturing processes, differences in testing equipment and procedures, and changes in the design, manufacture, and application of GCLs over time. Information on shear strength variability is presented by Sabatini et al. (2002), Chiu and Fox (2004), McCartney et al. (2004a), Zornberg et al. (2005) and McCartney et al. (2009). In general, good reproducibility of results was obtained for replicate tests using GCL and GM materials from the same manufacturing lots; however, significant variability, up to approximately $50 \%$, was obtained using materials from different lots. GMX/NP GCL interface strengths display less variability than internal strengths for NP GCLs (Chiu and Fox 2004). Also, shear strength variability for both NP GCLs and GMX/NP GCL interfaces has been shown to increase linearly with increasing normal stress (Zornberg et al. 2005; McCartney et al. 2009). The findings generally underscore the need for greater consideration of strength variability in design and indicate that additional shear testing is often needed to provide statistical strength data for such work.

\subsection{Other sources of shear strength information}

A complete presentation and interpretation of available data on stress-displacement and shear strength behavior for GCLs and GCL interfaces is beyond the scope of this report. In addition to many individual studies in the literature, Fox et al. (2002) and Chiu and Fox (2004) present findings from a large database of unpublished and published test data on the internal and interface shear strengths of unreinforced and NP GCLs. Zornberg et al. (2005), McCartney et al. (2009) and Zornberg and McCartney (2009) also present findings from a large database of GCL internal and GM/GCL interface shear strengths.

\section{DYNAMIC SHEAR STRENGTH}

\subsection{Importance of dynamic loading}

Waste disposal facilities and other facilities with geosynthetic liner systems are commonly constructed in seismic regions. For example, approximately one-half of the USA is classified as a seismic impact zone under Subtitle D of the Resource Conservation and Recovery Act (USEPA 1995). Design and long-term performance assessment for such facilities requires information on shear strength behavior under dynamic (i.e. high displacement rate) conditions. Dynamic shear tests have been conducted for monotonic (i.e. single direction) loading or cyclic loading. In comparison to static shear tests, a larger number of variables must be considered for dynamic shear tests, including displacement rate for monotonic tests and waveform, amplitude, frequency, and number of cycles for cyclic tests. Post-cyclic static shear strength is another important measurement for cyclic tests. Shear displacement information and degradation of strength parameters with stress reversals takes on greater significance for dynamic shear tests because such data are needed for displacement-based stability analyses (Matasovic et al. 1998). Although experimental studies on dynamic shear 
strength have been conducted for a variety of geosynthetic interfaces, including GT/GN, GM/GN, GT/GM and GM/ GM (Kavazanjian et al. 1991; Yegian and Lahlaf 1992; De and Zimmie 1998; Kim et al. 2005), data is limited for GCLs and GCL interfaces. The development of a better understanding of dynamic shear strength, including new constitutive models (e.g. Arab et al. 2012, 2013), is a current research need for GCLs.

\subsection{Unreinforced GCLs}

In the first study of GCL dynamic internal shear strength, Lai et al. (1998) performed stress-controlled cyclic simple shear tests on an unreinforced GM-supported GCL. Dry and hydrated specimens (diameter $=80 \mathrm{~mm}$ ) were subjected to normal stress levels ranging from 39 to $67 \mathrm{kPa}$ and sinusoidal excitations with a frequency of $0.09 \mathrm{~Hz}$. For the dry GCL specimens, shear strength did not degrade during 200 loading cycles for cyclic stress ratios (shear stress amplitude/static peak shear strength) less than one and post-cyclic static strength increased slightly due to bentonite densification. Cyclic shear strength of the dry specimens was also found to be independent of frequency for values between 0.09 and $0.25 \mathrm{~Hz}$. Shear strength of the hydrated GCL specimens was reduced by cyclic loading. Similar to natural clays, the number of cycles required to cause failure decreased with increasing cyclic stress ratio. For cyclic stress ratios of 0.53 or less, failure did not occur over 200 cycles of loading. For a cyclic stress ratio of 0.67 , failure occurred after 32 cycles of loading. Postcyclic static shear tests on hydrated specimens revealed no change in peak shear strength as compared to specimens that were not subjected to cyclic loading.

\subsection{Reinforced GCLs}

\subsubsection{Monotonic shear}

Nye and Fox (2007) and Fox et al. (2015) presented results from monotonic internal shear tests of a hydrated W/NW NP GCL conducted at four normal stress levels $\left(\sigma_{\mathrm{n}, \mathrm{s}}=141,348,692\right.$ and $\left.1382 \mathrm{kPa}\right)$ and seven displacement rates $(R=0.1,1,10,100,1000,10000 \mathrm{~mm} / \mathrm{min}$ and $\left.R_{\max }\right)$. The maximum displacement rate $\left(R_{\max }\right)$ ranged from $30,000 \mathrm{~mm} / \mathrm{min}$ at low normal stress to $25,000 \mathrm{~mm} /$ min at high normal stress. This range is approximately three orders of magnitude higher than the highest displacement rates used in previous investigations (Fox et al. 1998a; Eid et al. 1999; Zornberg et al. 2005) and led to complete shear failure in 0.4 to $0.5 \mathrm{~s}$. Stress-displacement relationships for $\sigma_{\mathrm{n}, \mathrm{s}}=141 \mathrm{kPa}$ are presented in Figure 12. The relationships show behavior similar to Figure $3 \mathrm{a}$ and indicate some dependency on displacement rate.

Peak shear strengths are presented in Figure 13a and, for each normal stress, increase and then decrease with increasing displacement rate. Maximum values of peak strength were obtained for $R=100$ to $10000 \mathrm{~mm} / \mathrm{min}$ and represent increases of approximately $20 \%$ above the corresponding static strength values $(R=0.1 \mathrm{~mm} / \mathrm{min})$. Beyond these maximum values, peak strengths decreased at the highest displacement rates. The trends in Figure 13a cannot be explained on the basis of excess pore pressures in the hydrated bentonite, as inferred from measured

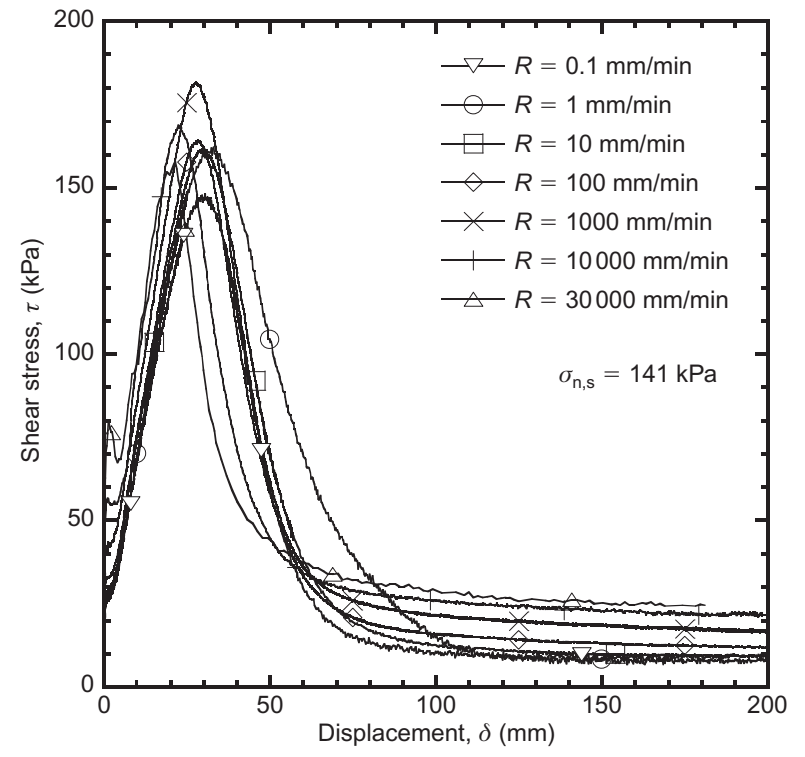

Figure 12. Shear stress-displacement relationships for monotonic shear tests of a hydrated W/NW NP GCL (Nye and Fox 2007)

volume change behavior, and suggest an increasing and then decreasing resistance of reinforcing fibers with increasing displacement rate (Fox et al. 2015). Figure 13a also indicates that, with the exception of tests performed at $\sigma_{\mathrm{n}, \mathrm{s}}=141 \mathrm{kPa}$ and $R=R_{\max }$, the standard displacement rate for static internal shear tests of hydrated GCLs ( $R=0.1 \mathrm{~mm} / \mathrm{min}$ ) yielded a conservative value of peak shear strength for each normal stress.

Corresponding residual shear strengths are presented in Figure 13b. For each normal stress, values decrease and then increase with increasing displacement rate, with a minimum at approximately $R=1 \mathrm{~mm} / \mathrm{min}$. This decreasing-increasing trend becomes more prominent with increasing normal stress. The decrease of residual strength between $R=0.1$ and $1 \mathrm{~mm} / \mathrm{min}$ is attributed to generation of positive shear-induced excess pore pressures. Beyond $R=1 \mathrm{~mm} / \mathrm{min}$, the gradual increase and then sharp increase in residual strength is attributed to rate-dependent undrained shear strength of the hydrated bentonite. Figure $13 \mathrm{~b}$ indicates that the standard displacement rate for static shear tests of hydrated GCLs $(R=0.1 \mathrm{~mm} / \mathrm{min})$ yielded unconservative values of residual shear strength, especially for higher normal stress levels.

Peak and residual strength envelopes are presented in Figure 14 and, for clarity, are drawn only for the static displacement rate $(R=0.1 \mathrm{~mm} / \mathrm{min})$ and the maximum displacement rate $\left(R=R_{\max }\right)$. Peak strength envelopes are bilinear, whereas residual strength envelopes are linear for $R=0.1 \mathrm{~mm} / \mathrm{min}$ and bilinear for $R=R_{\max }$. The static residual strength envelope has essentially zero cohesion intercept and a friction angle of $4.5^{\circ}$, which is in close agreement with published data for different types of hydrated GCLs (Sections 4.3, 4.4, 4.5). The lowermost residual strength envelope (not shown) corresponds to $R=1 \mathrm{~mm} / \mathrm{min}$ and has a low friction angle of $3.5^{\circ}$, which may reflect the presence of shear-induced excess pore pressures on the failure surface. 


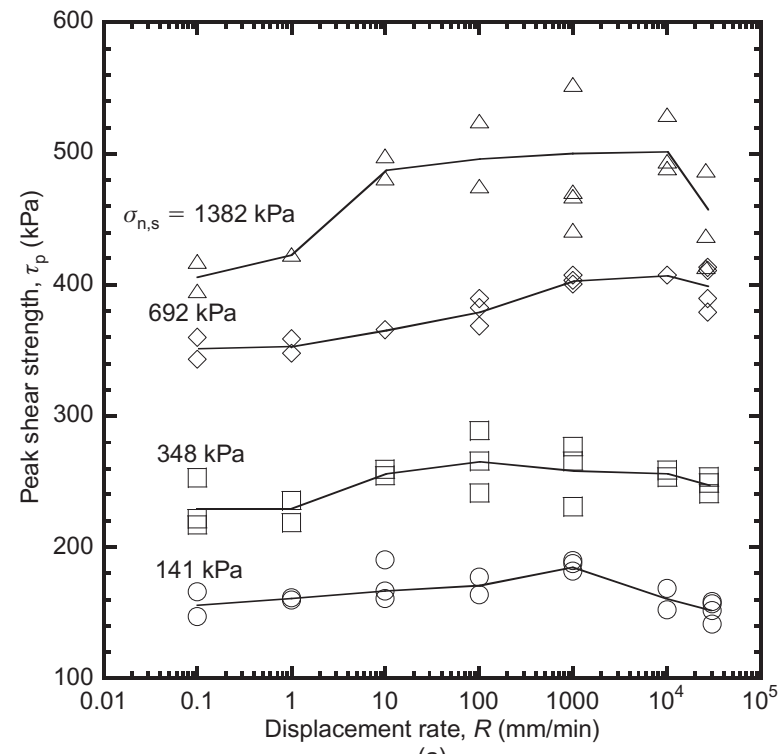

(a)

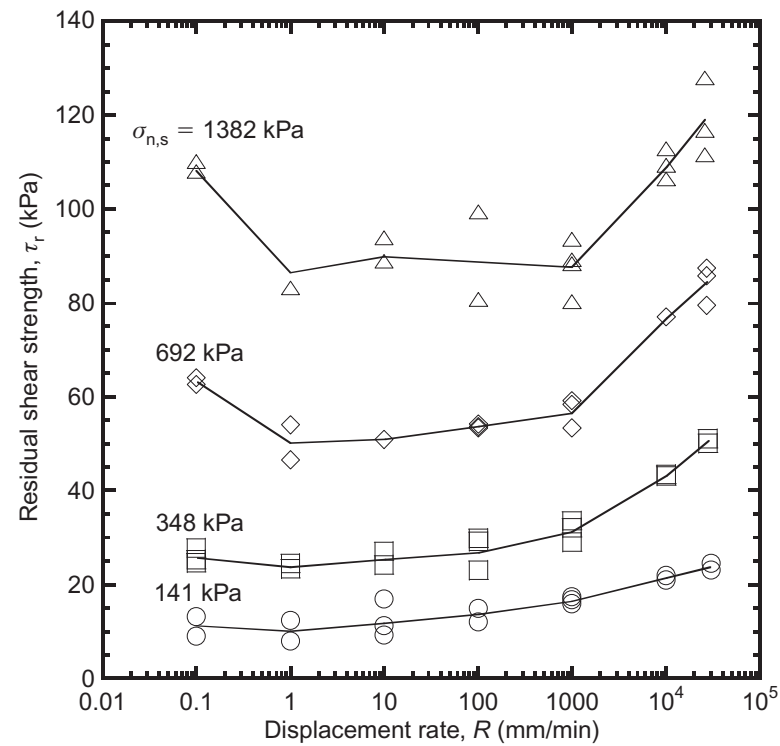

(b)

Figure 13. Monotonic shear tests of a hydrated W/NW NP GCL: (a) peak shear strengths; (b) residual shear strengths (Fox et al. 2015)

\subsubsection{Cyclic shear}

Fox et al. (2006) and Nye and Fox (2007) presented results from displacement-controlled cyclic internal shear tests conducted on the same hydrated W/NW NP GCL for $\sigma_{\mathrm{n}, \mathrm{s}}=141 \mathrm{kPa}$ and various combinations of displacement amplitude $\left(\delta_{\mathrm{a}}\right)$ and frequency $(f)$. An example of the data is shown in Figure 15 and corresponds to 50 cycles of sinusoidal displacement with $\delta_{\mathrm{a}}=15 \mathrm{~mm}$ and $f=1 \mathrm{~Hz}$. Measured shear stress for the duration of the test is shown in Figure 15a. Each loading cycle produced a maximum shear stress $\left(\tau_{\mathrm{m}}\right)$, which was equal to $130 \mathrm{kPa}$ for the first cycle and then decreased nonlinearly during subsequent cycles to a near-steady value of $37 \mathrm{kPa}$ for the 50th cycle. The plot of shear stress against displacement, shown in Figure 15b, also indicates strength degradation during cyclic loading. The hysteretic response is broadly similar to that for natural soils, although some differences are observed. The first quarter-cycle of loading $(\delta=0$ to

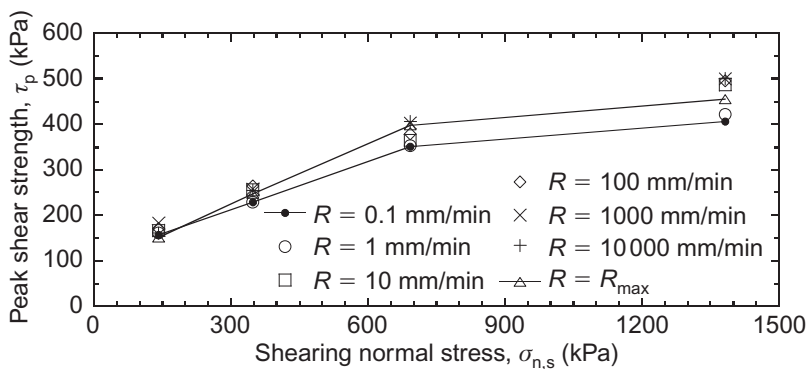

(a)

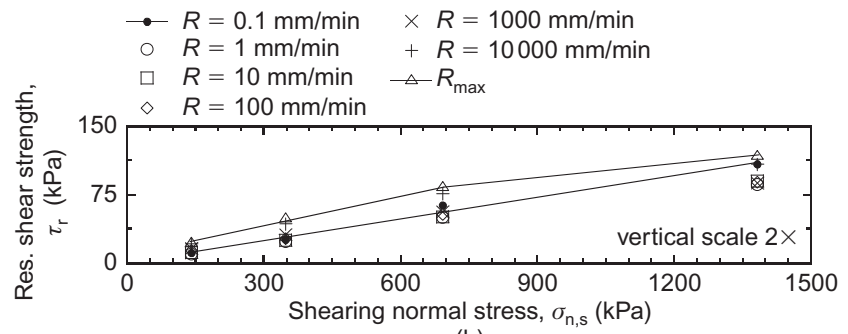

(b)

Figure 14. Shear strength envelopes for monotonic shear tests of a hydrated W/NW NP GCL: (a) peak shear strength; (b) residual shear strength (Fox et al. 2015)

$15 \mathrm{~mm}$ ) is similar to a monotonic shear test with shear stress rising to $\tau_{\mathrm{m}}$ as more needle-punched fibers become engaged with increasing displacement. Depending on the displacement amplitude, some fibers rupture or pull out of the geotextiles during this first stroke whereas others remain partially to fully intact. Upon reversal, the reinforcement relaxes and provides no resistance until it becomes re-engaged in the other direction during the third quarter-cycle $(\delta=0$ to $-15 \mathrm{~mm})$. As in Figure 15a, the progressive decrease of $\tau_{\mathrm{m}}$ indicates that the reinforcement experiences additional damage with continued cycling. Shear resistance during the middle part of each cycle corresponds to the dynamic shear strength of hydrated bentonite. This strength decreases slightly with increasing number of cycles, which may reflect progress toward a residual shear condition or generation of pore pressures on the failure surface. Dynamic bentonite strength was $24 \mathrm{kPa}$ during the 50th cycle, which is in close agreement with the monotonic residual shear strength measured at $R_{\max }$ for the same normal stress (Figure 13b) and yields a dynamic secant residual friction angle of $9.7^{\circ}$.

Cyclic loading can reduce the subsequent static shear strength for NP GCLs. Nye and Fox (2007) conducted six cyclic shear tests for $\sigma_{\mathrm{n}, \mathrm{s}}=141 \mathrm{kPa}, f=1 \mathrm{~Hz}$, and $\delta_{\mathrm{a}}$ ranging from 2 to $25 \mathrm{~mm}$. After cyclic loading, each specimen was subjected to static shear with $R=0.1 \mathrm{~mm} /$ min. Peak and residual static shear strengths are shown in Figure 16 along with corresponding data from a static shear test with no prior cycling $\left(\delta_{\mathrm{a}}=0\right)$. Larger cyclic displacement amplitude yielded progressively smaller post-cyclic static peak strength, which occurred as a result of greater damage to the needle-punched reinforcement. The reinforcement was almost completely ruptured for $\delta_{\mathrm{a}}=25 \mathrm{~mm}$, leaving the specimen with little more than residual strength afterward. Post-cyclic static residual strengths were unaffected by previous cyclic loading and yield a secant residual friction angle of $4.9^{\circ}$. 


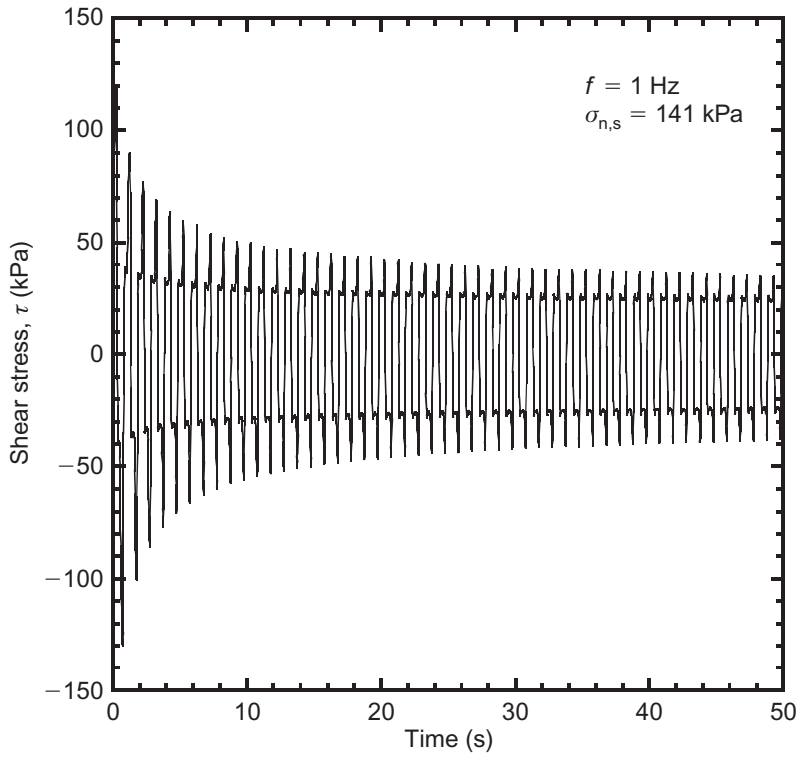

(a)

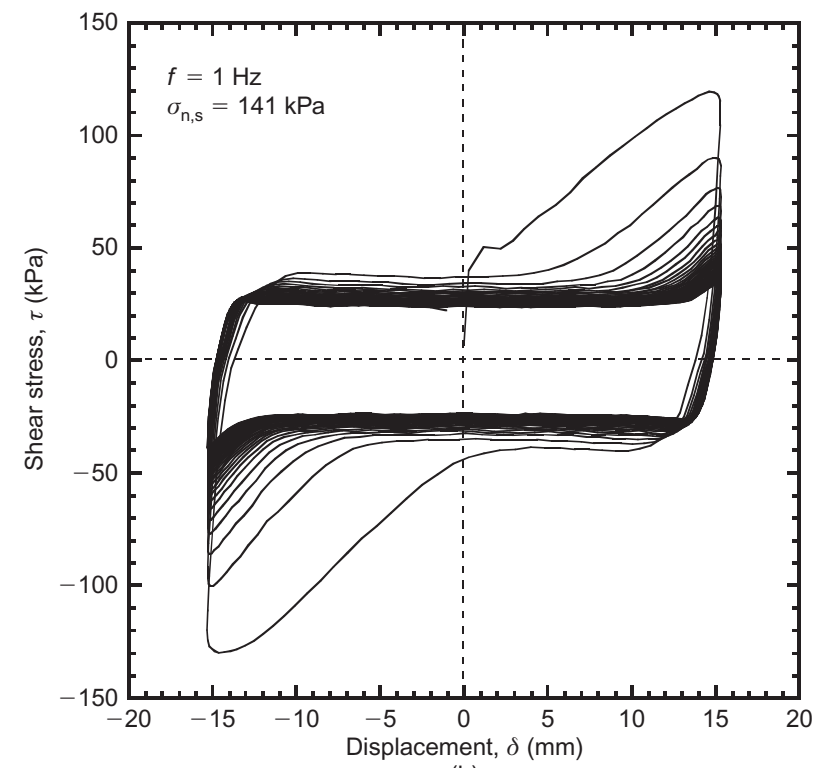

(b)

Figure 15. Cyclic shear test $( \pm 15 \mathrm{~mm})$ of a hydrated W/NW NP GCL: (a) shear stress plotted against time; (b) shear stress plotted against displacement (Fox et al. 2006)

\subsection{GMX/GCL composite liners}

\subsubsection{Monotonic shear}

Ross and Fox (2015) presented results from monotonic shear tests of a composite liner consisting of a HDPE GMX over a hydrated NW/NW NP GCL conducted at five normal stress levels $\left(\sigma_{\mathrm{n}, \mathrm{s}}=13,348,692,1382\right.$ and $2071 \mathrm{kPa})$ and five displacement rates $(R=0.1,1,100$, $10000 \mathrm{~mm} / \mathrm{min}$ and $\left.R_{\max }\right)$. $R_{\max }$ ranged from $30000 \mathrm{~mm} /$ $\mathrm{min}$ at low normal stress to $20000 \mathrm{~mm} / \mathrm{min}$ at high normal stress, and also was approximately three orders of magnitude higher than the highest displacement rates used in previous investigations (Triplett and Fox 2001; McCartney et al. 2009). Figure 17a presents peak shear strengths and indicates that failure mode of the GMX/GCL composite liners was dependent not only on normal stress as previously reported (e.g. Eid 2011; Fox and Ross 2011),

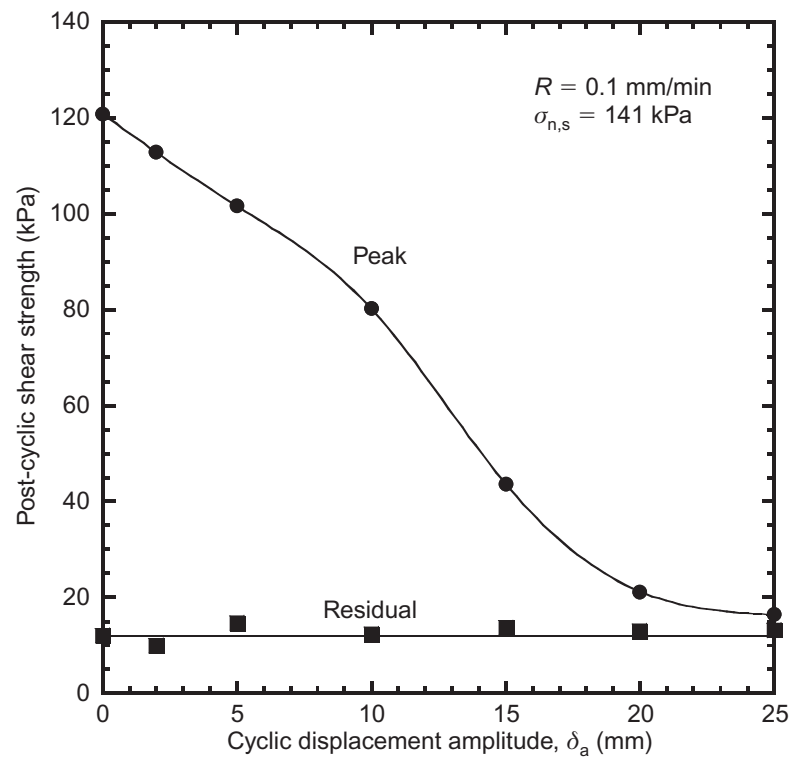

Figure 16. Post-cyclic peak and residual static shear strengths for a hydrated W/NW NP GCL (Nye and Fox 2007)

but also on displacement rate. GCL internal failures occurred at high normal stress and low displacement rate. As normal stress decreased or displacement rate increased, the failure mode transitioned to the GMX/GCL interface. The general increase of GCL internal shear strength with increasing displacement rate (Figure 13a) explains the failure mode transition observed at high normal stress levels in Figure 17a. The data also indicate that the standard displacement rate for static shear tests of GCL interfaces $(R=1 \mathrm{~mm} / \mathrm{min})$ yielded conservative values of peak shear strength.

Corresponding large displacement shear strengths are presented in Figure 17b. Displacement rate had little effect for $\sigma_{\mathrm{n}, \mathrm{s}}=13 \mathrm{kPa}$, which is in general agreement with the findings of Triplett and Fox (2001) for interface failures of similar materials at low normal stress. Large displacement strengths for $\sigma_{\mathrm{n}, \mathrm{s}}=348 \mathrm{kPa}$ are also approximately constant; however, these values decrease and then increase slightly with increasing displacement rate. For $\sigma_{\mathrm{n}, \mathrm{s}}=692 \mathrm{kPa}$, this trend becomes distinct, with a minimum value at $R=100 \mathrm{~mm} / \mathrm{min}$, and is not related to failure mode. Large displacement shear strengths measured for $\sigma_{\mathrm{n}, \mathrm{s}}=1382$ and $2071 \mathrm{kPa}$ show similar behavior and include the effects of changing failure mode. Relative to interface failures at higher displacement rates, partial to complete GCL internal failures yielded smaller values of $\tau_{200}$ due to the low strength of hydrated bentonite. At the highest stress level, the decrease of GCL internal residual strength between $R=0.1$ and $1 \mathrm{~mm} / \mathrm{min}$ is consistent with Figure 13b. The data of Figure $17 \mathrm{~b}$ indicate that the standard displacement rate for static shear tests of GCL interfaces $(R=1 \mathrm{~mm} / \mathrm{min})$ yielded unconservative values of large displacement shear strength for some normal stress conditions.

Peak and residual shear strength envelopes are presented in Figure 18 and again are drawn only for $R=1 \mathrm{~mm} / \mathrm{min}$ and $R_{\max }$. Peak strength envelopes are slightly nonlinear 


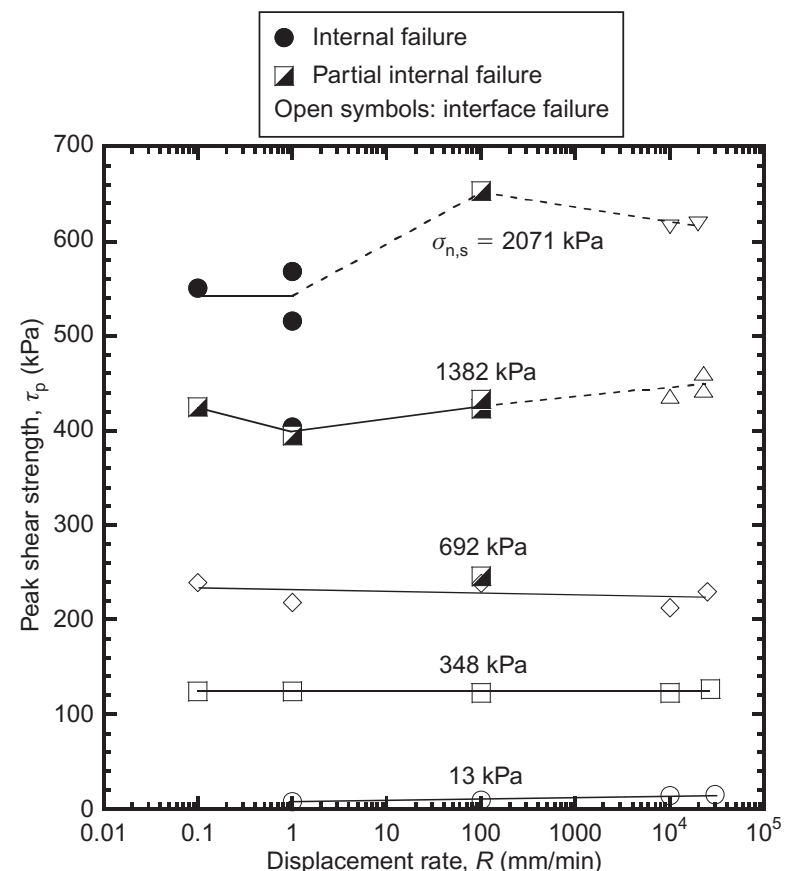

(a)

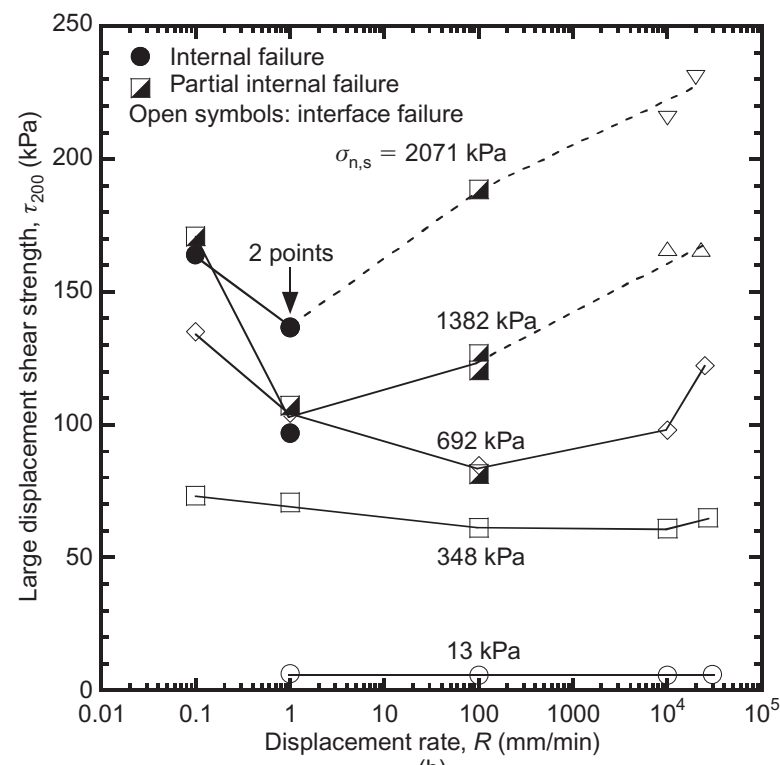

(b)

Figure 17. Monotonic shear tests of a hydrated GMX/NP GCL composite liner: (a) peak shear strengths; (b) large displacement shear strengths (Ross and Fox 2015)

(concave down) and show dependence on displacement rate at higher normal stress levels. Large displacement strength envelopes show greater dependence on displacement rate at higher normal stress due to the effect of changing failure mode. In particular, similar to Figure $8 \mathrm{~b}$, the $R=1 \mathrm{~mm} / \mathrm{min}$ envelope in Figure $18 \mathrm{~b}$ slopes downward slightly between $\sigma_{\mathrm{n}, \mathrm{s}}=692$ and $1382 \mathrm{kPa}$ as the failure mode changes from interface to internal shear.

\subsubsection{Cyclic shear}

Three studies have been conducted using shake tables to investigate the cyclic shear strength of HDPE GMS/GCL interfaces under low normal stress (Lo Grasso et al. 2002; Park et al. 2004; Kim et al. 2005). Lo Grasso et al. (2002)

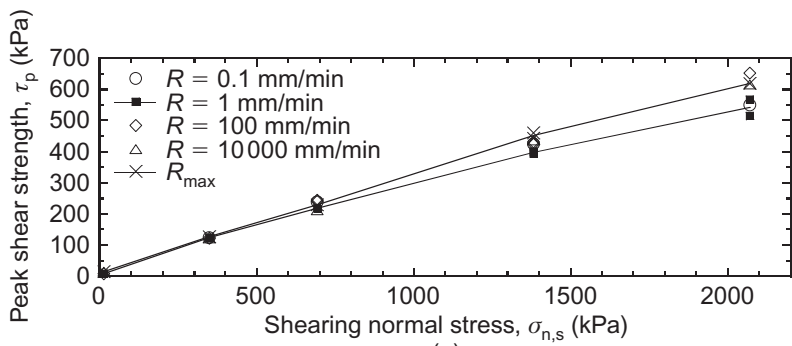

(a)

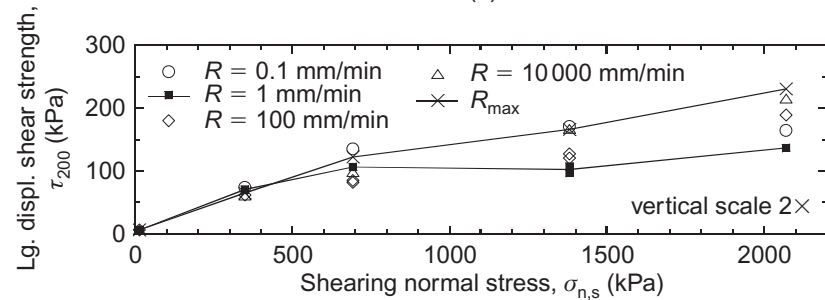

(b)

Figure 18. Strength envelopes for monotonic shear tests of a hydrated GMX/NP GCL composite liner: (a) peak shear strength; (b) large displacement shear strength (Ross and Fox 2015)

tested the interface between a GMS and W/W GTsupported GCL $\left(\sigma_{\mathrm{n}, \mathrm{s}}=3.2 \mathrm{kPa}\right)$ and reported that increasing frequency produced larger dynamic friction angles, with values of 17 and $21^{\circ}$ measured for 5 and $8 \mathrm{~Hz}$, respectively. Park et al. (2004) reported contrary results for a GMS sheared against an unreinforced GM-supported GCL and a W/NW NP GCL $\left(\sigma_{\mathrm{n}, \mathrm{s}}=1.6\right.$ to $6.8 \mathrm{kPa}, f=2$ to $10 \mathrm{~Hz}$ ). In those tests, normal stress and frequency did not affect dynamic friction angle. Kim et al. (2005) investigated the effects of displacement rate for a GMS sheared against dry and submerged (not fully hydrated) specimens of a NW/NW NP GCL $\left(\sigma_{\mathrm{n}, \mathrm{s}}=10.9\right.$ and $22.5 \mathrm{kPa})$. The tests used a cyclic triangular waveform with varying amplitudes $\left(\delta_{\mathrm{a}}=13\right.$ to $\left.127 \mathrm{~mm}\right)$ and displacement rates $(R=1$ to $10000 \mathrm{~mm} / \mathrm{min})$. To avoid the effects of progressive interface polishing for multiple tests on a single specimen, each specimen was 'presheared' prior to testing; thus, the reported data apply to large displacement shear conditions. Shear strengths for the dry specimens increased slightly with increasing displacement rate, whereas strengths for the submerged specimens were relatively insensitive to displacement rate.

Athanassopoulos et al. (2010) performed a displacement-controlled cyclic shear test of a sand/GCL/sand liner system $\left(\sigma_{\mathrm{n}, \mathrm{s}}=100 \mathrm{kPa}, \delta_{\mathrm{a}}=20 \mathrm{~mm}, f=1 \mathrm{~Hz}\right)$. The GCL was a W/NW NP product with a thin polyethylene GMS $\left(90 \mathrm{~g} / \mathrm{m}^{2}\right)$ laminated to the NW side. After 25 cycles, inspection of the failed specimen indicated that shearing occurred between the cover sand layer and geomembrane with no visible damage to the GCL. Hysteretic $\tau-\delta$ behavior of the failure surface was broadly similar to that observed for natural soils, and displayed strength and stiffness degradation as well as reduction in damping ratio with continued cycling. Precyclic and post-cyclic tests were conducted on the GCL material, including bentonite mass/area, tensile strength, peel strength, and hydraulic conductivity (with the laminated GMS removed). Test results indicated no significant 
changes in material properties and provided additional evidence that the GCL specimen did not sustain damage due to cyclic loading.

Ross et al. (2011) conducted a series of large-scale cyclic shear tests for a GMX/NP GCL (NW/NW) composite liner $\left(\sigma_{\mathrm{n}, \mathrm{s}}=13\right.$ to $2071 \mathrm{kPa}, \delta_{\mathrm{a}}=2$ to $30 \mathrm{~mm}$, $f=1 \mathrm{~Hz}$ ). With frequency held constant, the average displacement rate increased with increasing displacement amplitude. Similar to the corresponding monotonic shear tests (Figure 17a), specimen failure mode was dependent on normal stress and displacement amplitude. Interface failures occurred at low to intermediate normal stress $\left(\sigma_{\mathrm{n}, \mathrm{s}} \leqslant 692 \mathrm{kPa}\right)$ for all $\delta_{\mathrm{a}}$. At higher normal stress, partial to complete internal failures were observed for small $\delta_{\mathrm{a}}$ and interface failures were observed for large $\delta_{\mathrm{a}}$. Along with the monotonic tests, these results indicate a more complex relationship among normal stress, displacement rate and failure mode than has been previously reported for similar materials.

\section{LONG-TERM SHEAR STRENGTH}

\subsection{Importance of long-term strength}

The majority of research and essentially all design work involving shear strength of GCLs is based on data obtained from short-term strength tests in which failure occurs in minutes to hours. However, in practice GCLs are expected to sustain shear loads over time periods ranging from years to decades and often longer. For example, significant long-term shear stresses are applied to GCLs on slopes in landfill bottom liner and cover systems due to gravity forces. The implicit assumption in design is that short-term strength data are relevant to the long-term stability of GCLs. The potential difficulty is that the polypropylene- and polyethylene-based geosynthetics commonly used in GCLs are subject to creep and degradation effects, which are not evaluated by short-term tests. Creep is caused by rearrangement of polymer molecules to resist externally applied load, which can reduce the thickness of reinforcing fibers and thereby increase the tensile stress and facilitate additional creep. Polymer degradation occurs when fibers are exposed to oxygen and can accelerate creep by promoting stress cracking and reducing fiber strength. Another consideration is the effect of higher in-service temperatures on GCL creep and durability (Section 4.7). Although relatively little research has been conducted on these issues, appreciation of their importance has grown in recent years. For example, German regulations require a demonstration of 100 year strength for landfill bottom liner and cover system design (Zanzinger and Saathoff 2010), and this has provided motivation for some of the research discussed below. The development of better understanding of long-term strength is the single most important research need for shear strength of GCLs and GCL interfaces.

\subsection{Creep}

GCL creep is continuing shear displacement under constant normal and shear stress conditions. The creep stress ratio (or 'stress ratio') is defined as the applied shear stress divided by the short-term peak shear strength at the same normal stress. For low stress ratios, creep occurs at a progressively decreasing rate and ultimately leads to a stable condition. For high stress ratios, creep may begin to accelerate after a given time and lead to failure. The primary concern is that creep failure may occur for reinforced GCLs at stress ratios less than 1 due to reinforcing fibers or yarns that elongate, disentangle, rupture, or pull out of the supporting geotextiles over time.

Relatively few creep tests have been conducted on GCLs because of the difficulty and time involved. Koerner and Daniel (1993) reported that linear creep occurred for some types of hydrated NP GCLs at stress ratios less than $50 \%$ and that SB GCLs were stable under similar conditions. Heerten et al. (1995) conducted a long-term inclined plane test on a NP GCL $\left(F_{\mathrm{p}}=300 \mathrm{~N} / \mathrm{m}\right)$ for $\sigma_{\mathrm{n}, \mathrm{s}}=25 \mathrm{kPa}$ and a slope of $2 \mathrm{H}: 1 \mathrm{~V}$ and reported no failure for a test duration of $7500 \mathrm{~h}$ (313 days). von Maubeuge and Eberle (1998) also reported stable conditions for a similar test $\left(\sigma_{\mathrm{n}, \mathrm{s}}=52 \mathrm{kPa}, 2.1 \mathrm{H}: 1 \mathrm{~V}\right)$ on a NP GCL $\left(F_{\mathrm{p}}=290 \mathrm{~N} / \mathrm{m}\right)$ for a test duration of $40000 \mathrm{~h}$ (4.6 year). Direct shear creep tests were conducted by Siebken et al. (1997) and Trauger et al. (1997) for W/NW NP GCLs under incremental sustained loads. Trauger et al. (1997) also conducted an incremental-load creep test on a HDPE GMX/ NP GCL (W side) interface. The stress ratio was 90 to $99 \%$ in the Siebken et al. (1997) study, and 23 to $70 \%$ in the Trauger et al. (1997) study. For both investigations, the materials experienced relatively small shear displacements and displacement rates decreased rapidly with time to a stable condition for each load increment. Koerner et al. (2001) conducted incremental-load direct shear creep tests on one SB GCL and two NP GCLs. All three GCLs sustained stress ratios up to $60 \%$ without evidence of reinforcement pullout or rupture for test durations up to $5000 \mathrm{~h}$ (208 days).

Zanzinger and Alexiew (2002) conducted incrementalload and single-load direct shear creep tests on a SB GCL at low normal stress $\left(\sigma_{\mathrm{n}, \mathrm{s}}=20 \mathrm{kPa}\right)$. The short-term peak strengths for GCL material used in these tests were 67.6 and $54.8 \mathrm{kPa}$, respectively. Shear displacements from an incremental-load creep test with stress ratio increasing from 70 to $95 \%$ are presented in Figure 19. The GCL specimen experienced continuing creep after application of each load increment; however, no creep failure was observed. Figure 20 presents displacements and displacement rates from three single-load creep tests with stress ratios equal to 70,80 and $90 \%$. After $4800 \mathrm{~h}$ (200 days), the $90 \%$ specimen was subjected to incremental loads up to a stress ratio of $110 \%$ over a $1740 \mathrm{~h}$ (72 days) period. Ongoing creep produced increasing displacement and decreasing displacement rate with time for each stress ratio. Displacement rate decreased dramatically in the early stages of each test and increased with increasing shear stress. Interestingly, the final load (110\%) remained on the third specimen for $350 \mathrm{~h}$ without creep failure. The ability of this specimen to sustain applied shear stress higher than the short-term peak strength was attributed to stress redistribution in the reinforcement yarns over time. 


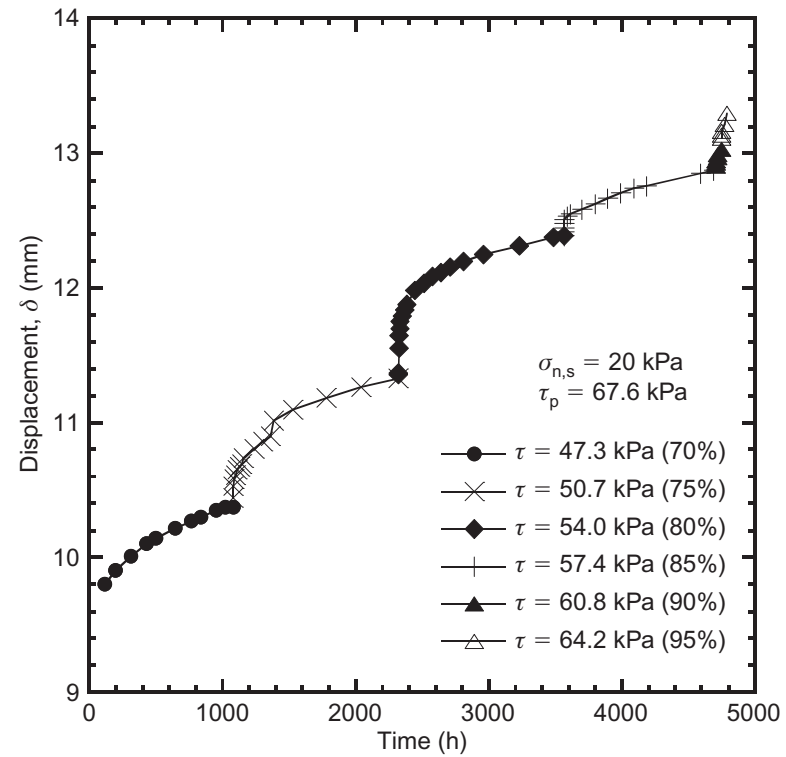

Figure 19. Incremental-load creep shear test of a hydrated SB GCL (after Zanzinger and Alexiew (2002), data used with permission)

Thies et al. (2002) investigated the effects of elevated temperature (up to $80^{\circ} \mathrm{C}$ ) on the creep behavior of hydrated specimens of four non-commercial NP GCLs. The observed time to failure was strongly dependent on temperature and did not correlate with peel strength. Based on this latter finding, Thies et al. (2002) concluded that short-term peel strength is not relevant for the assessment of long-term shear strength. In a related study, Müller et al. (2008) conducted inclined plane shear tests (2.5H:1 V) on NP GCLs using deionized water, tap water, and temperatures of 40,60 and $80^{\circ} \mathrm{C}$. GCLs tested in deionized water did not experience general ion exchange and produced times-to-failure that were dependent on fiber resin, product design, and temperature. Heat-treated GCLs experienced brittle rupture of fiber bundles near the anchoring points in the carrier geotextile, whereas nonheat-treated GCLs showed disentanglement of fiber bundles from the carrier geotextile. On the other hand, GCLs tested in tap water experienced ion exchange and did not undergo creep failure, even after 3 years of testing at $80^{\circ} \mathrm{C}$. Considering that ion exchange is expected to take place under field conditions within a few years (e.g. Meer and Benson 2007), these tests indicate ion exchange is beneficial to the long-term shear behavior of GCLs. In agreement with Thies et al. (2002), Müller et al. (2008) also found that short-term peel strength was not a reliable indicator of time-to-failure and long-term shear strength. Surprisingly, GCLs with higher peel strengths had shorter time-to-failure for the deionized water tests. Müller et al. (2008) concluded that stability design involving GCLs is questionable when based solely on short-term test results, including peel strength and short-term shear strength, and that long-term shear testing is necessary. Müller et al. $(2003,2008)$ also recommended that aging by air oven is more critical than immersion in water; however, accelerated testing by air oven may not be warranted for encapsulated GCLs due to limited oxygen availability in the field.

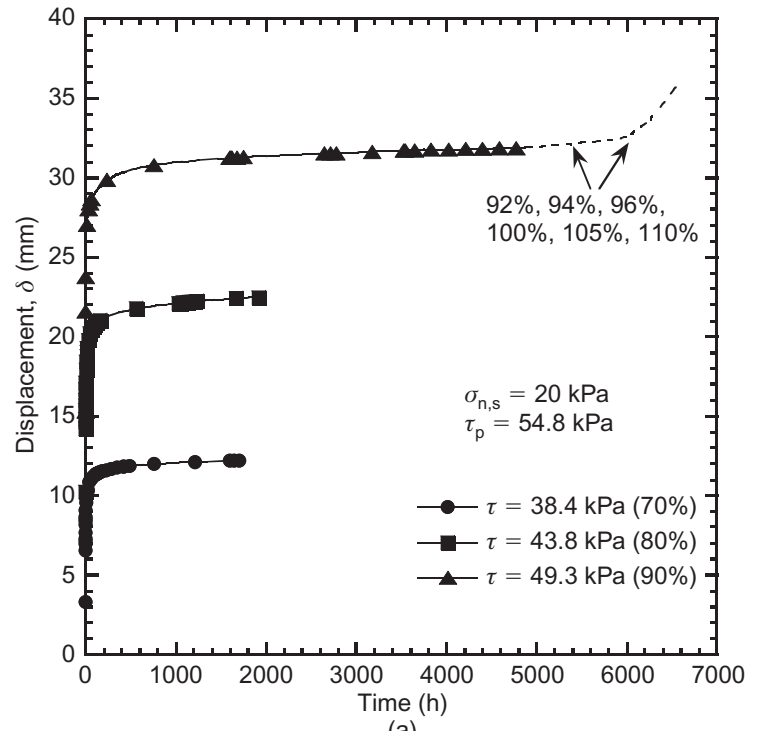

(a)

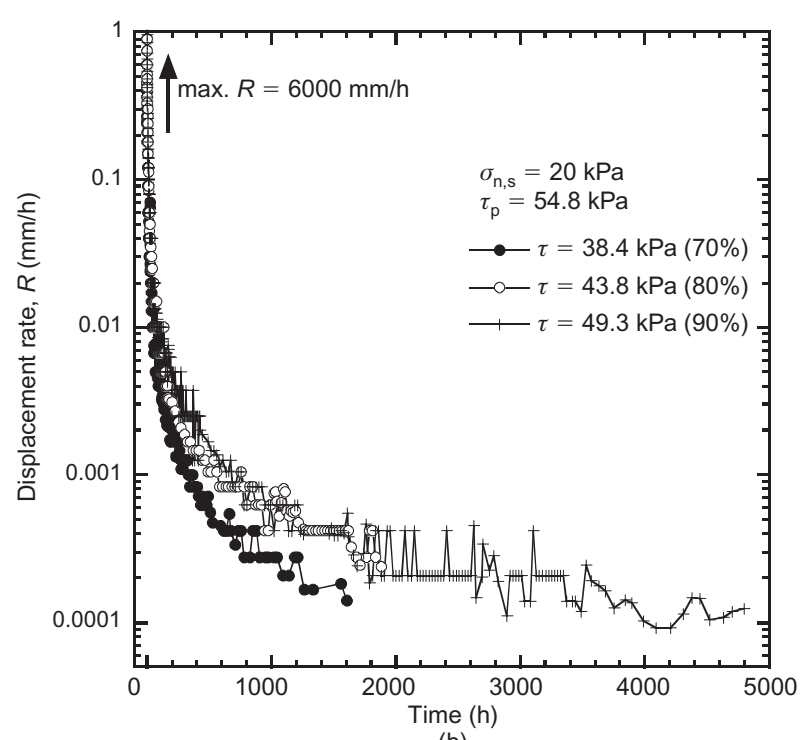

(b)

Figure 20. Single-load creep shear tests of a hydrated SB GCL: (a) displacement plotted against time; (b) displacement rate plotted against time (after Zanzinger and Alexiew (2002), data used with permission)

Zanzinger and Alexiew (2000), Koerner et al. (2001) and Zanzinger and Saathoff $(2010,2012)$ presented mathematical models for prediction of GCL creep behavior over long time periods, such as 100 years. The necessary extrapolation is typically performed using Arrhenius theory and three or more orders of magnitude in time (e.g. $1000 \mathrm{~h}$ creep test to 100 years design life), and thus the predictions involve considerable uncertainty. Additional long-term creep testing is needed for GCLs to verify and calibrate these approaches.

\subsection{Durability}

Investigations of GCL durability, or 'aging', involve the change of GCL material properties over time. Creep and aging are interrelated processes that occur simultaneously during the service life of a GCL. In this section, discussion is limited to the degradation of polymeric materials because bentonite ion exchange will only increase the 
shear strength of a GCL (Section 6.2). Discussion is further restricted to durability of reinforcing fibers which must sustain long-term tensile forces in NP GCLs, although it is recognized that stitching yarns also consist of individual fibers. Durability considerations for unreinforced GM-supported GCLs involve durability of the carrier GM. That process is better understood than the durability of tensioned reinforcing fibers in NP GCLs and is left for discussion in the GM literature.

Hsuan and Koerner (2002) presented a comprehensive summary of the physical and chemical degradation mechanisms for polypropylene and polyethylene fibers and suggested possible index and performance tests that can be used to measure these effects. The primary factors involved in fiber durability are stress level, environmental conditions (e.g. oxygen level), required lifetime, and polymer formulation (e.g. type and amount of antioxidants). Fiber diameter is also an important factor for resistance to stress cracking (Seeger et al. 2002). Thomas (2002) measured long-term oxidation effects for a NW polypropylene GT, typical of those in NP GCLs, using forced-air ovens for temperatures ranging from 70 to $100^{\circ} \mathrm{C}$ and exposure times up to 400 days. Using a second-order kinetic model, the material was predicted to retain $50 \%$ of its strength for 30 years at $20^{\circ} \mathrm{C}$. A service lifetime approaching 100 years was estimated for buried applications because the degradation rate in an $8 \%$ oxygen environment should be several times slower than the rate in air. Seeger et al. (2002) tested the degradation of over 500 individual polypropylene and polyethylene fibers in temperature-controlled $\left(60\right.$ and $\left.80^{\circ} \mathrm{C}\right)$ deionized water baths. Fiber rupture occurred after relatively small strains and load levels and often while creep rates were still decreasing. As such, failure times could not be estimated using typical extrapolation methods for creep data. Since oxidation could be ruled out for these tests, the cause of failure was concluded to be environmental stress cracking. This study illustrates the importance of performing longterm tensile tests in water for load bearing fibers that will be in contact with water during their service life.

\subsection{Field tests}

Full-scale field tests and failure investigations have played an important role in understanding the internal and interface shear behavior for GCLs (Tanays et al. 1994; Feki et al. 1997; Stark et al. 1998; Daniel et al. 1998). The advantages of such tests are that GCL shear strength is mobilized under typical field conditions that may include effects of geomembrane wrinkles, subgrade irregularities, panel overlaps, construction procedures, changing climatic conditions (e.g. wet/dry and freeze/thaw), and bentonite hydration from humidity and native soil moisture. Disadvantages of field tests include the inability to closely control test conditions and make precise load and displacement measurements for large test plots in the natural environment. For example, displacement measurement errors for wire extensometers used in field test plots were estimated as $\pm 5 \mathrm{~mm}$ by Feki et al. (1997) and $\pm 10 \mathrm{~mm}$ by Koerner et al. (1997). Thus, the ability to obtain accurate creep measurements is questionable and field test results may be limited to the obvious failure or no-failure possibilities. The other main disadvantage is the high cost and time required for construction and monitoring of field test sections.

Tanays et al. (1994) and Feki et al. (1997) presented results for a SB GCL placed on $2 \mathrm{H}: 1 \mathrm{~V}$ and $1 \mathrm{H}: 1 \mathrm{~V}$ slopes at a municipal solid waste landfill in Montreuil/Barse, France. The subgrade soil was clayey and GCL panels were anchored at the top of each slope. GCLs for the $2 \mathrm{H}: 1 \mathrm{~V}$ slopes were covered with $0.3 \mathrm{~m}$ of gravel or silty sand. Measured displacements were small and remained essentially unchanged for the 500 day observation period. The GCL for the $1 \mathrm{H}: 1 \mathrm{~V}$ slope was covered with a W GT and a 0.17 m-thick silty sand layer supported with geocells. One day after installation, GCL extension occurred at the top of the slope and the average tensile strain was $5.5 \%$. Measured displacements then decreased with time over the 3 month observation period. Although the plot remained stable, it was concluded that partial failure of the GCL occurred at some measurement points due to the high strain levels. Stark et al. (1998) presented a case study of a slope failure involving a non-encapsulated GMsupported GCL in a landfill bottom liner system. Failure occurred within the GCL due to hydration of the bentonite and over-building of an interim landfill slope.

The Cincinnati, Ohio, USA, test plots have yielded the most significant information on field shear performance of GCLs (Daniel et al. 1998). Fourteen full-scale plots were constructed in November 1994 to test long-term stability of unreinforced and reinforced GCLs on $3 \mathrm{H}: 1 \mathrm{~V}$ and $2 \mathrm{H}: 1 \mathrm{~V}$ slopes. All GCL configurations on the $3 \mathrm{H}: 1 \mathrm{~V}$ slopes performed satisfactorily for years with no failures observed, including one plot with a non-encapsulated GMsupported GCL placed with the unreinforced bentonite facing down against moist subgrade soil. Three failures occurred on the $2 \mathrm{H}: 1 \mathrm{~V}$ slopes. The first two slides occurred 20 and 50 days after construction with the failure surface located at the interface between SB and NP GCLs (W GT in both cases) and an overlying HDPE GMX. These slides occurred without warning and were attributed to reduction of GMX/GCL interface shear strength caused by time-dependent bentonite hydration from moisture in the underlying subgrade. A third slide occurred 495 days after construction due to internal failure of an encapsulated GMX-supported GCL. This slide was caused by unexpected bentonite hydration, possibly from edge drainage trenches or cuts made in the top GMX for instrumentation. The Daniel et al. (1998) study, including associated laboratory direct shear tests, produced several key findings: (1) for reinforced GCLs, GMX/GCL interface shear strengths were lower than internal shear strengths under low normal stress conditions, (2) the NW GT side of a reinforced GCL had higher interface strength than the W GT side when placed against a GMX, (3) hydrated bentonite migrated through the W GTs of some reinforced GCLs and reduced GMX/GCL interface strength over time, (4) the $2 \mathrm{H}: 1 \mathrm{~V}$ test plots were too steep to yield a safety factor that is normally considered adequate and the $3 \mathrm{H}: 1 \mathrm{~V}$ test plots yielded safety factors of at least 1.5 for project conditions, and (5) observed 
failures and non-failures were consistent with limit equilibrium stability analyses using peak shear strengths obtained from short-term shear tests. Based on this latter observation, Daniel et al. (1998) concluded that the Cincinnati test plots confirm the accuracy of current design methods and thus field test sections should generally not be required. Daniel (2013) noted, in hindsight, that the $2 \mathrm{H}: 1 \mathrm{~V}$ failures are not surprising because slope angles were close to interface friction angles and that results of the project pointed the industry toward using NW/NW GCLs to deliver enhanced interface shear strength for slope applications.

\subsection{Long-term design strength}

Similar to geosynthetic reinforcement applications, the reduction in long-term shear strength due to creep and aging of reinforced GCLs may possibly be addressed by performing long-term creep tests and developing strength reduction factors that are applied to short-term strength data. Marr and Christopher (2003) presented a conceptual approach for the estimation of long-term internal design strength for NP GCLs using such factors. The method assumes that creep and aging only affect the strength of the polymeric reinforcement and that the difference between GCL peak and residual shear strengths is solely due to presence of the reinforcement. Short-term peak and residual internal shear strengths are first obtained according to appropriate testing procedures. Residual strengths can be estimated using $c_{\mathrm{r}}=0$ and $\phi_{\mathrm{r}}=5^{\circ}$ (Sections 4.3, 4.4). At each normal stress, reduction factors are applied to the difference between peak and residual shear strengths and the resulting value is added to the residual strength to give a reduced peak strength. In the absence of projectspecific test data, Marr and Christopher (2003) recommended a reduction factor of 3 for creep and reduction factors of 1.1 and 2.0 for 100 and 300 years of aging, respectively. Consistent with Thies et al. (2002) and Müller et al. (2008), Marr and Christopher (2003) also noted that temperature, normally assumed to be $20^{\circ} \mathrm{C}$, has a strong influence on GCL creep behavior and should be considered when selecting appropriate reduction factors.

As an example, Figure 21 presents long-term peak strength envelopes for a W/NW NP GCL at 100 and 300 years calculated using the data presented in Figure $3 \mathrm{~b}$. The above method considerably reduces peak shear strength because of the high total reduction factors (3.3 and 6.0 for 100 and 300 years, respectively). Experimental research is needed to determine if such factors are appropriate for NP GCLs and if corresponding reduction factors are needed for GMX/NP GCL interfaces.

\section{SELECTION OF STRENGTH ENVELOPES FOR DESIGN}

\subsection{Displacements in liner systems}

Shear displacements occur within landfill liner systems due to a variety of mechanisms, including construction activities (McKelvey 1994), thermal expansion/contraction, mobilization of passive resistance of a waste buttresses on

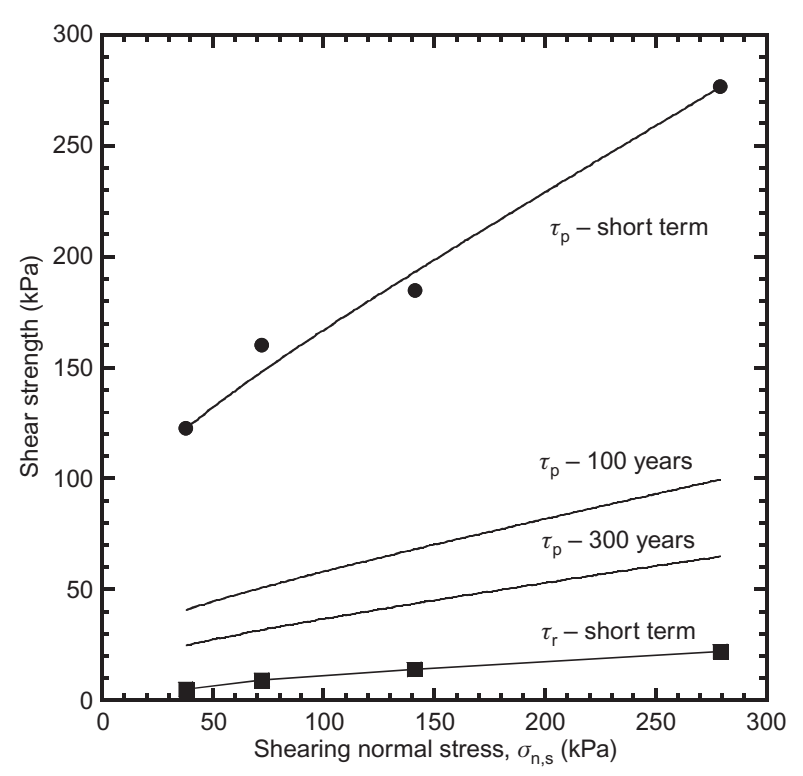

Figure 21. Measured short-term peak and residual shear strength envelopes for a hydrated W/NW NP GCL and calculated long-term peak shear strength envelopes using the method of Marr and Christopher (2003)

a base liner (Stark and Poeppel 1994), strain incompatibility between waste materials and geosynthetic interfaces (Reddy et al. 1996; Eid et al. 2000), earthquakes (Kavazanjian et al. 2011), waste placement procedures (Yazdani et al. 1995; Koerner and Soong 1998), and waste settlement (Long et al. 1995). For example, displacements along a bottom liner system are generally assumed to be nonuniform and progressive (Byrne 1994; Stark and Poeppel 1994; Gilbert and Byrne 1996; Reddy et al. 1996; Gilbert et al. 1996b; Filz et al. 2001; Stark and Choi 2004; Jones and Dixon 2005; Dixon et al. 2012; Sia and Dixon 2012). Shear failure will occur at the interface with the lowest peak strength, which may or may not correspond to the interface with the lowest residual strength. Thus, the residual strength of a GCL or GCL interface should only be used for design if the GCL or GCL interface exhibits the lowest peak strength in a liner system and it is anticipated that the corresponding displacement at peak may be exceeded. The selection of design strength envelopes for a multi-layer system in which individual components display nonlinear strength envelopes and post-peak strength reduction requires careful analysis, including consideration of the possibility of unrepresentative test data. This is discussed in the following sections for landfill bottom liner and cover systems. Gilbert (2001) and Marr and Christopher (2003) provide additional discussion on the topic.

\subsection{Bottom liner systems}

Stark and Poeppel (1994) proposed the following limit equilibrium analysis method for stability of bottom liner systems with side slopes.

1. Assign residual shear strengths to the side slopes and peak shear strengths to the base of the liner system and satisfy a factor of safety greater than 1.5. 
2. Assign residual shear strengths to the side slopes and base of the liner system and satisfy a factor of safety greater than 1.0. A safety factor of 1.1 should be satisfied if large displacement shear strengths are used instead of true residual values.

The method assumes that large displacements occur along the side slopes of a bottom liner system and failure progresses from the side slopes to the base. Filz et al. (2001) found that this method was unconservative for back-analysis of the Kettleman Hills landfill failure and, as an alternative, recommended that the average degree of strength mobilization above residual be taken as $10 \%$ of the increment from residual to peak. An important issue in applying either of these or other methodologies for stability analysis involves the determination of which materials/interfaces in the liner system reach a residual strength condition. Because peak strength envelopes for geosynthetics are often stress-dependent, it may be necessary to construct combination design strength envelopes using segments from the individual strength envelopes of liner system components.

As an example, Figure 22 presents peak strength envelopes for three GMS interfaces that are assumed to constitute the weakest potential shear surfaces of a composite liner system: (1) NW GT/GMS, (2) clay/GMS, and (3) GN/GMS. For $\sigma_{\mathrm{n}, \mathrm{s}}<280 \mathrm{kPa}$, the GN/GMS interface exhibits the lowest peak strength and is the critical interface. For $\sigma_{\mathrm{n}, \mathrm{s}}>280 \mathrm{kPa}$, the clay/GMS interface is critical. Therefore, a combination design peak strength envelope, illustrated by the dashed lines in Figure 23, should be used to characterize the peak strength of the liner system. This envelope represents the lowest peak shear strength at each normal stress. Figure 24 shows the individual residual strength envelopes for the same interfaces and Figure 25 shows the combination design residual strength envelope (dashed) for the liner system. The combination design residual strength envelope corresponds

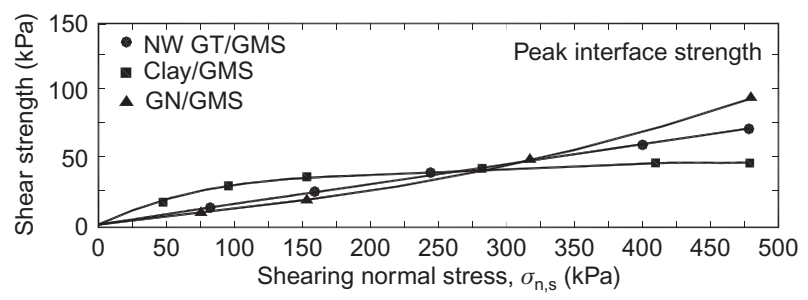

Figure 22. Peak shear strength envelopes for three interfaces of a composite liner system (Stark and Poeppel 1994)

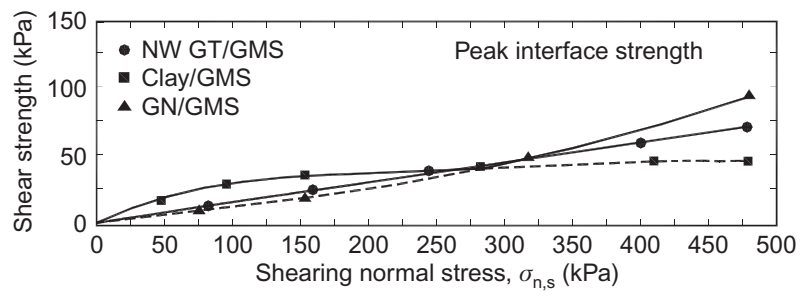

Figure 23. Combination design peak shear strength envelope for a composite liner system

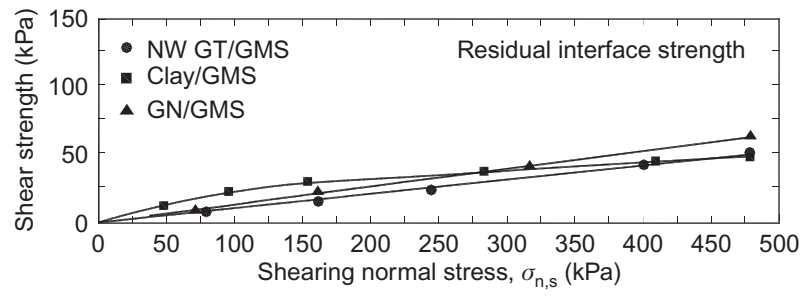

Figure 24. Residual shear strength envelopes for three interfaces of a composite liner system (Stark and Poeppel 1994)

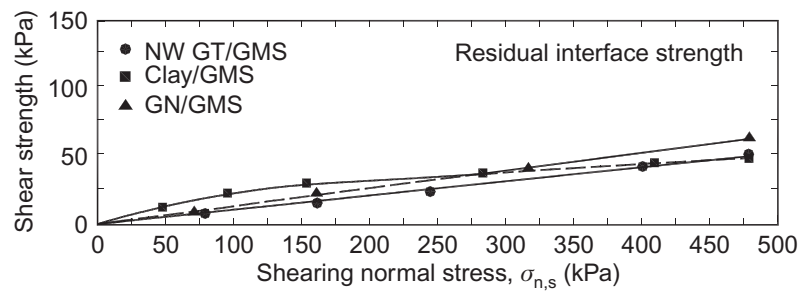

Figure 25. Combination design residual shear strength envelope for a composite liner system

to the combination design peak strength envelope and does not simply represent the lowest residual shear strength at each normal stress. Although the NW GT/ GMS interface exhibits the lowest residual shear strength, this residual envelope is not used for design because the peak strength of the NW GT/GMS interface will not be exceeded (Figure 23) and thus a residual strength condition will not occur along the NW GT/GMS interface. In summary, designers should not use the minimum residual strength envelope, but instead determine which materials/ interfaces will reach a residual strength condition and then use the corresponding combination residual strength envelope for design. As a note of caution, the analysis illustrated in Figures 22 to 25 is only meaningful if the various measured strength envelopes are representative. This requires quality replicate shear tests using projectspecific materials and conditions.

Proper selection of combination strength envelopes for design is particularly important when a bottom liner system contains a hydrated reinforced GCL because of its high peak strength and low residual strength. The residual strength envelope for any hydrated GCL will plot below the NW GT/GMS residual strength envelope in Figure 24. However, the peak strength envelope for unreinforced encapsulated GCLs and reinforced GCLs will likely be significantly higher than for many other interfaces in a liner system. If so, $\delta_{\mathrm{p}}$ of the GCL will not be exceeded, the GCL will not reach a residual strength condition, and the GCL internal residual strength envelope should not be used for design. In this context, engineered slip interfaces having smaller $\tau_{\mathrm{p}}$ and larger $\tau_{\mathrm{r}}$ than a GCL (e.g. GT/GM, $\mathrm{GN} / \mathrm{GM}$, and sand/GM) have been proposed to increase the available residual strength within a liner system and restrict shear displacement to an interface above the barrier layers (Gilbert et al. 1996a; Luellen et al. 1999; Gilbert 2001). In many cases, short-term peak strengths are appropriate for design of bottom liner systems because 
the majority of shear displacements occur during construction and filling and because bottom liner slopes will often be buttressed by waste placement before long-term strengths are required.

\subsection{Cover systems}

The method for selection of the design strength envelope for cover systems is different from bottom liner systems because shear displacements are expected to be more uniform. Back-analysis of cover system failures by the second author indicates that peak strengths are mobilized throughout a cover system, largely due to the absence of waste placement, settlement, and buttressing effects. However, considerable shear displacements may occur in cover systems during construction. These displacements can be minimized by placing cover materials from bottom to top on slopes or including veneer reinforcement (Koerner and Soong 1998). Therefore, the stability of cover systems should be analyzed using the lowest available peak shear strengths and the appropriate combination design peak strength envelope as shown in Figure 23. The only difference is that the normal stress range will be much smaller (possibly a single value), which may eliminate the need for a combination envelope. Long-term peak strengths are appropriate for this case because cover systems must sustain permanent shear stresses.

\subsection{Design strength envelope for encapsulated GCLs}

Encapsulated GCLs are becoming more common in bottom liner systems to increase environmental protection. In this case, the design strength envelope depends on the amount of bentonite hydration that will occur over the life of the facility (Thiel et al. 2001, 2006; Erickson and Thiel 2002; Giroud and Daniel 2004; Giroud et al. 2004). Common configurations for analysis consider an encapsulated bentonite layer formed using a GT-supported GCL between two welded GMs or GM-supported GCL panels that are overlapped at the edges and overlain by a welded GM. Water can migrate into either type of GCL from defects in the GMs or GM seams and into the GMsupported GCL at overlaps, and then flow laterally in the bentonite layer (diffusion of water vapor through the GMs is expected to be negligible). Lateral water flow along GM wrinkles may also contribute to bentonite hydration (Cowland 1997).

Analytical solutions indicate that decades are required for the hydration front from a GM defect to migrate a relatively small distance (e.g. a few meters) within the bentonite layer of an encapsulated GCL. Thus, a very long time would be required for the development of a large hydrated area by this mechanism that could significantly impact shear strength and stability (Giroud and Daniel 2004). Analyses conducted by Giroud et al. (2004) confirmed that the hydrated area from defects in the upper GM is negligible compared to the hydrated area from panel overlaps for a GM-supported GCL, assuming the frequency and size of defects are representative of good construction quality assurance practice. Analyses have also indicated that, for typical parameter values, many decades are required to hydrate a significant portion of the bentonite layer area from GM overlaps (Giroud et al. 2004). For landfill liner systems with $300 \mathrm{~mm}$ overlaps, Thiel et al. (2001) calculated that approximately 10 to $35 \%$ of the encapsulated bentonite will become hydrated over a design period of 250 years, depending on moisture condition of the subgrade. Long-term field data are needed to validate these analytical predictions. Once the percentage of bentonite hydration is established, GCL shear tests are performed for dry and fully hydrated conditions and the data used to construct prorated strength envelopes (Thiel et al. 2001).

An alternative guideline is proposed herein that does not require rigorous analysis; the internal shear strength of an encapsulated GCL can be taken as the average of unhydrated and hydrated shear strengths. This conservatively assumes that $50 \%$ of the bentonite will become hydrated over the life of a facility. The concept is illustrated in Figure 26, which shows peak and large displacement strength envelopes for unhydrated and hydrated direct shear specimens of a composite liner consisting of a NW/NW NP GCL encapsulated between two GMXs. Small holes were drilled in each GMX to permit GCL hydration for the hydrated tests. The design peak and large displacement strength envelopes are drawn as bisectors between corresponding unhydrated and hydrated strength envelopes. Acceptable and unacceptable zones for

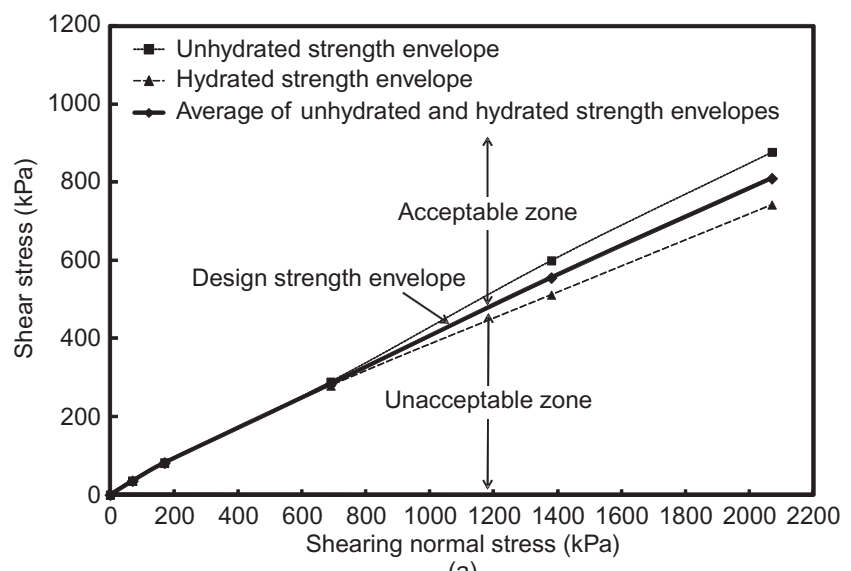

(a)

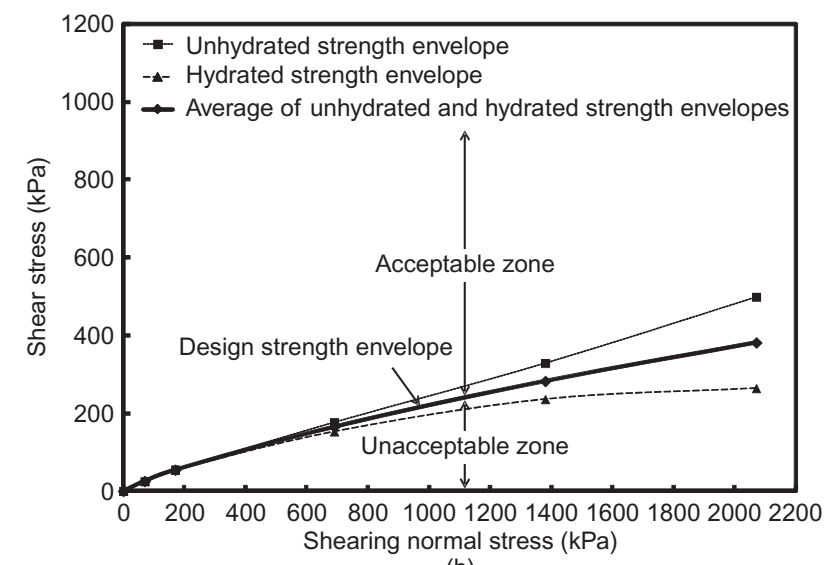

(b)

Figure 26. Design shear strength envelopes for an encapsulated NW/NW NP GCL assuming $50 \%$ bentonite hydration: (a) peak shear strength; (b) large displacement shear strength 
later conformance testing of this composite liner are also indicated (Section 8.7).

\section{LABORATORY MEASUREMENT OF GCL SHEAR STRENGTH}

\subsection{Role of laboratory shear tests}

Considering the high cost and difficulty of conducting long-term tests, short-term laboratory tests are expected to remain the primary means by which shear strengths are measured for GCLs and GCL interfaces. Long-term laboratory strength tests and field performance tests will continue to be needed on a research basis to develop and calibrate design methodologies that account for hydration, durability, creep, and other factors under service conditions.

\subsection{Assessment of shear test quality}

The results of shear tests on GCLs and GCL interfaces can be affected by many variables, including product type, product manufacturing conditions (e.g. old versus new needle boards), soil type and preparation conditions (if applicable), type of shear device, equipment-specific factors (e.g. specimen gripping surfaces), specimen size, conditioning procedure (e.g. hydration liquid, hydration procedure, and consolidation procedure), drainage conditions, shearing normal stress, direction of shear, shearing procedure, and maximum shear displacement. Because improperly performed tests can give inaccurate results, it is important to carefully consider test procedures and to examine test data for inconsistencies and potential flaws. Good quality displacement-controlled shear tests will produce $\tau-\delta$ relationships that are generally similar in appearance to those shown in Figures 2 and 3a and exhibit smooth transitions from the start of loading to peak strength and then large displacement/residual strength. Provided that the failure mode is consistent, relationships obtained for replicate specimens should display good similarity with increasing normal stress. Other examples of high quality $\tau-\delta$ relationships are provided by Triplett and Fox (2001) and Fox and Ross (2011) for direct shear and Eid et al. (1999) for torsional ring shear.

In contrast, Figure 27 shows $\tau-\delta$ relationships for a NW/NW NP GCL and a GMX/NP GCL (NW/NW) interface that were obtained from a production testing laboratory and suggest problems occurred during shear. These relationships display double peaks, unusually broad peaks, poor similarity with increasing normal stress, and an absence of post-peak strength reduction for internal shear (Figure 27a, $\sigma_{\mathrm{n}, \mathrm{s}}=96 \mathrm{kPa}$ ). The erroneous relationships in Figure 27 were probably caused by slippage of the test specimens on the gripping surfaces (Section 8.6). Resulting progressive failure effects will produce inaccurate (likely conservative) peak strengths and inaccurate (likely unconservative) large displacement strengths (Fox and Kim 2008). Machine friction problems are another possible cause of erroneous relationships and can result in unconservative peak and large displacement strengths. Shear stress-displacement relationships can be examined

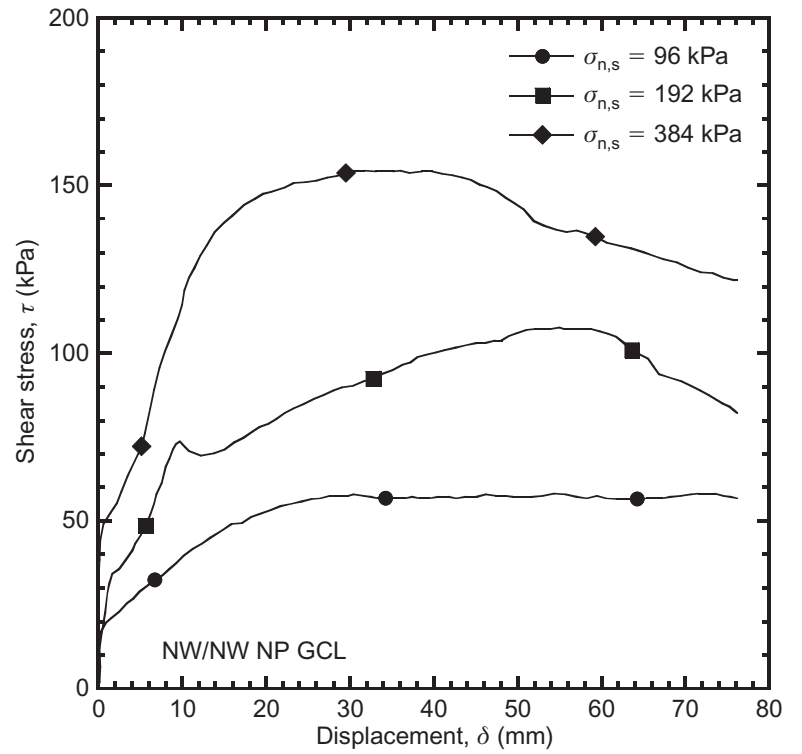

(a)

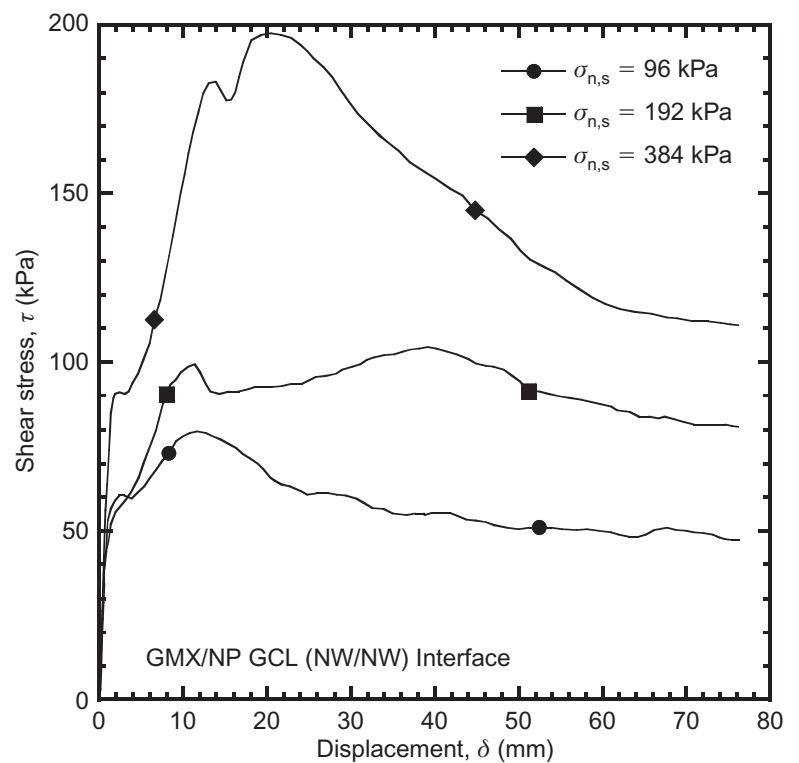

(b)

Figure 27. Examples of erroneous shear stress-displacement relationships: (a) hydrated NW/NW NP GCL; (b) hydrated GMX/NP GCL (NW/NW) interface (Fox and Kim 2008)

to make a preliminary assessment of the quality of GCL shear tests and should be routinely included as part of a test results package.

\subsection{ASTM standard test method}

ASTM D 6243 is the current standard test method for measurement of internal and interface shear strengths for GCLs in the USA. This standard requires that GCLs be tested in direct shear with a minimum specimen dimension of $300 \mathrm{~mm}$. Square or rectangular specimens are recommended. Smaller specimens are permitted if it can be demonstrated that the smaller shear device introduces no bias from scale or edge effects. The test specimen is sheared between two shearing blocks, each of which is covered with a gripping surface (i.e. rough surface) that transfers shear stress to the specimen. Clamping of geosynthetics at the ends of the shearing blocks is 
permitted to facilitate shear at the desired location within the specimen. The gripping/clamping system should securely hold the specimen to the shearing blocks, develop sufficient shear resistance to prevent non-uniform displacement, and not interfere with measured shear strength. The gripping surfaces should also be rigid and permit free drainage of the specimen if necessary.

Test specifications are provided by the user and include specimen configuration, soil compaction criteria (if applicable), conditioning procedure, normal stress level(s) and shearing procedure. The GCL specimen should be fully hydrated unless otherwise specified. Once hydrated and (possibly) consolidated, the specimen is sheared to a minimum displacement of $75 \mathrm{~mm}$ using displacementcontrolled or stress-controlled methods, the latter of which includes constant stress rate, incremental stress, and constant stress creep. Displacement control is needed to measure post-peak response. For displacement-controlled tests, ASTM D 6243 provides some guidance on displacement rates; specifically, $R=0.1 \mathrm{~mm} / \mathrm{min}$ for internal shear and, if excess pore pressures are not expected to develop, $R=1 \mathrm{~mm} / \mathrm{min}$ for interface shear. However, the standard also notes that these rates are based on research conducted for limited conditions and that other conditions may require determination of appropriate displacement rates. After shearing is completed, the normal stress is removed and the specimen is inspected carefully to identify the failure mechanism and any evidence of tensile strains within the geotextiles or at the clamps. A test may need to be repeated, possibly using improved gripping surfaces, if evidence of unusual strain patterns or failure at a location other than the intended shear surface is observed. A sample is taken from the center of the GCL to measure final water content.

\subsection{Specimen size}

The size of GCL specimens for internal and interface shear tests is almost always larger than for shear tests on natural soils. This is because: (1) larger shear displacements are often required to reach peak strength and residual strength conditions, (2) textural elements of many geosynthetics (e.g. GN and GMX) are larger than for many soils, and (3) the spacing of some types of GCL reinforcement (e.g. SB) may be up to $100 \mathrm{~mm}$. Large specimens also tend to reduce edge effects and the effects of local variability in material properties (e.g. needle-punched fiber density), making test results more reproducible. The disadvantages of shearing large GCL specimens are that tests are more difficult to perform, equipment is larger and more expensive, and the maximum possible normal stress may be lower. For these reasons, Stark and Eid (1996) and Gilbert et al. (1997) suggested that tests performed on small specimens can be used to compliment large-scale shear tests. Smaller specimens $(100 \mathrm{~mm} \times 100 \mathrm{~mm})$ have also been recommended for shear tests on unreinforced GCLs (Zelic et al. 2002) and NP GCLs (Koerner et al. 1998). Olsta and Swan (2001) showed good agreement for internal shear strengths of a hydrated W/NW NP GCL obtained using large $(300 \mathrm{~mm} \times 300 \mathrm{~mm})$ and smaller $(150 \mathrm{~mm} \times$ $150 \mathrm{~mm}$ ) direct shear boxes. The smaller box was used to conduct shear tests at high normal stress (1050 to $2800 \mathrm{kPa})$.

\subsection{Shear devices}

\subsubsection{Direct shear}

Shear strengths for GCLs and GCL interfaces have been measured primarily using direct shear methods. The direct shear device has several advantages. First, shear occurs in one direction, which matches field behavior and is important for GCLs and GCL interfaces that display inplane anisotropy (Section 4.6). Second, direct shear test specimens can be relatively large (Section 8.4). Third, shear displacement is nominally uniform over the specimen, which tends to minimize progressive failure effects and allows for accurate measurement of peak shear strength. In practice, shear displacement may not be uniform if the gripping surfaces are inadequate (Section 8.6). The primary disadvantage of the standard $300 \mathrm{~mm} \times 300 \mathrm{~mm}$ direct shear device is that the maximum shear displacement (typically 50 to $100 \mathrm{~mm}$ ) is not sufficient to measure the residual shear strength of most GCLs and GCL interfaces. Fox et al. (1997) developed a direct shear machine capable of shearing larger GCL specimens $(406 \mathrm{~mm} \times 1067 \mathrm{~mm})$. The maximum displacement $(203 \mathrm{~mm})$ was sufficient to achieve residual shear conditions for GCLs (Fox et al. 1998a) but not for GMX/NP GCL interfaces (Triplett and Fox 2001). Another disadvantage of the direct shear device is that the area of the failure surface can decrease during shear, which increases the shearing normal stress and requires an area correction for data reduction. To avoid this problem, many direct shear devices have a top shearing block that moves across a longer bottom shearing block. This results in the movement of previously unsheared material into the failure surface, which can potentially alter the measured $\tau-\delta$ response. Numerical simulations presented by Fox and Kim (2008), however, showed that the effect of fresh material moving into the failure surface was insignificant for a GMX/NP GCL interface. The large size of standard direct shear specimens also increases the possibility for errors in the applied normal stress and may limit the maximum normal stress level. A rigid loading plate that uniformly compresses a GCL specimen will provide a near-uniform normal stress distribution. However, the accuracy of the total applied load should also be verified by the laboratory or certified by the manufacturer, especially for devices that use an air bladder loading system (Marr 2001). This can be accomplished by placing load cells between the shearing blocks to measure the actual load applied to the specimen. If necessary, a correction factor can then be calculated by comparing the actual load to the nominal load based on bladder air pressure. Other disadvantages of the direct shear device are possible tilting of the upper box during shear for some designs and setting of the gap height between upper and lower shear boxes (Section 8.8).

Fox et al. (2006) developed a unique large direct shear machine for static and dynamic testing of GCLs and GCL interfaces (Figure 28). Based in part on the earlier design of Fox et al. (1997), the main features of this machine 


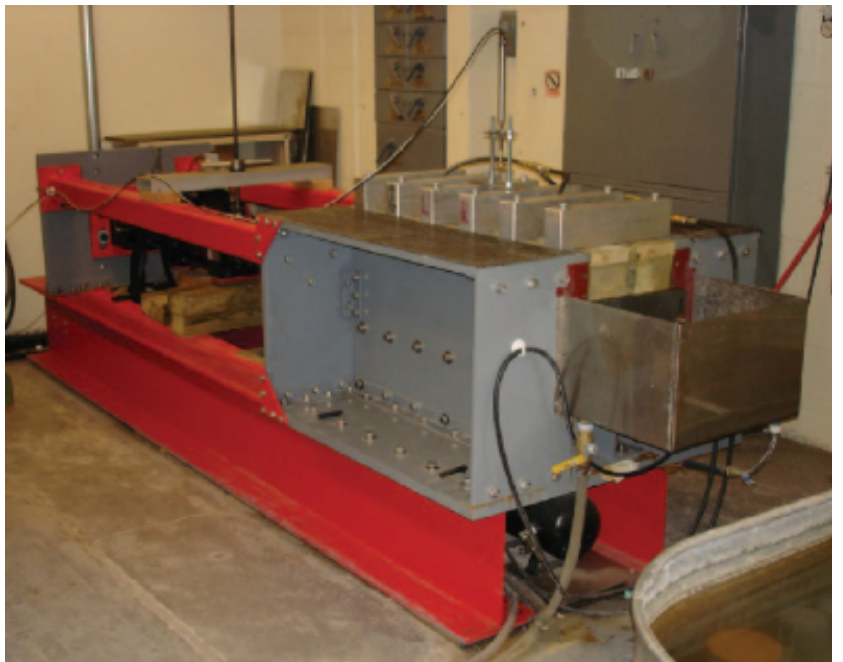

Figure 28. Large dynamic direct shear machine (Fox et al. 2006)

include a specimen size of $305 \mathrm{~mm} \times 1067 \mathrm{~mm}$, a maximum normal stress of $2071 \mathrm{kPa}$, a maximum shear displacement of $254 \mathrm{~mm}$, negligible machine friction, and the capability to measure specimen volume change. Subsequent modifications have allowed for a maximum normal stress of $4145 \mathrm{kPa}$ with a specimen size of $152 \mathrm{~mm} \times 1067 \mathrm{~mm}$ (Fox et al. 2014). Test specimens are sheared between a horizontal pullout plate and the floor of the test chamber, each of which is covered with a firm gripping surface. A $245 \mathrm{kN}$ hydraulic actuator imparts single-direction or bidirectional (i.e. back-and-forth) motion to the pullout plate. The maximum displacement rate is $30000 \mathrm{~mm} / \mathrm{min}$ and the maximum frequency is $4 \mathrm{~Hz}$ for sinusoidal loading with a displacement amplitude of $25 \mathrm{~mm}$. Normal stress is provided by two bellowed air bladders that rest on an overlying stationary load plate. Between the load plate and pullout plate, a layer of 517 free-rolling stainless steel balls reduces frictional resistance of the machine to $0.27 \%$ of the applied normal stress. Vertical displacement of the load plate indicates specimen volume change and is continuously monitored during hydration and shear using an LVDT. GCL specimens are hydrated from a water reservoir at the back of the machine through a network of drainage channels in both shearing surfaces.

\subsubsection{Torsional ring shear}

The torsional ring shear device has been used for shear tests of GCLs and GCL interfaces, primarily for research purposes (Stark and Eid 1996; Eid and Stark 1997). The most important advantage of this device is the capability for unlimited shear displacement and measurement of residual shear strength. Unlike direct shear, the area of the failure surface is constant during shearing and normal stress is typically applied using dead weights. The ring shear device also has several disadvantages. Because failure occurs simultaneously on an annular surface, shear displacement does not occur in one direction. Measured shear strengths instead represent an average of local shear resistance in all directions and will be affected if a GCL or GCL interface displays significant in-plane anisotropy. This limitation has not been found to be significant for NP GCLs because most needle-punched reinforcement appears to be isotropic (Eid et al. 1999). The small size of ring shear specimens (e.g. $100 \mathrm{~mm}$ diameter) prevents shear testing of SB GCLs (due to anisotropy and large reinforcement spacing) and may necessitate additional replicate shear tests to verify that measured strengths are representative. The geometry and small size of ring shear specimens can enhance edge effects, such as lateral bentonite squeezing. Finally, shear displacement is not uniform across the width of the specimen, which can cause different parts of the specimen to fail at different times during the test (i.e. progressive failure). Progressive failure theoretically proceeds from the outer edge of the specimen to the inner edge and can reduce the measured value of peak shear strength for materials that display post-peak strength reduction. The error is a function of the diameter ratio (inside diameter/outside diameter) of the device. The measurement of residual shear strength is unaffected by non-uniform displacement across the specimen. For data reduction purposes, shear displacement is taken at the average radius of the specimen and the average shear stress is calculated from specimen geometry and the applied moment (Bishop et al. 1971; Bromhead 1979). Values of peak strength measured from ring shear tests are usually in agreement with those measured from direct shear tests if the diameter ratio exceeds 0.7 (Stark and Poeppel 1995). Comparative tests on GMX/dry bentonite and hydrated GMX/NP GCL interfaces using ring shear (diameter ratio $=0.4$ ) and direct shear devices yielded $\tau_{\mathrm{p}}$ values, but not $\tau-\delta$ relationships, that were in close agreement (Stark and Eid 1996; Eid and Stark 1997).

The experience of the second author indicates that the torsional ring shear device is easier to use and produces more consistent results than the ASTM D 6243 direct shear device. A combination of ring shear and direct shear tests can be conducted to satisfy the requirement of direct shear testing in ASTM D 6243. For example, the second author initially performs ring shear tests to measure peak and residual strengths due to ease of specimen hydration, consolidation, and shearing. One or more direct shear tests are then conducted to verify the measured $\tau-\delta$ and strength relationships. The torsional ring shear device has been effectively used for research and production testing to obtain peak and residual strengths for slope design.

\subsubsection{Inclined plane shear}

The inclined plane (i.e. tilt table) shear device has been used to measure shear strengths of geosynthetic interfaces, particularly in Europe (Gourc et al. 1996; Briancon et al. 2002, 2011; Pitanga et al. 2009); however, relatively few results have been reported for GCLs (Alexiew et al. 1995; Heerten et al. 1995; von Maubeuge and Eberle 1998). Inclined plane and direct shear devices share many of the same advantages and limitations. For the inclined plane, specimens are often larger (up to $1 \mathrm{~m}$ or more in size), normal stress is limited to low values (typically $<50 \mathrm{kPa}$ ), displacement is measured as a function of tilt angle, and 
shearing is force-controlled (by gravity). Thus, the inclined plane device is well suited for constant stress creep tests of landfill cover systems. Failure occurs quickly and post-peak response is not measured in the standard device. Large displacement strengths can be obtained with special equipment to limit travel of the upper box after failure (Lalarakotoson et al. 1999; Stolz et al. 2012). Briancon et al. (2011) introduced a new procedure for the test, which measures the force required to restrain the top box beyond a limiting displacement and yields more accurate values of friction angle. A disadvantage of the inclined plane device is that stress conditions on the failure surface change with increasing tilt angle. This effect can be partly compensated by using a device in which the front and rear walls of the upper box are tilted away from vertical prior to the start of a test (Lalarakotoson et al. 1999; Briancon et al. 2011).

\subsubsection{Implications for practice}

Direct shear is expected to remain the preferred general test method for GCLs because it can be used for any type of GCL product, a large range of normal stress is possible, large specimens can be tested, post-peak response can be obtained, and shear strengths are measured in one direction. Torsional ring shear and inclined plane shear devices will continue to be used for research and production purposes. Accurate values of peak strength can be measured using $300 \times 300 \mathrm{~mm}$ direct shear specimens but residual strengths generally cannot be measured. The disadvantage of limited displacement for direct shear devices has been partially eliminated now that internal residual shear strengths for all hydrated GCLs are known to be essentially the same and equal to the residual strength of hydrated bentonite (Fox et al. 1998a). Torsional ring shear provides the only reasonable means to obtain residual shear strengths for some GCLs and GCL interfaces (e.g. GMX/NP GCL) but should not be used if materials display in-plane anisotropy. None of the above shear devices is well suited for control of drainage conditions or measurement of pore pressures on the failure surface during shear. Pore pressure measurements could be used to indicate the maximum allowable displacement rate for drained shear conditions or calculate effective normal stresses on the failure surface for faster undrained shear conditions. Application of backpressure may permit such measurements; however, this capability has yet to be developed.

\subsection{Specimen gripping surfaces}

One of the most important features of a GCL shear device is the type of gripping surface that secures the test specimen to the shearing blocks. The most accurate shear strength data is obtained when the intended failure surface has the lowest shear resistance of all possible sliding interfaces. In this case, shear displacement is uniform over the failure surface, $\tau_{\mathrm{p}}$ occurs everywhere simultaneously, and the relationship between average $\tau$ (total shear force/ area) and average $\delta$ (relative displacement of shearing blocks) is representative of actual material behavior. However, if one of the gripping surfaces constitutes the weakest interface, failure will occur at that interface and render a test invalid. The gripping surfaces in most GCL shear devices are composed of wood, plastic, or metal plates and may not be sufficiently rough to shear strong specimens (e.g. reinforced GCLs) without the use of end clamps, especially at low normal stress. Thus, to avoid unsuccessful shear tests, geosynthetic clamps are commonly used to force failure at the intended interface. Clamping systems usually consist of bolted bar or mechanical compression clamps that fix the geosynthetics to one or both ends of the shearing blocks. In some cases, geosynthetics have been stapled to wooden shearing blocks (Bressi et al. 1995) or simply wrapped around the ends of shearing blocks and anchored with the applied normal force (Frobel 1996; Zornberg and McCartney 2009).

Several studies have reported effective gripping surfaces for GCLs and GCL interface materials. Good success has been obtained using a "textured steel grip" that consists of parallel wood working rasps attached to the shearing blocks (Pavlik 1997; Trauger et al. 1997; Olsta and Swan 2001). Fox et al. (1997) used modified metal connector plates (i.e. 'truss plates' for wood truss construction), which have the advantage of providing a well-drained surface in addition to a large number of sharp 1-2 mm-tall triangular teeth $\left(1\right.$ tooth $\left./ \mathrm{cm}^{2}\right)$ that uniformly grip a GCL specimen. These plates provide a sufficiently firm grip that even strong NP GCLs can be sheared internally at normal stress levels as low as $17 \mathrm{kPa}$ without the use of end clamps (Fox et al. 1998a). Nail plates molded in epoxy with a high density of short sharp nails (1 nail/ $\mathrm{cm}^{2}$ ), each $2 \mathrm{~mm}$ in height, have worked successfully (Zanzinger and Alexiew 2000) and led to the development of an improved stainless steel nail plate with better drainage (Zanzinger and Saathoff 2010). Good success has also been reported for a 'pyramid-tooth gripping surface', which is machined from solid stainless steel and has a large number of gripping teeth and drainage holes (Allen and Fox 2007). Triplett and Fox (2001) glued single-sided GMX specimens to the top shearing block for GMX/NP GCL interface strength tests. This method prevented slippage of the GMX but was limited to lower normal stresses (approximately $\sigma_{\mathrm{n}, \mathrm{s}}<280 \mathrm{kPa}$ ) by the shear strength of the adhesive. Stronger adhesives have permitted tests at substantially higher normal stress levels (2071 kPa) using this method (Fox and Ross 2011; Ross and Fox 2015). Gluing is not recommended for GCL specimens because of possible interference with the failure mechanism (e.g. pull out of fibers and rupture of stitches). Gluing has been used for NP GCLs tested in ring shear (Stark and Eid 1996; Eid et al. 1999); however, careful steps were followed to ensure that the adhesive was not applied to materials near the failure surface.

Due to extensibility of the geosynthetics, shear displacement will not be uniform on the failure surface for any GCL or GCL interface test in which the geosynthetics become tensioned at end clamps. To illustrate the concept, Figure 29a shows a schematic diagram of a direct shear test of the interface between a GMX and GCL. The upper and lower shearing blocks are covered with a non-specific gripping surface and are used to apply normal stress and 

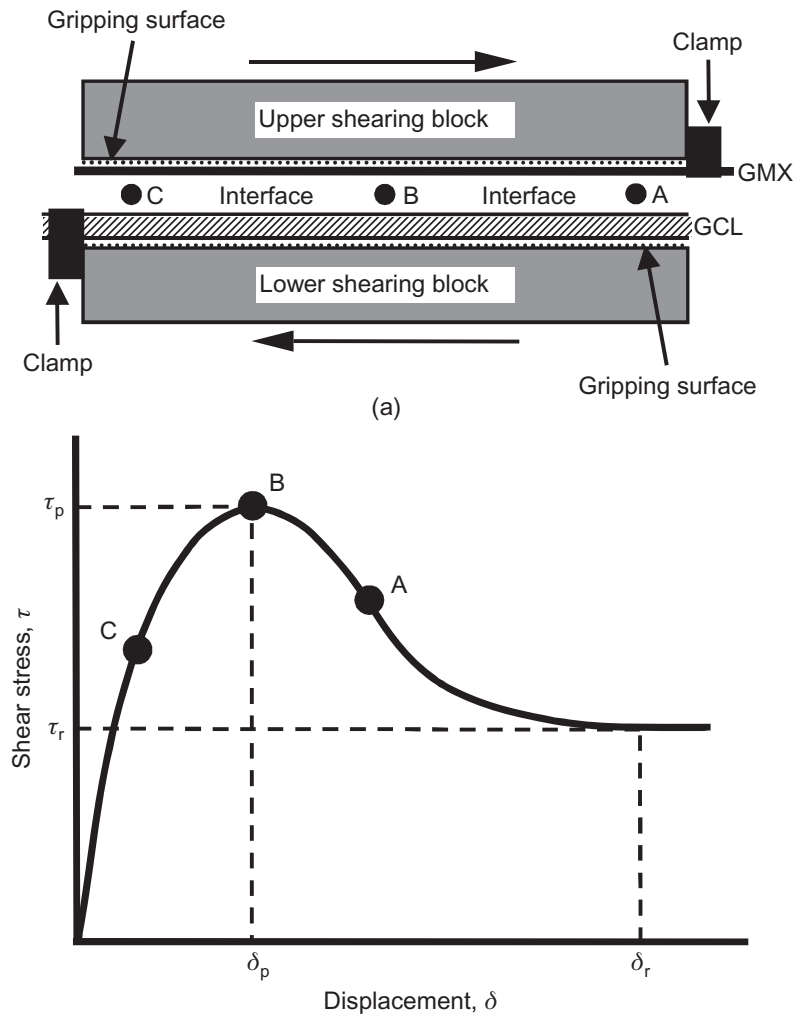

(b)

Figure 29. Illustration of progressive failure concept: (a) GMX/GCL interface shear test; (b) stress conditions for three points on the interface (Fox and Kim 2008)

shear stress to the specimen in the conventional fashion. The right-hand side of the GMX is clamped to the upper shearing block and the left-hand side of the GCL is clamped to the lower shearing block. Directions of relative shear displacement are indicated. The interface between the GMX and GCL is separated for clarity and three points (A, B, C) are identified for discussion. Figure 29b shows the true $\tau-\delta$ relationship for the GMX/GCL interface. Assuming that the upper gripping surface has the lowest shear resistance, the GMX will slide on the upper surface and develop tension at the right clamp. Extension of the GMX specimen will cause shear failure along the GMX/GCL interface to first occur at the right-hand side (point A) and then progress to the left. At some later time, point $\mathrm{A}$ is in a post-peak condition, point $\mathrm{B}$ is at peak strength, and point $\mathrm{C}$ has not yet reached peak strength (Figure 29b). Thus, different sections of the failure surface have different shear stresses at any given time and the measured $\tau-\delta$ relationship is not representative of true material behavior. The measured peak strength will be less than the actual peak strength for materials/interfaces that experience post-peak strength reduction. The error depends on several factors, including specimen length, relative shear strengths of the various interfaces involved, extensibility of the geosynthetics, and the true $\tau-\delta$ relationship for the intended failure surface (Fox and Kim 2008).

Figure 30 shows the effect of geotextile clamping on measured $\tau-\delta$ relationships for internal shear of a W/NW NP GCL (Fox et al. 1997). For the first test, the

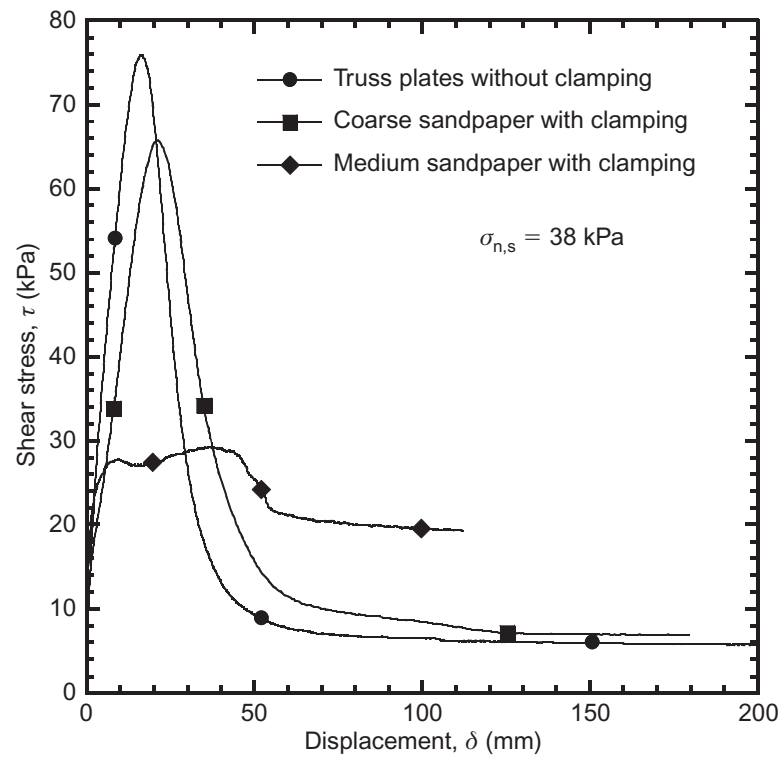

Figure 30. Effect of geotextile clamping on measured shear stress-displacement relationships for a W/NW NP GCL (Fox et al. 1997)

shearing surfaces were covered with medium coarse sandpaper and the supporting geotextiles were clamped at the ends. At $\delta=112 \mathrm{~mm}$, the W GT failed in tension just behind the clamp. Final inspection revealed that the W GT slipped on the sandpaper and the GCL did not fail internally. Interestingly, the measured $\tau-\delta$ relationship for this specimen shares some features (wide peak, double peak) similar to those in Figure 27a. A second test was performed using coarse sandpaper and the same clamping system. In this case, the geotextiles became tensioned at the clamps as before but the GCL specimen failed internally. The resulting $\tau-\delta$ relationship had well-defined peak and large displacement shear strengths. A third replicate shear test was conducted using modified truss plates without clamping. The truss plates produced higher peak strength, smaller displacement at peak, and slightly lower residual strength. Inspection of the failed specimen revealed a uniform internal shear failure at the W GT/ bentonite interface.

To further investigate these effects, Fox and Kim (2008) conducted a controlled study of progressive failure for a GMX/NP GCL interface. The key experimental results, in the form of eight $\tau-\delta$ relationships, are presented in Figure 31. Four relationships were measured from interface shear tests in which the GMX specimens were glued to the upper shearing surface and did not slip during shear. As such, these relationships provide a close approximation of true interface strength behavior. Four relationships were also measured for tests in which GMX specimens were not glued and instead clamped at the ends. Under these conditions, the GMX specimens slipped on the upper shearing surface and experienced non-uniform tensile strains during shear. Stress-displacement relationships for the clamped tests display familiar trends of shear stress rising to a peak value and then decreasing at larger displacements. However, similar to Figure 30, the use of end clamps to force failure at the GMX/GCL interface 


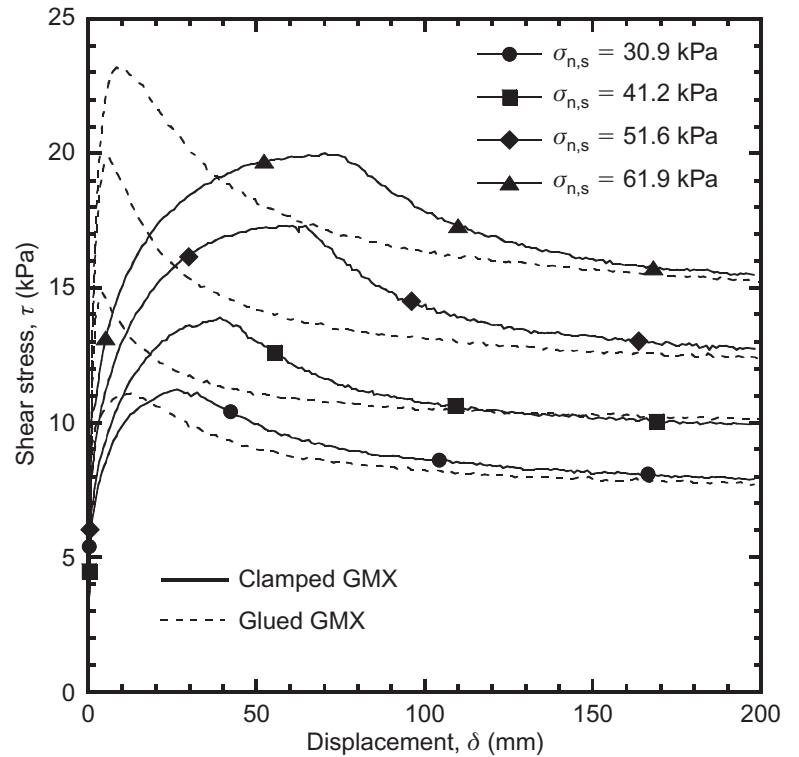

Figure 31. Shear stress-displacement relationships for glued and clamped GMX/GCL interface shear tests (Fox and Kim 2008)

resulted in smaller peak strengths, broader peaks, larger displacements at peak, and higher values of large displacement strength. The relationships appear to be approaching the same residual condition for each normal stress. The data in Figures 30 and 31 and the numerical model developed by Fox and Kim (2008) indicate that geosynthetic clamping can have a significant influence on direct shear results for GCLs or GCL interfaces when one or both shearing blocks have the lowest shear resistance of all possible sliding surfaces.

Gripping surfaces should enforce uniform shear of the test specimen over the entire failure surface at all levels of displacement. To achieve this, the surfaces must prevent slippage between the specimen and the shearing blocks. In addition, the surfaces should not interfere with the measured shear strength over a wide range of normal stress and provide excellent drainage for hydrated GCL tests. Since publication of the original SOA report (Fox and Stark 2004), ASTM D 6243 has been revised to recommend modified truss plates as the preferred gripping surface for GCLs.

\subsection{Specimen selection and trimming}

A significant source of uncertainty for GCL and GCL interface shear tests is associated with selection of materials. For example, representative samples of NP GCLs may be difficult to obtain due to variation in needle-punched fiber density that occurs with ongoing wear of needle boards during production. Such variations can have important implications for analysis and design. To illustrate, assume that samples of a NP GCL product are submitted for testing with a lower average fiber density than the material delivered for construction. Based on measured shear strengths, a designer may conclude the critical failure mode is GCL internal shear when the critical failure mode in the field is actually interface shear. Ideally, GCL specimens that are tested to obtain design strength parameters would be selected from rolls delivered to or designated for the actual project site. However, this is impractical in most cases as design work is typically performed well in advance of construction. The next best alternative is to obtain samples of the same product and from the same manufacturing plant that will produce the future construction material. In this case, conformance tests are needed at the time of construction to confirm that the delivered materials are at least as strong as the original test materials. It is important to establish who has the responsibility for properly conducting and interpreting such tests (Section 9) (Smith and Criley 1995; Evans et al. 1998).

Once GCL and other geosynthetic sample rolls have been delivered for testing, the conservative approach is to take specimens from the weakest areas of the rolls. For internal strength of a NP GCL, these areas could be determined using peel tests (Marr 2001). Alternately, test specimens can be taken at regular intervals across each roll to obtain average strength parameters. Test specimens should be trimmed using a sharp utility knife or scissors such that the geosynthetics are not damaged, the reinforcement is not damaged (if applicable), and a minimal amount of bentonite is lost. One method to reduce bentonite loss is to wet the periphery of each GCL specimen a few minutes prior to cutting. The effects of poor specimen trimming procedures are unlikely to be of primary importance for shear strength tests due to the large size of standard GCL direct shear specimens.

\subsection{Gap setting and multi-interface tests}

In direct shear devices, the upper shear box is separated from the lower shear box by a gap. The gap should be vertically aligned with the intended failure surface, taking into account possible volume change of a GCL specimen and any underlying materials during conditioning and shear. An improper gap setting may interfere with the failure mechanism or allow friction to develop between the boxes. A larger gap can allow for a multi-interface test and thus failure to occur along the weakest interface. This can reduce the number of required tests and lead to better understanding of the shear behavior and potential weaknesses in a liner system. A properly designed and conducted series of multi-interface tests will directly yield combination design peak and residual strength envelopes (Sections 7.2, 7.3). Multi-interface tests can also yield different, and presumably more accurate, shear strength parameters due to local out-of-plane deformation effects (Section 4.5). Such effects are most likely to occur for specimens that contain coarse (i.e. gravelly) soils or geosynthetics with larger-scale geometric features, such as a geonet or geocomposite drain.

The main disadvantage of multi-interface shear tests is that strength parameters are obtained only for the failure surface. This is of no consequence if the materials and test procedures are representative of field conditions. However, as there is always some uncertainty, knowing that another material or interface with a significantly lower residual strength (such as a hydrated GCL) almost failed could be important. Another difference for the multi-interface test 
is that measured shear displacements are cumulative values for the entire specimen and thus are larger than displacements on the failure surface. To address this issue, Lin et al. (2014) recently described a method to measure the individual displacement for each component of a composite liner during shear. Multi-interface tests may be more difficult to perform and interpret than singleinterface tests and often require that the designer and testing laboratory have more experience to avoid errors. If concerns arise, the critical materials should be tested individually as a check on strength parameters.

\subsection{Normal stress range and number of tests}

Careful selection of the normal stress range for GCL shear tests is important because strength envelopes are commonly nonlinear and normal stress level can affect the failure mode of a test specimen (Sections 4.5, 5.4). GCLs in bottom liner systems are subjected to normal stress that is initially low and increases to a high value (up to $1000 \mathrm{kPa}$ or more) with time. If not encapsulated, these GCLs will hydrate under low normal stress and then slowly consolidate, over months or years, during waste placement operations. Stability analyses and associated GCL shear tests should be conducted for low, intermediate, and high normal stress conditions in this case. On the other hand, GCLs in cover systems are subjected to low normal stress (10 to $25 \mathrm{kPa}$ ) that is nearly constant after construction. Stability analyses and shear tests need only be conducted for low normal stress in this case.

Consistent with ASTM D 6243, a minimum of three shear tests are recommended to define the strength envelope for a GCL or GCL interface over the appropriate normal stress range for a given application. More tests should be conducted if the normal stress range is large or if the initial data points show significant scatter or deviation from linearity. If shear strengths are needed for a small normal stress range (e.g. landfill cover system), a minimum of three tests are still recommended to account for material/test variability and to characterize the strength envelope for the critical interface. If shear strengths are needed only for a single normal stress, then a minimum of two replicate tests are recommended.

\subsection{Specimen conditioning stage}

\subsubsection{Need for conditioning}

The conditioning stage involves hydration and, in some cases, consolidation of a GCL specimen prior to shearing. Specimen conditioning plays an important role for strength tests of GCLs and GCL interfaces because shear strengths can be sensitive to bentonite moisture content and possibly the sequence of hydration and normal stress application. Unhydrated conditions yield the highest GCL internal and GM/GCL interface strengths (e.g. Chiu and Fox 2004; McCartney et al. 2009), which is attributed not only to lack of bentonite swelling and associated tensioning of GCL reinforcement, but also to absence of bentonite extrusion and shear-induced excess pore pressures. In addition, Stark and Eid (1996) suggested that extruded bentonite may lessen the pullout resistance of needle-punched fibers by lubricating frictional connections with the anchoring GT. There is some data to support this concept. Bergado et al. (2006) measured peel strengths of 705 and $542 \mathrm{~N} / \mathrm{m}$ for dry and hydrated specimens of a W/NW NP GCL, respectively.

Early work by Daniel et al. (1993) indicated that full GCL hydration can be expected in the field unless the bentonite is encapsulated between two geomembranes. Thus, GCL shear tests should generally be conducted in the fully hydrated condition to be conservative (Gilbert et al. 1997; Stark 1997; Daniel 2013). Recent studies have also shown that the final degree of hydration is affected by many factors, including initial moisture content of the subsoil, temperature, heat cycles, confining pressure, and method of GCL manufacture (Rayhani et al. 2011; Anderson et al. 2012; Chevrier et al. 2012; Siemens et al. 2012). Such factors may need to be taken into account for special cases. For encapsulated GCLs, bentonite hydration can occur through GM defects and overlaps, and thus shear tests are required for both dry and hydrated conditions (Section 7.4). Once hydrated, GCLs may not remain fully hydrated as field studies have indicated that desiccation can occur over long-term service conditions (e.g. Benson et al. 2007).

After hydration, GCLs often experience increasing normal stress in the field and shear strength values are needed at higher normal stress levels (Section 8.9). For landfill bottom liners, GCL specimens ideally would be hydrated under the appropriate low normal stress and then slowly consolidated to various shearing normal stress levels that span the range needed for stability analysis. Following this field stress sequence for the conditioning stage can produce lower bentonite shear strengths because the bentonite has greater ability to absorb water, undergo particle rearrangement, and expand at low normal stress (Section 8.10.4). The difficulty is that the time required for such a procedure is often prohibitive. For example, Zornberg et al. (2005) reported internal shear strengths for three NP GCL specimens that were hydrated at low normal stress for more than $48 \mathrm{~h}$, consolidated in stages over a $540 \mathrm{~h}$ period, and then slowly sheared using $R=0.0015 \mathrm{~mm} / \mathrm{min}$. These data points were obtained after approximately 1 year of cumulative laboratory testing time. To avoid long testing times, GCL consolidation is typically conducted much more quickly over a period of 2 days or less (Zornberg et al. 2005; McCartney et al. 2009). However, there may be unintended consequences if consolidation occurs too rapidly in the laboratory, such as higher levels of bentonite extrusion and lingering excess pore pressures that can yield unrepresentative (low) shear strengths. Thus, important questions remain regarding recommended conditioning procedures for GCL specimens when normal stress increases after hydration in the field.

\subsubsection{Hydration liquid}

GCL specimens can be hydrated, although not necessarily saturated, by inundation inside or outside of a shear device. Hydration can also be accomplished using a spray bottle to control the amount of liquid added to a specimen. Tap water is almost always used as the hydration liquid due to convenience and because its chemistry is comparable to 
the pore water in most soils. A site-specific liquid can also be used. GCL shear strengths have been obtained for different hydration liquids, with deionized water, tap water, mild leachate, harsh leachate, and diesel fuel yielding progressively higher values (Koerner 1998). GCL hydration with tap water is therefore conservative. In general, if a hydration liquid increases the free swell of bentonite, the shear strength of a hydrated GCL or GCL interface is expected to decrease due to higher water content of the bentonite, greater tensioning of reinforcement, and greater potential for bentonite extrusion (Gilbert et al. 1997). For research purposes, Eid and Stark (1997) used deionized water to remove this variable from the testing process.

\subsubsection{Hydration normal stress and hydration time}

Ideally, GCL specimens should be hydrated to equilibrium (i.e. until volume change ceases) under the normal stress expected in the field at the time of hydration. Experimental work conducted by Daniel et al. (1993), Gilbert et al. (1996a), Stark et al. (1998), Anderson et al. (2012) and others indicate that, depending on conditions, full hydration of non-encapsulated GCLs can require a hydration time $\left(t_{\mathrm{h}}\right)$ as long as several weeks, and possibly several months. For example, delayed failure of three of the Cincinnati test plots (Section 6.4) occurred about two months after installation and was attributed to gradual bentonite hydration (Daniel et al. 1998; Daniel 2013). GCL hydration time in the field will be short in comparison with typical construction schedules and, as such, the corresponding hydration normal stress $\left(\sigma_{\mathrm{n}, \mathrm{h}}\right)$ in the laboratory will often be a low value.

A hydration time of several weeks or more is generally impractical for production shear testing of GCLs and GCL interfaces. As an alternative, Gilbert et al. (1997) suggested that a GCL can be considered fully hydrated when the change in thickness is less than $5 \%$ over a $12 \mathrm{~h}$ period. However, use of this criterion may still require $t_{\mathrm{h}}=10$ to 20 days. Another method is to monitor change in thickness until the specimen has reached $100 \%$ primary swelling as determined by ASTM D 4546. The time required for full GCL hydration depends on drainage conditions and generally decreases with increasing $\sigma_{\mathrm{n}, \mathrm{h}}$. In addition, depending on $\sigma_{\mathrm{n}, \mathrm{h}}$, hydration may reveal a change from compression to expansion behavior over time (De Battista 1996; Marr 2001). Gripping surfaces that do not provide adequate drainage pathways may prevent a GCL specimen from becoming fully hydrated. Free drainage conditions on both sides of a GCL specimen will shorten the hydration time. If only one side is freely draining, as in the case of a GM/GCL composite liner, a longer hydration time may be necessary.

McCartney et al. (2009) reported a series of direct shear tests in which NP GCL specimens were hydrated at the shearing normal stress with no consolidation (i.e. $\sigma_{\mathrm{n}, \mathrm{h}}=\sigma_{\mathrm{n}, \mathrm{s}}$ ). Internal peak shear strengths decreased with increasing hydration time up to $t_{\mathrm{h}}=48 \mathrm{~h}$; however, no further decreases were observed beyond $48 \mathrm{~h}$. Similar findings were reported for a GMX/NP GCL interface for hydration times up to $t_{\mathrm{h}}=24 \mathrm{~h}$. Thus, although GCLs continue to hydrate beyond 2 days, little further decrease in shear strength is expected if shearing occurs at the same normal stress. Most production testing laboratories hydrate GCLs for 1 to 2 days, which is consistent with these findings.

\subsubsection{Effect of consolidation}

For unreinforced GCLs, internal shear strength decreases with increasing bentonite water content at a given shearing normal stress (Daniel et al. 1993; Zelic et al. 2002). Figure 32a shows peak and residual strength envelopes for five encapsulated GMX/GM-supported GCL specimens that were hydrated at $\sigma_{\mathrm{n}, \mathrm{s}}$ (Eid and Stark 1997). Figure $32 \mathrm{~b}$ shows corresponding shear strengths for a second set of replicate specimens that were hydrated at $\sigma_{\mathrm{n}, \mathrm{h}}=17 \mathrm{kPa}$ and then slowly consolidated in small increments to $\sigma_{\mathrm{n}, \mathrm{s}}=50,100,200$ and $400 \mathrm{kPa}$ prior to shearing. Each specimen was hydrated/consolidated until vertical deformation (swelling or compression) reached equilibrium under the applied normal stress, which required several months for the second set of tests. A 25 to $30 \%$ reduction in shear strength was measured for the consolidated specimens. Hydration at low normal stress resulted in more water being adsorbed into the double layers of the clay particles, more particle rearrangement and greater bentonite expansion. This additional water was not completely expelled during subsequent consolidation, which resulted in higher bentonite water contents for the consolidated specimens and consequently lower shear strengths (Eid and Stark 1997).

The most definitive data on the effects of consolidation for reinforced GCLs is presented by McCartney et al. (2009), based on earlier work by McCartney et al. (2004b). Internal peak strengths for NP GCL specimens hydrated under the shearing normal stress $\left(\sigma_{\mathrm{n}, \mathrm{h}}=\sigma_{\mathrm{n}, \mathrm{s}}\right.$, $t_{\mathrm{h}}=24 \mathrm{~h}$ ) were compared with corresponding strengths for specimens hydrated under low normal stress

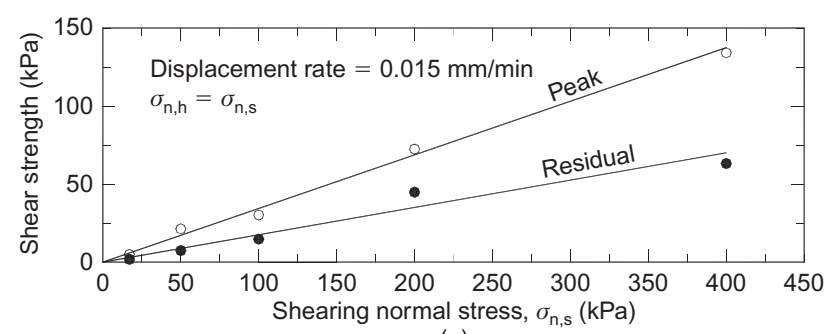

(a)

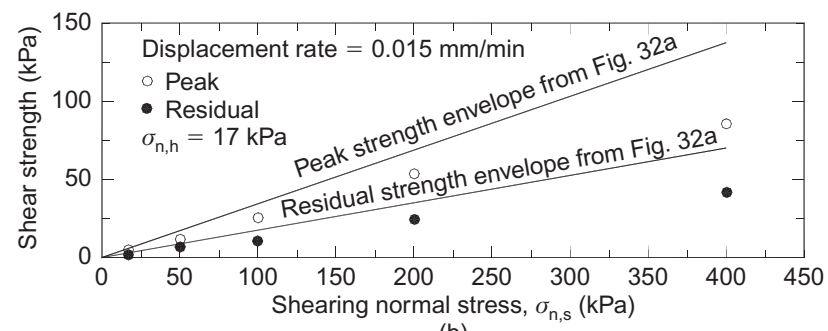

(b)

Figure 32. Peak and residual shear strengths for an encapsulated GMX/GM-supported GCL: (a) hydrated at the shearing normal stress; and (b) hydrated at $\sigma_{\mathrm{nh}}=17 \mathrm{kPa}$ and then consolidated to the shearing normal stress (Eid and Stark 1997) 
$\left(\sigma_{\mathrm{n}, \mathrm{h}}=6.9 \mathrm{kPa}\right)$ and then consolidated to the shearing normal stress with $24 \mathrm{~h}$ permitted for consolidation prior to shearing. The two conditioning procedures produced essentially the same peak strength envelopes. These tests were conducted for low normal stress $\left(\sigma_{\mathrm{n}, \mathrm{s}}<30 \mathrm{kPa}\right)$ and it is unclear whether or not the findings are applicable for higher normal stress conditions. For another series of tests, McCartney et al. (2009) reported that internal peak strength of NP GCLs decreased when the stress increment was applied rapidly with no time permitted for consolidation (i.e. shearing began immediately). This strength reduction can be attributed to the presence of excess pore pressures within the GCL.

Specimen consolidation procedure also can affect GCL interface shear strengths, depending on conditions. Laboratory and field tests have shown that swelling bentonite can extrude through the supporting geotextiles of a GCL and smear on adjacent materials, forming a slippery interface (Byrne 1994; Stark and Eid 1996; Gilbert et al. 1997; Pavlik 1997; Daniel et al. 1998; Eid et al. 1999; Triplett and Fox 2001; Vukelic et al. 2008; Daniel 2013). In these studies, extruded bentonite was more commonly observed on the $\mathrm{W}$ side of a W/NW NP GCL than the NW side. Triplett and Fox (2001) and Vukelic et al. (2008) reported that the amount of extruded bentonite increased with increasing normal stress. Fox and Stark (2004) suggested that the amount of extruded bentonite will generally increase as the GT becomes thinner, the bentonite becomes softer (i.e. lower $\sigma_{\mathrm{n}, \mathrm{h}}$ ), and as more water flows into the interface from the GCL during consolidation (i.e. due to larger consolidation increment, larger transmissivity of the interface, or larger hydraulic conductivity of the adjacent material). These concepts are generally supported by the experimental results of Vukelic et al. (2008) and Chen et al. (2010) for GMX/NP GCL(W side) specimens. These studies found that the amount of extruded bentonite increased with increasing loading (i.e. consolidation) rate, shear displacement caused additional bentonite extrusion, and bentonite extrusion significantly reduced GMX/NP GCL interface strength. However, for slow loading conditions in which the normal stress was increased from 0.1 to $200 \mathrm{kPa}$ over a 25 day period, there was no visible extruded bentonite at the GMX/NP GCL interface (Chen et al. 2010). Vukelic et al. (2008) also reported no extruded bentonite for specimens that were hydrated and sheared under constant normal stress (i.e. no consolidation).

Similar to GCL internal shear tests, incomplete consolidation can reduce the shear strength for a GM/GCL interface. Hewitt et al. (1997) measured lower peak and large displacement strengths for GMX/NP GCL(NW side) and GMX/SB GCL interfaces when shearing began $15 \mathrm{~min}$ after the application of the final consolidation increment. McCartney et al. (2009) reported lower shear strengths for a GMX/NP GCL(W side) interface when the stress increment was rapidly applied with no time permitted for consolidation (i.e. shearing began immediately). Strength reduction in these tests can be attributed to excess pore pressures on the interface. However, unlike Hewitt et al. (1997), McCartney et al. (2009) reported no such strength reduction for a GMX/NP GCL(NW side) interface under low to moderate normal stress conditions. This is attributed to higher interface transmissivity for these specimens.

McCartney et al. (2009) also investigated the effect of consolidation for GM/NP GCL interfaces under low normal stress conditions. Peak shear strengths for a GMX/ NP GCL(W side) interface hydrated for $72 \mathrm{~h}$ with no consolidation (i.e. $\sigma_{\mathrm{n}, \mathrm{s}}=\sigma_{\mathrm{n}, \mathrm{h}}$ ) were compared with strengths for replicate specimens hydrated under zero normal stress (i.e. $\sigma_{\mathrm{n}, \mathrm{h}}=0$ ) for $72 \mathrm{~h}$ and then consolidated at the shearing normal stress for $48 \mathrm{~h}$. The consolidated specimens had lower peak strengths, which can be attributed to extruded bentonite and/or excess pore pressures on the failure surface. Although less data are available, existing results suggest that peak shear strengths for GMX/NP GCL(NW side) interfaces are less sensitive to conditioning procedure. The database of McCartney et al. (2009) also indicates that large displacement strengths for both NP GCLs and GMX/NP GCL interfaces are insensitive to conditioning procedure.

\subsubsection{Accelerated conditioning procedure}

Hydration to equilibrium followed by slow consolidation to the shearing normal stress will often be impractical for production shear tests where GCL specimens are conditioned in the shear device. There are two ways to circumvent this problem. First, some direct shear devices have separate shear frame and shear box assemblies so that multiple GCL specimens can be hydrated and consolidated simultaneously outside of the shear frame. As a result, shear tests are not delayed by the lengthy time required to condition each specimen. Second, a two-stage accelerated procedure can be used to reduce the in-device time for GCL specimens to reach hydration equilibrium (Fox et al. 1998a). According to this method, a GCL specimen is initially hydrated outside of the shear device for 2 days under a low normal stress $(1 \mathrm{kPa})$ by adding just enough water to reach the expected final water content for the test. These final water content values are estimated from previous test results. Thus, the first stage does not correspond to a free swell (i.e. inundated) condition. For the second stage, the specimen is placed in the shear device and hydrated with free access to water for an additional 2 days under the desired normal stress $\sigma_{\mathrm{n}, \mathrm{h}}$. Most GCL specimens attain equilibrium in less than $24 \mathrm{~h}$, and often less than $6 \mathrm{~h}$, using this procedure (Fox et al. 1998a, 2006; Triplett and Fox 2001; Fox and Ross 2011). Such rapid equilibration times can only occur if the gripping surfaces permit good water access for a GCL specimen (Sections 8.3, 8.6).

Fox et al. (1998a) investigated the performance of the two-stage accelerated conditioning procedure for two W/NW NP GCL specimens. One specimen was placed dry in the shear device and hydrated with free access to water under $\sigma_{\mathrm{n}, \mathrm{h}}=38 \mathrm{kPa}$. The second specimen was hydrated using the accelerated procedure. Measurements of vertical displacement of the loading platen during hydration in the shear device (i.e. second stage) are compared in Figure 33. Zero vertical displacement corresponds to just before $\sigma_{\mathrm{n}, \mathrm{h}}$ 


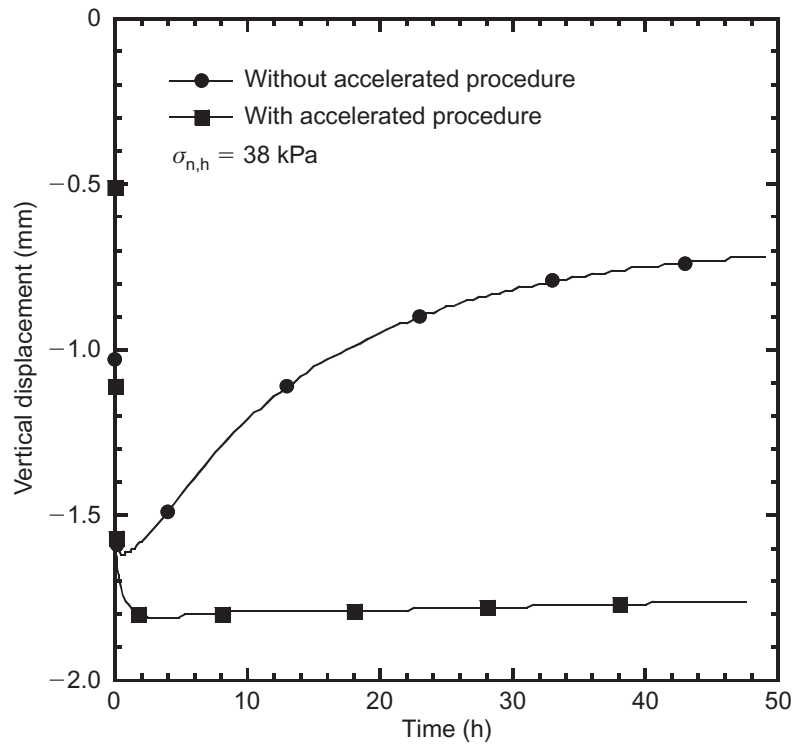

Figure 33. Effect of two-stage accelerated conditioning procedure for a W/NW NP GCL (Fox et al. 1998a)

was applied and negative values indicate compression. The data show that volume change essentially ceased after $2 \mathrm{~h}$ for the GCL specimen hydrated using the accelerated procedure. Shear tests indicated that the accelerated procedure had no significant effect on the measured $\tau-\delta$ relationships for these specimens. Another example is provided in Figure 34, which shows that volume change in the shear device essentially ceased after $4 \mathrm{~h}$ for two additional W/NW NP GCL specimens hydrated using the accelerated procedure $\left(\sigma_{\mathrm{n}, \mathrm{h}}=141 \mathrm{kPa}\right)$.

\subsubsection{Recommended conditioning procedures}

Based on available evidence, the following GCL conditioning procedures are recommended for internal and interface shear tests. If the shear strength for a GCL or GCL interface is desired at the hydration normal stress in

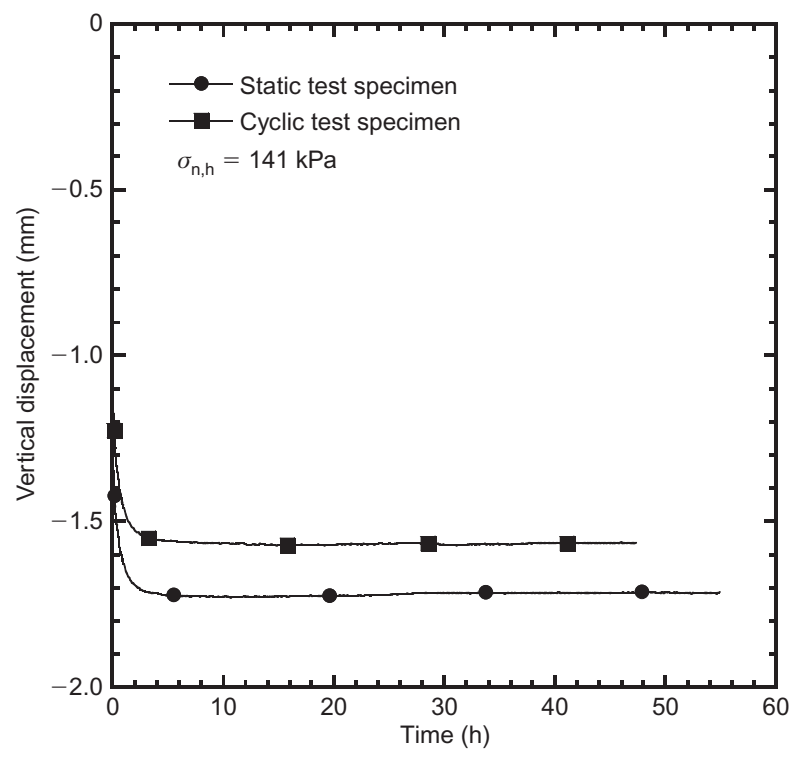

Figure 34. Volume change behavior during second-stage of two-stage accelerated conditioning procedure for two W/NW NP GCLs (Fox et al. 2006) the field, shearing can begin once the hydration stage has completed. For example, GCL specimens would typically be hydrated and sheared under constant (low) normal stress for a landfill cover system. The hydration normal stress should be maintained on the specimen for a minimum of 2 days prior to shearing. If shear strength is required at a normal stress level above the hydration normal stress, such as for a landfill bottom liner system, there are two options: (1) hydrate the specimen under low normal stress and slowly consolidate to the shearing normal stress, and (2) hydrate the specimen under the shearing normal stress using the two-stage accelerated procedure. The second author recommends the first method because it follows the field hydration and stress sequence. The first author recommends the second method as a practical alternative. The advantages and limitations of each method are discussed in the following paragraphs.

For the first method, the GCL specimen is hydrated for a minimum of 2 days under the normal stress expected in the field at the time of hydration and then slowly consolidated to the shearing normal stress. A single rapid normal stress change from $\sigma_{\mathrm{n}, \mathrm{h}}$ to $\sigma_{\mathrm{n}, \mathrm{s}}$ is not appropriate for hydrated GCLs unless the change is small (e.g. $\left.\sigma_{\mathrm{n}, \mathrm{s}}-\sigma_{\mathrm{n}, \mathrm{h}} \leqslant 0.5 \sigma_{\mathrm{n}, \mathrm{h}}\right)$ or unless the change simulates actual field conditions. Instead, consolidation stresses should be applied in small increments over an extended time period to avoid excessive bentonite extrusion from the specimen. Continuous (i.e. ramp) loading is preferred. The maximum rate of stress increase for a continuousloading procedure will depend on specimen type, hydration normal stress, shearing normal stress, and experience, but is recommended to extend over a minimum of 5 days, including 1 day of constant normal stress prior to shear. Incremental-loading consolidation procedures are also possible; however, this approach increases the risk of bentonite extrusion and should only be used with a small stress-increment-ratio (i.e. change in normal stress/previous normal stress). Consolidation stresses should generally be applied using daily or half-day increments and, following Fox et al. (2004), a maximum stress-incrementratio of 0.5 . Vertical displacement measurements (if available) can be used to establish the duration of each stress increment (e.g. using $\sqrt{t}$ or $\log t$ graphical procedures). A new stress increment can be applied before consolidation is completed for the previous increment; however, a GCL specimen should be fully consolidated under the final (i.e. shearing) normal stress over a minimum of 2 days. Considering the above procedures, the required time for the first conditioning method may be 1 week or more. The only way to avoid the impact of long GCL consolidation times on a testing program is to simultaneously condition multiple GCL specimens in separate shear boxes outside of the shear frame (Section 8.10.5). If normal stress application occurs too quickly a GCL specimen is likely to experience higher amounts of bentonite extrusion and may contain excess pore pressures at the start of shearing, both of which can reduce measured shear strength, in particular for GM/GCL interface tests. More research is needed to identify the most appropriate consolidation procedure for hydrated GCLs. 
For the second method, the GCL specimen is hydrated under the shearing normal stress using the two-stage accelerated procedure. Thus, there is no consolidation and the recommended hydration time in the shear device is 2 days, which leads to significant time and cost savings. Although the field hydration and stress sequence is not followed during this procedure, the risk of excessive bentonite extrusion and lingering excess pore pressures, which can occur with the first method if consolidation occurs too quickly, is avoided. There is some evidence to support use of the second method. The data of McCartney et al. (2009) suggest that internal peak strengths for NP GCLs will be in close agreement using the two methods; however, the consolidation time may have been too short for specimens to reach equilibrium in that study. For GMX/GCL interfaces, slow consolidation conditions, such as expected in the field, produce little to no bentonite extrusion (Chen et al. 2010). This will be more closely simulated by hydration under the shearing normal stress (Vukelic et al. 2008), similar to the accelerated procedure. Thus, unless consolidation is conducted slowly for the first method, the second method may produce conditions closer to the field.

\subsection{Specimen shearing stage}

\subsubsection{Importance of displacement rate}

With the exception of stress-controlled creep tests, GCL shear tests should be displacement-controlled to permit measurement of post-peak behavior. The only issue remaining for the shearing stage is the recommended rate(s) of shear displacement. The maximum allowable displacement rate is important because it significantly affects the time and cost required to perform GCL shear tests. Shear strength of hydrated GCLs is expected to be rate-dependent because displacement rate can affect shearinduced excess pore pressures and bentonite extrusion, and because both hydrated bentonite and geosynthetics display creep and strain rate effects. Conversely, the strength of dry unreinforced GCLs should display minimal displacement rate effects. Eid and Stark (1997) demonstrated that, indeed, peak and residual shear strengths of dry encapsulated GCLs are essentially constant for $R \leqslant 1 \mathrm{~mm} / \mathrm{min}$, as shown in Figure 35 . Therefore, the industry default displacement rate of $R=1 \mathrm{~mm} / \mathrm{min}$ is recommended for such tests. The remainder of this section is concerned with the appropriate displacement rate(s) for static shear tests of hydrated GCLs and GCL interfaces. Dynamic shear tests are conducted at much faster rates and are discussed in Section 5.

Further insight into mechanisms responsible for displacement rate effects can be gained by examination of Figure 36, which presents internal peak and residual shear strengths for unfilled and filled specimens of a hydrated W/NW NP GCL $\left(\sigma_{\mathrm{n}, \mathrm{h}}=\sigma_{\mathrm{n}, \mathrm{s}}=17 \mathrm{kPa}, R=0.015\right.$ to $36.5 \mathrm{~mm} / \mathrm{min}$ ) (Stark and Eid 1996). For the unfilled specimens, the dry powdered bentonite was removed prior to hydration by holding the specimens vertically and lightly tapping the geotextiles. Bentonite was not removed from the filled specimens. Peak strengths for both unfilled and filled specimens are approximately constant for

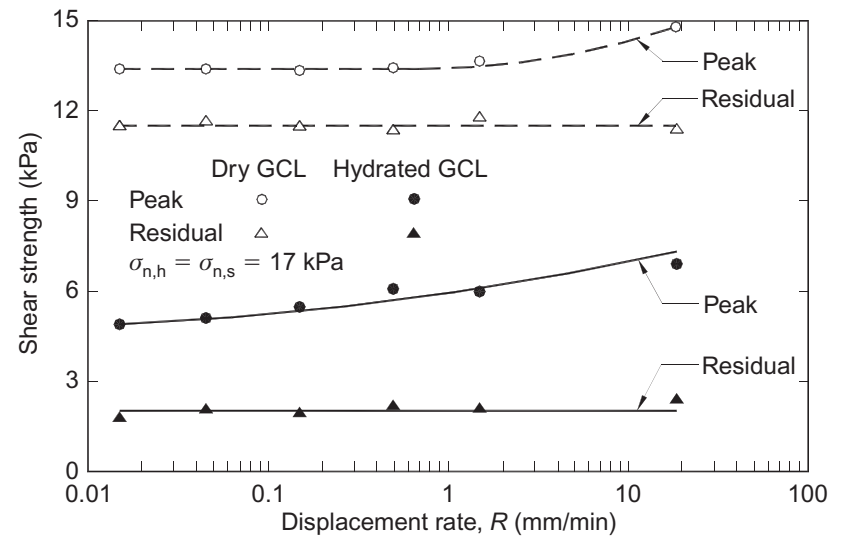

Figure 35. Effect of displacement rate on interface shear strengths for dry and hydrated specimens of an encapsulated GMX/GMS-supported GCL (Eid and Stark 1997)

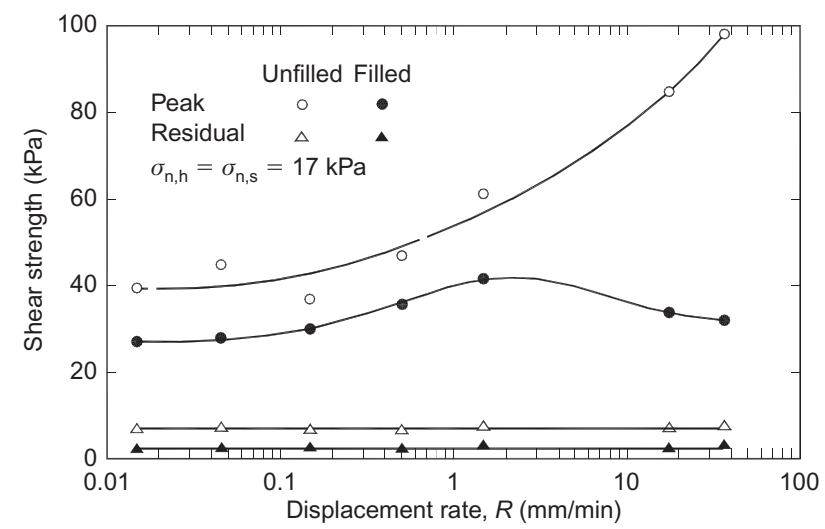

Figure 36. Effect of displacement rate on internal shear strengths for unfilled and filled specimens of a hydrated W/NW NP GCL (Stark and Eid 1996)

$R \leqslant 0.04 \mathrm{~mm} / \mathrm{min}$. For $R=0.04$ to $1.5 \mathrm{~mm} / \mathrm{min}$, peak strengths show similar increases, which suggests the displacement rate effect in this range lies with the geosynthetics and may include rapid pullout or rupture of reinforcing fibers. Peak strengths then diverge for $R>1.5 \mathrm{~mm} / \mathrm{min}$, possibly due to shear-induced excess pore pressures generated in the filled specimens. Thus, the relative importance of different mechanisms that control internal shear resistance may vary with displacement rate. The data also show that residual strengths for the unfilled and filled specimens were independent of displacement rate at this low normal stress.

\subsubsection{Displacement rate effects for hydrated unrein- forced GCLs}

Several studies have investigated the effect of displacement rate on measured shear strength for hydrated unreinforced GCLs. Daniel et al. (1993) tested specimens of a GM-supported GCL at several water contents $\left(\sigma_{\mathrm{n}, \mathrm{s}}=27\right.$ to $139 \mathrm{kPa}, R=0.0003$ and $0.26 \mathrm{~mm} / \mathrm{min}$ ). For each water content, peak strength was significantly higher, often by 100 to $200 \%$, at the higher displacement rate. Eid and Stark (1997) measured shear strengths for a hydrated encapsulated GMX/GMS-supported GCL using a torsional ring shear device $\left(\sigma_{\mathrm{n}, \mathrm{h}}=\sigma_{\mathrm{n}, \mathrm{s}}=17 \mathrm{kPa}, R=0.015\right.$ to 
$18.5 \mathrm{~mm} / \mathrm{min}$ ). All failures occurred at the GMX/hydrated bentonite interface. Results are presented in Figure 35 and indicate that peak strengths increased approximately $13 \%$ per log cycle of displacement rate. Residual strengths were determined to be independent of displacement rate (although the $\tau_{\mathrm{r}}$ data suggest a slightly increasing trend). Gilbert et al. (1997) conducted direct shear tests to evaluate displacement rate effects for an unreinforced GCL $\left(\sigma_{\mathrm{n}, \mathrm{h}}=\sigma_{\mathrm{n}, \mathrm{s}}=17\right.$ and $\left.170 \mathrm{kPa}\right)$. Normalized peak shear strengths $\left(\tau_{\mathrm{p}} / \sigma_{\mathrm{n}, \mathrm{s}}\right)$ are plotted against displacement rate in Figure 37. Peak strengths generally increased with increasing displacement rate, especially for the lower normal stress where the strength at $1.0 \mathrm{~mm} / \mathrm{min}$ is approximately $40 \%$ higher than the strength at $0.0005 \mathrm{~mm} / \mathrm{min}$. Displacement rate effects were less significant at the higher normal stress. Zelic et al. (2002) showed that, on average, peak strengths of an unreinforced GT-supported GCL increased 54\% and end-of-test $(\delta=15 \mathrm{~mm})$ strengths increased $111 \%$ when the displacement rate was increased from 0.0015 to $1.2 \mathrm{~mm} / \mathrm{min}$. Zelic et al. (2002) also concluded that cohesion intercept is controlled more by total test duration and final bentonite water content, whereas friction angle is controlled by displacement rate.

\subsubsection{Displacement rate effects for hydrated reinforced GCLs}

Several studies have also investigated the effect of displacement rate on measured shear strength for hydrated reinforced GCLs. Berard (1997) conducted direct shear tests on six W/NW NP GCLs and reported that increasing the displacement rate from 0.01 to $1 \mathrm{~mm} / \mathrm{min}$ yielded a $41 \%$ average increase in peak strength $\left(\sigma_{\mathrm{n}, \mathrm{s}}=25\right.$ to $100 \mathrm{kPa}$ ). Fox et al. (1998a) found that displacement rate had a relatively minor effect on peak and residual shear strengths of $\mathrm{W} / \mathrm{W} \mathrm{SB}$ and $\mathrm{W} / \mathrm{NW}$ NP GCLs $\left(\sigma_{\mathrm{n}, \mathrm{h}}=\sigma_{\mathrm{n}, \mathrm{s}}=72 \mathrm{kPa}, R=0.01\right.$ to $\left.10 \mathrm{~mm} / \mathrm{min}\right)$. The data

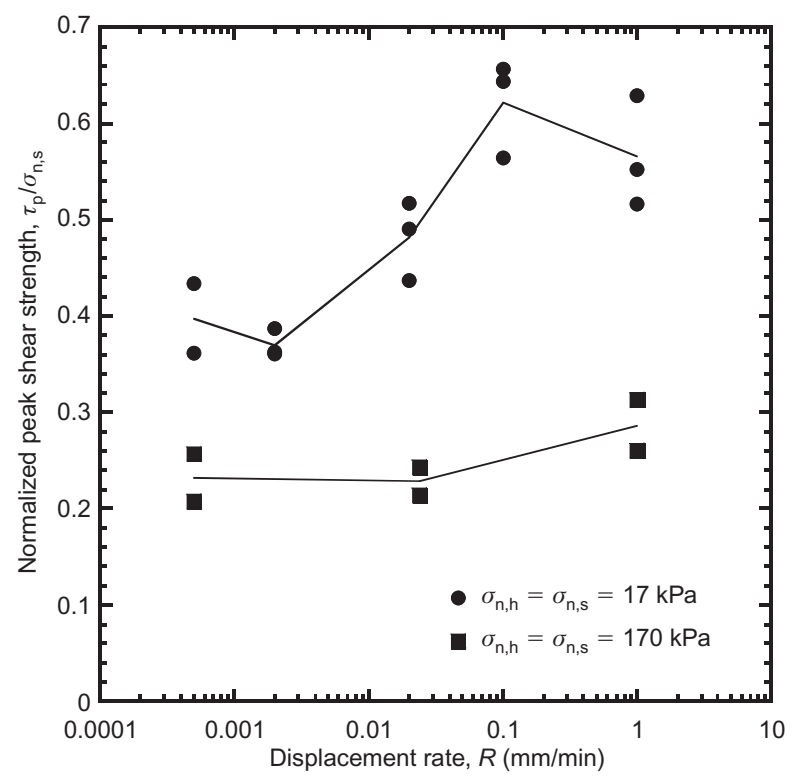

Figure 37. Effect of displacement rate on normalized peak shear strength for a hydrated unreinforced GCL (after Gilbert et al. (1997), data used with permission) are presented in Figure 38 and indicate that both values increased 3 to $5 \%$ for each log cycle of displacement rate. These trends are attributed to the strain rate-dependent strength of the hydrated bentonite because: (1) any shearinduced excess pore pressures should have been positive (based on volume change behavior), which would reduce strength with increasing displacement rate, and (2) $\tau_{\mathrm{r}}$ values show the same general trend as $\tau_{\mathrm{p}}$, which suggests the rate effect is not associated with the geosynthetic reinforcement.

Stark and Eid (1996) and Eid et al. (1999) investigated displacement rate effects for a heat-treated W/NW NP GCL using torsional ring shear tests $\left(\sigma_{\mathrm{n}, \mathrm{s}}=17\right.$ to $400 \mathrm{kPa}, R=0.015$ to $36.5 \mathrm{~mm} / \mathrm{min})$. Results are presented in Figure 39. With increasing displacement rate, peak strengths for $\sigma_{\mathrm{n}, \mathrm{s}}=17$ and $100 \mathrm{kPa}$ reached maximum values with lower values on either side, whereas peak strengths for $\sigma_{\mathrm{n}, \mathrm{s}}=200$ and $400 \mathrm{kPa}$ were nearly constant until values started to increase at higher displacement rates. Explanations provided for this complex behav-

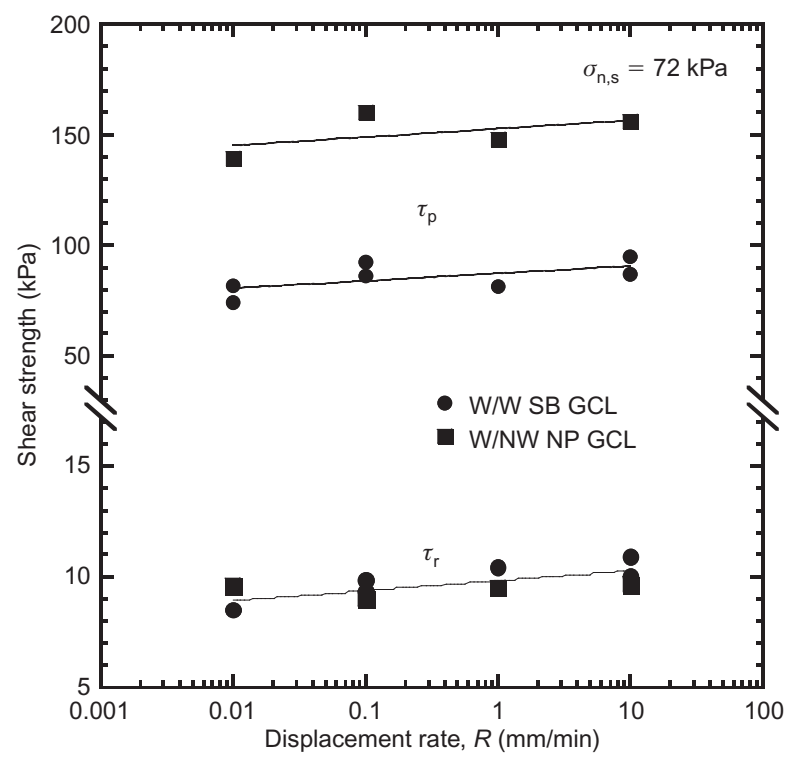

Figure 38. Effect of displacement rate on internal shear strengths for hydrated reinforced GCLs (Fox et al. 1998a; Fox and Athanassopoulos 2012)

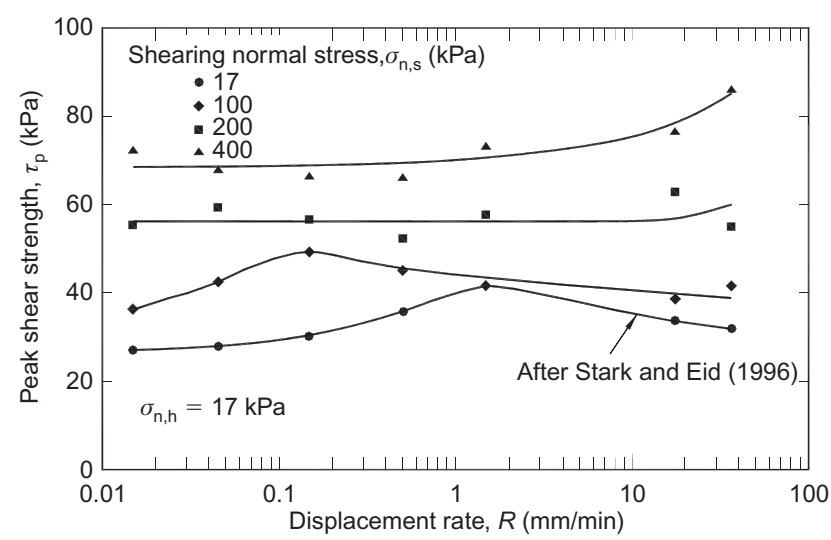

Figure 39. Effect of displacement rate on peak shear strength for a hydrated heat-treated W/NW NP GCL (Eid et al. 1999) 
ior involve shear-induced excess pore pressures, rapid pullout or rupture of needle-punched fibers, and undrained frictional resistance of the hydrated bentonite. Eid et al. (1999) also concluded that residual shear strengths were independent of displacement rate at all normal stress levels. Zornberg et al. (2005) reported displacement rate effects for a W/NW NP GCL in direct shear $\left(\sigma_{\mathrm{n}, \mathrm{s}}=50\right.$ and $520 \mathrm{kPa}, R=0.0015$ to $1 \mathrm{~mm} / \mathrm{min}$ ). Peak strengths increased linearly with increasing $\log$ displacement rate for $\sigma_{\mathrm{n}, \mathrm{s}}=50 \mathrm{kPa}$ and decreased linearly with increasing $\log$ displacement rate for $\sigma_{\mathrm{n}, \mathrm{s}}=520 \mathrm{kPa}$. The data of Fox et al. (2015) show that, in the static range $(R \leqslant 1 \mathrm{~mm} /$ min), peak strengths for a W/NW NP GCL were approximately constant with increasing displacement rate (Figure 13a). Large displacement strengths decreased with increasing displacement rate and this effect became more significant with increasing normal stress (Figure 13b). The reduction of large displacement strength is attributed to shear-induced excess pore pressures and, as such, $R=0.1 \mathrm{~mm} / \mathrm{min}$ would be more representative of static loading (i.e. drained) conditions in the field.

\subsubsection{Displacement rate effects for hydrated GMX/NP GCL interfaces}

Triplett and Fox (2001) found that displacement rate had little effect, on average, for peak and large displacement interface shear strengths between a hydrated W/NW NP GCL (W side) and three types of HDPE GMs (1 GMS, 2 GMX) $\left(\sigma_{\mathrm{n}, \mathrm{s}}=72 \mathrm{kPa}, R=0.01\right.$ to $\left.10 \mathrm{~mm} / \mathrm{min}\right)$. Results are presented in Figure 40. This conclusion is consistent with data from Stark et al. (1996) for a GMX/NW GT interface $\left(\sigma_{\mathrm{n}, \mathrm{s}}=96 \mathrm{kPa}, R=0.029\right.$ to $\left.36.7 \mathrm{~mm} / \mathrm{min}\right)$ and McCartney et al. (2009) for a large GMX/GCL database $\left(\sigma_{\mathrm{n} . \mathrm{s}} \leqslant 345 \mathrm{kPa}, R=0.025\right.$ to $1 \mathrm{~mm} / \mathrm{min}$ ). Ross and Fox (2015) also found that displacement rate had little effect on the static shear strengths of a GMX/NP GCL interface at

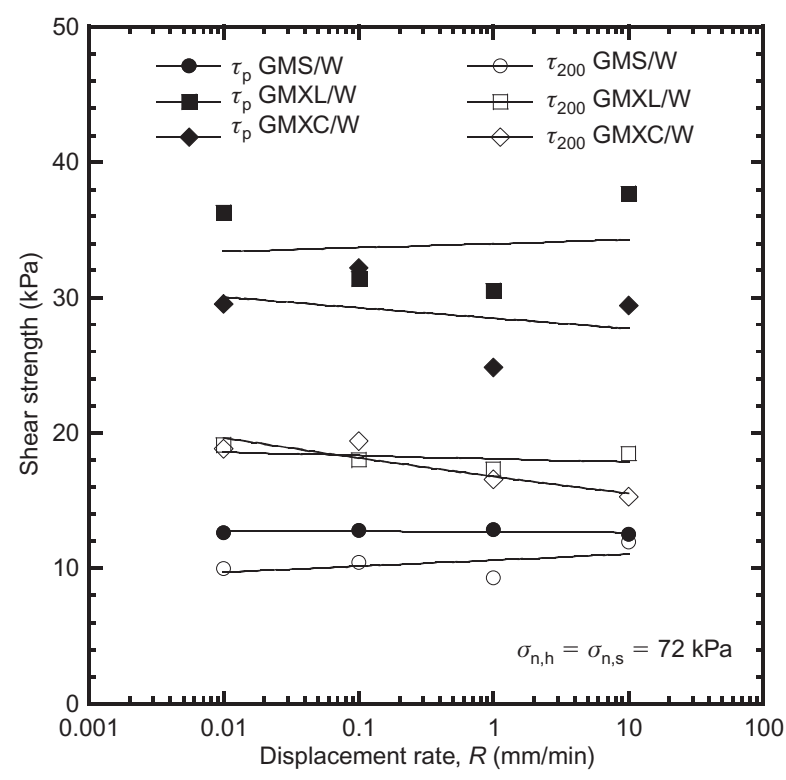

Figure 40. Effect of displacement rate on interface shear strengths between a hydrated W/NW NP GCL and smooth (GMS), laminated textured (GMXL), and coextruded textured (GMXC) geomembranes (Triplett and Fox 2001) low normal stress (Figure 17). At higher normal stress $\left(\sigma_{\mathrm{n}, \mathrm{s}}=348\right.$ and $\left.692 \mathrm{kPa}\right)$, Figure 17 shows that peak interface strengths were approximately constant and large displacement interface strengths decreased with increasing displacement rate in the static range. The reduction of large displacement strength was significant for $\sigma_{\mathrm{n}, \mathrm{s}}=692 \mathrm{kPa}$ and is attributed to shear-induced excess pore pressures on the failure surface.

\subsubsection{Recommended maximum displacement rates}

Recommended maximum displacement rates for static shear tests of GCLs and GCL interfaces are consistent with those of the original SOA report (Fox and Stark 2004) and subsequent revisions to ASTM D 6243. The recommended values are $0.1 \mathrm{~mm} / \mathrm{min}$ for internal shear tests of hydrated GCLs, $1 \mathrm{~mm} / \mathrm{min}$ for internal shear tests of dry encapsulated GCLs, and, if excess pore pressures are not expected to develop, $1 \mathrm{~mm} / \mathrm{min}$ for interface shear tests involving hydrated GCLs. Excess pore pressures are more likely to develop at high shearing normal stress and $0.1 \mathrm{~mm} / \mathrm{min}$ may be needed for interface shear tests at these levels to better simulate static loading conditions in the field. The recommended maximum displacement rate for multi-interface shear tests is also $1 \mathrm{~mm} / \mathrm{min}$ and, if failure occurs within a hydrated GCL, the test should be repeated using $0.1 \mathrm{~mm} / \mathrm{min}$. If failure occurs on a geosynthetic/geosynthetic interface away from the GCL specimen, and excess pore pressures are not expected to develop, ASTM D 5321 recommends a maximum displacement rate of $5 \mathrm{~mm} / \mathrm{min}$. Dynamic shear tests should be conducted in accordance with project-specific requirements. Recent data from Fox et al. (2015) and Ross and Fox (2015) suggest that displacement rate effects for GCLs and GCL interfaces may be more complicated that previously considered and additional research is needed on this issue.

\subsection{Final inspection and water contents}

Failed GCL and GCL interface specimens should be inspected carefully after shearing to assess the surface(s) on which failure occurred and the general nature of the failure. Unusual distortion or tearing of a specimen should be noted and may indicate problems with the gripping surfaces (Section 8.6). The condition of geosynthetics at specimen end clamps (if applicable) also should be noted. Evidence of high tensile forces at the clamps, such as tearing or necking of the geosynthetics, are indications that progressive failure may have occurred during shear. Depending on the extent of localized distress, such a test may be invalid and need to be repeated using improved gripping surfaces.

Final water contents of the GCL and subgrade soil (if applicable) should be taken to assess the level and uniformity of hydration that was achieved. Five water content measurements are recommended for a GCL specimen (e.g. one center and four corners). The shear device must be disassembled quickly after shearing is completed for measured water contents to have validity. Figure 41a shows a plot of final water content $\left(w_{\mathrm{f}}\right)$ and internal residual shear strength against normal stress, as obtained 


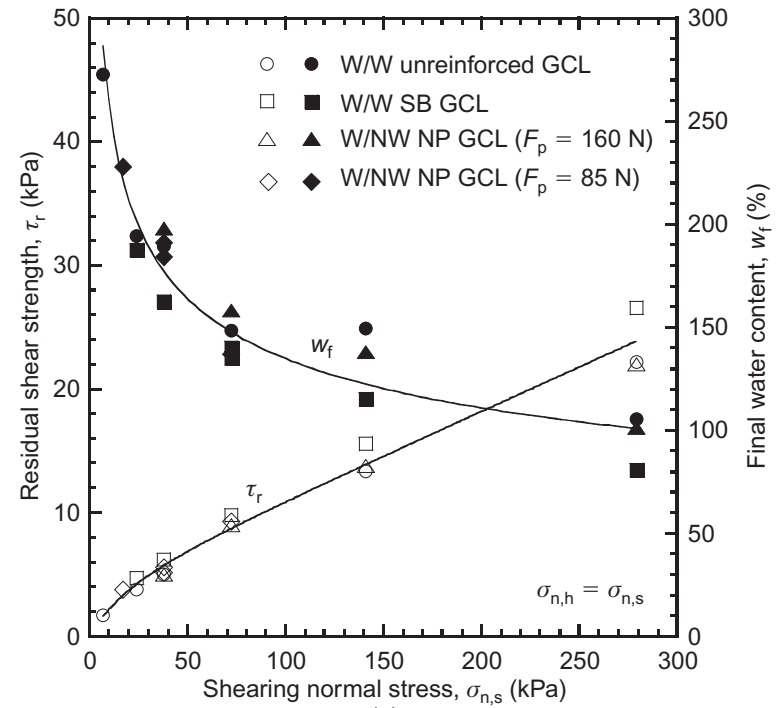

(a)

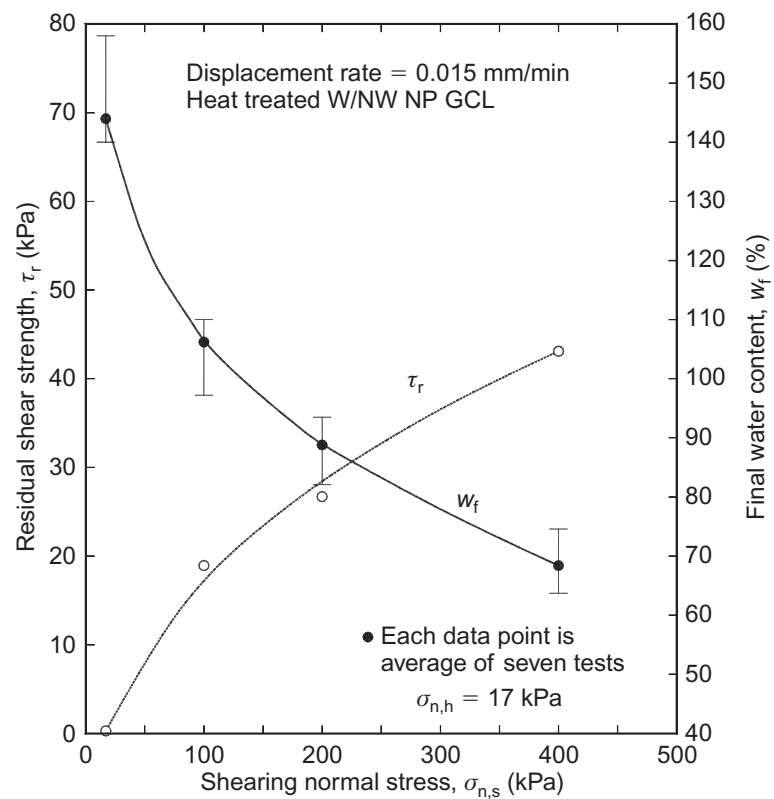

(b)

Figure 41. Residual shear strengths and final water contents for hydrated GCLs tested in: (a) direct shear (Fox et al. 1998a); and (b) torsional ring shear (Eid et al. 1999)

from direct shear tests of several GCLs (Fox et al. 1998a). The specimens were conditioned using the two-stage accelerated procedure (Section 8.10.5). Similar data obtained for a NW/NW NP GCL over a larger normal stress range is presented by Fox and Ross (2011) and in good agreement with the $w_{\mathrm{f}}$ trend shown in Figure 41a. A corresponding plot for torsional ring shear tests on a heattreated W/NW NP GCL $\left(F_{\mathrm{p}}=270 \mathrm{~N} / \mathrm{m}\right)$ is shown in Figure 41b (Eid et al. 1999). These specimens were hydrated at $\sigma_{\mathrm{n}, \mathrm{h}}=17 \mathrm{kPa}$ and then slowly consolidated to the shearing normal stress. The plots show that water content decreases nonlinearly with increasing normal stress and higher final water contents and residual strengths were measured for the direct shear tests. Considering the different conditioning procedures and the discussion in Section 8.10.4, water contents for the direct shear tests would be expected to be lower than for the ring shear tests. The reason for this discrepancy is unclear; however, the direct shear $w_{\mathrm{f}}$ values were measured from whole GCL samples whereas the ring shear values were measured from bentonite sampled in the immediate vicinity of the failure surface using a spatula. Figure 41 may be used to determine if complete hydration occurred in a laboratory shear test. If the average final water content is significantly lower than values indicated by Figure 41, full GCL hydration may not have been achieved.

\section{SPECIFICATION OF TESTING PROGRAM AND DELIVERY OF RESULTS}

Shear tests for GCLs and GCL interfaces generally should be conducted in accordance with appropriate standard testing procedures (e.g. ASTM D 6243 in the USA). However, simply requiring that tests be conducted according to ASTM D 6243 is not sufficient. Test conditions should be specified by the responsible engineer. Marr (2001) provides examples of language that also can be included to reduce the likelihood for disputes and delays with regard to GCL shear tests. This section presents a list of additional considerations to ensure that quality test results are obtained.

When contracting for GCL shear tests, a user should require the following.

1. Regular calibration of test equipment for accuracy of normal stress and shear force (minimum once per year recommended).

2. Specimen gripping surfaces that can impart uniform shearing without slippage.

3. Proper conditioning of GCL specimens, including slow consolidation to the shearing normal stress (if applicable).

4. Measurement of specimen volume change during conditioning and shearing (if possible).

5. Thorough inspection and photographs of failed specimens.

6. Measurement of final GCL water contents and subgrade soil water contents (if applicable).

When contracting for GCL shear tests, a user should provide the following.

1. GCL material (obtained from or designated for actual project if possible).

2. Subgrade soil (if applicable).

3. Geosynthetic interface materials (if applicable).

4. Hydration liquid (if different from tap water).

When contracting for GCL shear tests, a user should specify the following.

1. Specimen selection, trimming, and archiving procedures.

2. Number and type of tests.

3. Specimen configurations (bottom to top).

4. Soil compaction procedure (if applicable). 
5. Number of interfaces (single or multiple) to be tested at the same time.

6. Orientation of specimens (machine or transverse direction).

7. Conditioning procedure.

8. Shearing procedure, including normal stress levels, minimum final displacement, and displacement rates.

When receiving the results of GCL shear tests, a user should expect the following.

1. Description of specimen selection, trimming, and archiving procedures.

2. Description of test equipment.

3. Description of specimen configurations.

4. Description of test conditions (conditioning, shearing).

5. Shear stress-displacement relationships.

6. Specimen volume change data during conditioning and shearing (if available).

7. Peak and large displacement shear strengths and possibly shear strength parameters (see below).

8. Location and condition of failure surfaces.

9. Photographs of equipment, failed specimens, and failure surfaces.

10. Final GCL water contents and subgrade soil water contents (if applicable).

In general, shear strength parameters for design should be determined by the responsible engineer based on project-specific considerations. If strength parameters are provided by the testing laboratory (typically based on linear regression), the engineer should evaluate whether or not these parameters are appropriate considering the true trend, variability and final shear displacement of the data, the normal stress range of interest, and necessary conservatism for the project. A similar evaluation must be made at the time of construction if shear strength parameters are provided with the results of conformance tests. At this stage, the construction quality assurance/quality control subcontractor generally has the responsibility to determine if actual liner materials meet the required strength specifications.

\section{CONCLUSIONS AND RECOMMENDATIONS}

The foregoing state-of-the-art report has led to the following conclusions and recommendations for the shear strength and shear strength testing of GCLs and GCL interfaces.

1. Reported values of GCL internal and interface shear strengths show significant variability due to variability in component materials and manufacturing processes, differences in testing equipment and procedures, and changes in the design, manufacture, and application of GCLs over time. As a result, shear strength parameters for final design must be measured using project-specific materials and conditions.

2. All GCLs and most GCL interfaces experience postpeak strength reduction, in which the measured shear strength decreases after the peak and ultimately reaches a residual value. Dry unreinforced GMXsupported GCLs generally have similar internal peak strengths and much higher internal residual strengths than hydrated reinforced GCLs.

3. The current practice of characterizing GCL shear strength parameters in terms of total normal stress and then using these parameters for drained effective stress stability analyses appears to be either appropriate or conservative.

4. Depending on the materials and shearing normal stress range, peak strength envelopes for GCLs and GCL interfaces can be linear, multi-linear or nonlinear, whereas residual strength envelopes are often approximately linear and may contain discontinuities. Discontinuities can occur if the failure mode of a multi-interface specimen changes with increasing normal stress.

5. Unconservative fitting practices must be avoided in the determination of strength envelopes from test data, especially when linear relationships are used to characterize nonlinear data. Shear strength parameters should not be extrapolated outside of the normal stress range for which they were obtained. Under some conditions these problems can be avoided by directly entering shear strength data into slope stability software.

6. The internal residual friction angle for hydrated GCLs with natural sodium bentonite will typically range from 4 to $5^{\circ}$. The interface large-displacement friction angle for hydrated GM/NP GCL interfaces, including GMS/NP GCL, is larger than for internal shear of hydrated NP GCLs.

7. Static shear tests indicate that, in most cases, contemporary NP GCLs have larger peak strengths than GMX/NP GCL interfaces. GMX/NP GCL composite liners can experience GCL internal failure if the normal stress is sufficiently high. The normal stress at failure mode transition can vary widely, depending on specific materials and test conditions.

8. Multi-interface GCL specimens can yield higher shear strength when a coarse (i.e. gravelly) soil is in close proximity to the failure surface and causes local out-of-plane deformations. The common practice of performing single-interface shear tests using rigid backing plates is likely to be conservative with regard to shear strength of GMX/GCL composite liners that are in contact with coarse soils.

9. The shear strength of GCLs and GCL interfaces can display in-plane anisotropy. Shear strength may be different in machine and transverse directions (i.e. rotated $90^{\circ}$ ), and also in opposite machine directions (i.e. rotated $180^{\circ}$ ). Direct shear tests should be conducted in the weakest machine direction (if applicable) to avoid overestimating shear strength in the field. 
10. Good reproducibility of shear strength has been reported for replicate tests using GCL and GM materials from the same manufacturing lots; however, significant variability, up to approximately $50 \%$, has been reported using materials from different lots. Shear strengths of GMX/NP GCL interfaces display less variability than internal strengths of NP GCLs. Shear strength variability increases approximately linearly with increasing normal stress.

11. Dynamic shear tests indicate that, depending on normal stress, peak and large-displacement shear strengths of hydrated NP GCLs and GMX/NP GCL interfaces can be significantly affected with increasing displacement rate. The failure mode of GMX/NP GCL composite liners is dependent on displacement rate at high normal stress.

12. GCLs display creep and degradation effects, which are not evaluated by short-term tests. Long-term strength behavior is strongly dependent on temperature and water chemistry and may not correlate with results from short-term tests, including peel strength and short-term shear strength. In field tests, GCLs and GCL interfaces have sustained design-level shear stress without failure for many years; failures that have occurred were successfully predicted using short-term shear strengths.

13. The selection of appropriate peak and residual strength envelopes for design should be based on considerations of expected shear displacement in a bottom liner or cover system. As peak strength envelopes for geosynthetics are often nonlinear, it may be necessary to construct combination design strength envelopes using segments from the individual strength envelopes of system components. The combination design peak strength envelope corresponds to the lowest peak shear strength of all components at each normal stress. The combination design residual strength envelope corresponds to the combination design peak strength envelope and does not simply represent the lowest residual shear strength of all components at each normal stress.

14. Quality shear tests will produce smooth shear stressdisplacement relationships that display good similarity and do not contain double peaks or large undulations. Relationships for internal shear of hydrated reinforced GCLs should show large postpeak strength reduction. Shear stress-displacement relationships can be examined to make a preliminary assessment of the quality of GCL shear tests and should be routinely included as part of a test results package.

15. Direct shear is expected to remain the preferred general test method for GCLs because it can be used for any type of GCL product, a large range of normal stress is possible, large specimens can be tested, post-peak response can be obtained, and shear strengths are measured in one direction. Residual shear strengths are generally not measured due to the limited travel of standard $300 \mathrm{~mm} \times 300 \mathrm{~mm}$ direct shear devices. Torsional ring shear provides the only reasonable means to obtain residual shear strengths for some GCLs and GCL interfaces but should not be used if materials display in-plane anisotropy.

16. Specimen gripping surfaces are important for the proper functioning of a GCL shear device. Gripping surfaces should be rigid, provide good drainage, and prevent slippage of the test specimen. Inadequate gripping surfaces may allow specimen slippage and cause progressive failure to occur during shear. The effect of progressive failure is to reduce peak shear strength and increase large displacement (but not residual) shear strength for materials that display post-peak strength reduction.

17. An important source of uncertainty for GCL and GCL interface shear tests is associated with selection of materials. Project-specific shear tests are meaningful only if the specimens are representative of field materials. Ideally, test specimens would be selected from rolls delivered to or designated for the actual project site. As this is usually not possible, conformance tests should be performed at the time of construction to confirm that the delivered materials are at least as strong as the original test materials.

18. Multi-interface shear tests can reduce the amount of testing required and provide better simulation of field conditions, including local out-of-plane deformation effects. Such tests will automatically give the peak and residual combination strength envelopes for design, but are limited in that strength parameters are only obtained for the failure surface. Multiinterface tests may be more difficult to perform and interpret than single-interface tests and often require that the designer and testing laboratory have more experience to avoid errors.

19. It is important to select the appropriate normal stress range for GCL shear tests because strength envelopes are commonly nonlinear and the normal stress level can affect the failure mode of a test specimen.

20. Conditioning procedure can affect the measured shear strength of GCLs and GCL interfaces. Encapsulated GCLs should be sheared in the dry and hydrated conditions and the data used to construct prorated peak and residual strength envelopes. In general, non-encapsulated GCLs should be conditioned by either: (i) hydration under low normal stress followed by slow consolidation (if applicable) to the shearing normal stress, or (ii) hydration under the shearing normal stress using the two-stage accelerated procedure.

21. Recommended values of maximum displacement rate for static shear tests are $0.1 \mathrm{~mm} / \mathrm{min}$ for internal shear tests of hydrated GCLs, $1 \mathrm{~mm} / \mathrm{min}$ for internal shear tests of dry encapsulated GCLs, and, if excess pore pressures are not expected to develop, $1 \mathrm{~mm} /$ min for interface shear tests involving hydrated GCLs. Excess pore pressures are more likely to develop at high shearing normal stress and $0.1 \mathrm{~mm} /$ min may be needed for interface shear tests at these 
levels to better simulate static loading conditions in the field. The recommended maximum displacement rate for multi-interface shear tests is also $1 \mathrm{~mm} / \mathrm{min}$ and, if failure occurs within a hydrated GCL, the test should be repeated using $0.1 \mathrm{~mm} / \mathrm{min}$. If failure occurs on a geosynthetic/geosynthetic interface away from the GCL specimen, and excess pore pressures are not expected to develop, ASTM D 5321 recommends a maximum displacement rate of $5 \mathrm{~mm} /$ min. Dynamic shear tests should be conducted in accordance with project-specific requirements.

22. Failed GCL and GCL interface specimens should be inspected carefully after shearing to assess the surface(s) on which failure occurred and the general nature of the failure. Unusual distortion or tearing of a specimen may invalidate test results and require that the test be repeated using improved gripping surfaces. Final water contents of the GCL and subgrade soil (if applicable) should be taken after shearing to assess the level and uniformity of hydration that was achieved.

\section{FUTURE RESEARCH NEEDS}

The following research needs are identified for the shear strength and shear strength testing of GCLs and GCL interfaces.

1. Long-term strength under sustained stress remains largely unknown and is the single most important source of uncertainty for shear strength of GCLs and GCL interfaces. Data obtained since the original SOA report has raised additional questions with regard to the applicability of short-term strength data to predict long-term strength performance. Further research is needed to identify test methods for creep and polymer degradation that are representative of field conditions and to develop practical design methods for prediction of long-term shear strength.

2. High quality data are available for GCL internal and GM/GCL interface shear strengths. Much less information is available on shear strength behavior for other common GCL interfaces (e.g. soil/GCL and drainage geocomposite/GCL), especially at high normal stress. Although published data cannot substitute for project-specific tests, additional comparative studies are needed.

3. Further research is needed on GCL conditioning procedures. In particular, questions remain with regard to the recommended procedure for GCL consolidation and whether or not the two-stage accelerated procedure can be used as an expedient substitute for the more time-consuming procedure of GCL hydration under low normal stress following by slow consolidation to the shearing normal stress.

4. Although important gains have been made, further research is needed on the effect of displacement rate on shear strength of GCLs and GCL interfaces. Shear data obtained since the original SOA report indicate that displacement rate effects are more complicated than previously considered, especially at high normal stress.

5. GCLs are often utilized for landfill construction in seismic regions. Further research is needed on the shear strength of GCLs and GCL interfaces, including encapsulated GCLs, for dynamic loading conditions. Strength behavior for non-harmonic and seismic loading has not been investigated.

6. GCLs in landfill bottom liner and cover systems may experience high temperatures during their service life. Although experimental and numerical studies have focused on thermo-hydro-mechanical behavior and potential for desiccation at elevated temperatures (e.g. Boardman and Daniel 1996; Southen and Rowe 2005a, 2005b; Azad et al. 2011, 2012; Rowe and Verge 2013), little information has been published on corresponding effects for shear strengths of GCLs and GCL interfaces.

7. Sparse data are available on shear strength anisotropy for GCLs and GCL interfaces. No information has been published on shear strength in the transverse direction, which may be important for certain design conditions. Also, index tests are needed for quick identification of the weakest shear direction for a GCL or GCL interface. One possibility for GCL interfaces may be to use a small tilt table for measurement of index friction angle (Narejo 2003).

8. Additional comparative studies are needed to assess the feasibility and importance of conducting multiinterface shear tests for GCLs on a routine basis. Standardized procedures will be required if practice moves toward such a test as an alternative to the current single-interface test.

9. Further development of constitutive models is needed for static and dynamic shear strength of GCLs and GCL interfaces. Related research for other geosynthetic (i.e. non-GCL) interfaces may be useful in this regard (Esterhuizen et al. 2001; Li and Imaizumi 2006; Bacas et al. 2011).

10. Additional field case studies are needed to document shear strength performance and stability of GCL liner systems, including long-term creep and durability effects and hydration of encapsulated GCLs over time.

Finally, it is noteworthy that research has addressed some of the needs identified in the original SOA report. In particular, progress has been made with regard to standardized gripping surfaces, standardized displacement rates for static shear tests, dynamic shear strength, progressive failure effects, and GCL conditioning procedures.

\section{ACKNOWLEDGMENTS}

Some of the data presented in this paper were obtained with funding provided by Grant No. CMMI-0800030 from the U.S. National Science Foundation, and a grant from CETCO of Hoffman Estates, Illinois, USA. This support is gratefully acknowledged. Additional data were contributed by J. Olsta and R. Erickson of CETCO. Our thanks 
also go to H. Zanzinger of SKZ-German Plastics Center, Würzburg, Germany, who provided the data for Figures 19 and 20a, and R. B. Gilbert, Professor in the Department of Civil, Architectural and Environmental Engineering at the University of Texas-Austin, who provided the data for Figure 37. In addition, we thank E. Newman, former graduate research assistant at the University of Illinois at Urbana-Champaign, and P. Chiu, former graduate research assistant at the University of California-Los Angeles, for assistance with figures for the original SOA report. The views expressed in this paper are solely those of the authors and no endorsement by the sponsors is implied.

\section{NOTATION}

Basic SI units are given in parentheses.

\begin{tabular}{|c|c|}
\hline$a_{\mathrm{o}}$ & constant $\left(\mathrm{N} / \mathrm{m}^{2}\right)$ \\
\hline$a_{\infty}$ & constant $\left(\mathrm{N} / \mathrm{m}^{2}\right)$ \\
\hline$c_{\mathrm{i}, \mathrm{ld}}$ & $\begin{array}{l}\text { cohesion intercept for interface large } \\
\text { displacement strength envelope }\left(\mathrm{N} / \mathrm{m}^{2}\right)\end{array}$ \\
\hline$c_{\mathrm{i}, \mathrm{p}}$ & $\begin{array}{l}\text { cohesion intercept for interface peak } \\
\text { strength envelope }\left(\mathrm{N} / \mathrm{m}^{2}\right)\end{array}$ \\
\hline$c_{\mathrm{i}, \mathrm{r}}$ & $\begin{array}{l}\text { cohesion intercept for interface residual } \\
\text { strength envelope }\left(\mathrm{N} / \mathrm{m}^{2}\right)\end{array}$ \\
\hline$c_{\mathrm{ld}}$ & $\begin{array}{l}\text { cohesion intercept for internal large } \\
\text { displacement strength envelope }\left(\mathrm{N} / \mathrm{m}^{2}\right)\end{array}$ \\
\hline$c_{\mathrm{p}}$ & $\begin{array}{l}\text { cohesion intercept for internal peak } \\
\text { strength envelope }\left(\mathrm{N} / \mathrm{m}^{2}\right)\end{array}$ \\
\hline$c_{\mathrm{r}}$ & $\begin{array}{l}\text { cohesion intercept for internal residual } \\
\text { strength envelope }\left(\mathrm{N} / \mathrm{m}^{2}\right)\end{array}$ \\
\hline$c_{\tan }$ & $\begin{array}{l}\text { cohesion intercept for tangent strength } \\
\text { envelope }\left(\mathrm{N} / \mathrm{m}^{2}\right)\end{array}$ \\
\hline$c_{\sigma_{1}-\sigma_{3}}$ & $\begin{array}{l}\text { cohesion intercept for strength envelope } \\
\text { drawn between } \sigma_{1} \text { and } \sigma_{3}\left(\mathrm{~N} / \mathrm{m}^{2}\right)\end{array}$ \\
\hline$f$ & cyclic shear frequency $(1 / \mathrm{s})$ \\
\hline$F_{\mathrm{p}}$ & peel strength $(\mathrm{N} / \mathrm{m})$ \\
\hline$p$ & constant (dimensionless) \\
\hline $\begin{array}{r}p_{\mathrm{a}} \\
R\end{array}$ & $\begin{array}{l}\text { atmospheric pressure }\left(\mathrm{N} / \mathrm{m}^{2}\right) \\
\text { shear displacement rate }(\mathrm{m} / \mathrm{s})\end{array}$ \\
\hline$R_{\max }$ & maximum shear displacement rate $(\mathrm{m} / \mathrm{s})$ \\
\hline$t_{\mathrm{h}}$ & hydration time $(\mathrm{s})$ \\
\hline$w_{\mathrm{f}}$ & final GCL water content (dimensionless) \\
\hline$\delta_{\infty}$ & constant $\left(^{\circ}\right)$ \\
\hline$\delta$ & shear displacement $(\mathrm{m})$ \\
\hline$\delta_{\mathrm{a}}$ & cyclic shear displacement amplitude (m) \\
\hline$\delta_{\mathrm{p}}$ & $\begin{array}{l}\text { shear displacement at peak shear } \\
\text { strength }(\mathrm{m})\end{array}$ \\
\hline$\delta_{\mathrm{r}}$ & $\begin{array}{l}\text { shear displacement at residual shear } \\
\text { strength }(\mathrm{m})\end{array}$ \\
\hline$\Delta \phi$ & constant $\left({ }^{\circ}\right)$ \\
\hline$\phi_{\mathrm{i}, \mathrm{ld}}$ & $\begin{array}{l}\text { friction angle for interface large } \\
\text { displacement strength envelope }\left({ }^{\circ}\right)\end{array}$ \\
\hline$\phi_{\mathrm{i}, \mathrm{p}}$ & $\begin{array}{l}\text { friction angle for interface peak strength } \\
\text { envelope }\left(\left(^{\circ}\right)\right.\end{array}$ \\
\hline$\phi_{\mathrm{i}, \mathrm{r}}$ & $\begin{array}{l}\text { friction angle for interface residual strength } \\
\text { envelope }\left({ }^{\circ}\right)\end{array}$ \\
\hline$\phi_{1 \mathrm{~d}}$ & $\begin{array}{l}\text { friction angle for internal large } \\
\text { displacement strength envelope }\left(^{\circ}\right)\end{array}$ \\
\hline$\phi_{\mathrm{o}}$ & constant $\left(^{\circ}\right)$ \\
\hline
\end{tabular}

$\phi_{\mathrm{p}} \quad$ friction angle for internal peak strength envelope $\left({ }^{\circ}\right)$

$\phi_{\mathrm{r}}$ friction angle for internal residual strength envelope $\left(^{\circ}\right)$

$\phi_{\text {sec }}$ secant friction angle $\left(^{\circ}\right)$

$\phi_{\tan }$ friction angle for tangent strength envelope $\left({ }^{\circ}\right)$

$\phi_{\sigma_{1}-\sigma_{3}}$ friction angle for strength envelope drawn between $\sigma_{1}$ and $\sigma_{3}\left({ }^{\circ}\right)$

$\sigma_{\mathrm{n}, \mathrm{h}}$ hydration normal stress $\left(\mathrm{N} / \mathrm{m}^{2}\right)$

$\sigma_{\mathrm{n}, \mathrm{s}}$ shearing normal stress $\left(\mathrm{N} / \mathrm{m}^{2}\right)$

$\sigma_{\mathrm{o}}$ constant $\left(\mathrm{N} / \mathrm{m}^{2}\right)$

$\sigma_{1}, \sigma_{2}, \sigma_{3}$ values of shearing normal stress $\left(\mathrm{N} / \mathrm{m}^{2}\right)$

$\tau$ shear stress $\left(\mathrm{N} / \mathrm{m}^{2}\right)$

$\tau_{\text {ld }}$ large displacement shear strength $\left(\mathrm{N} / \mathrm{m}^{2}\right)$

$\tau_{\mathrm{m}}$ maximum shear stress $\left(\mathrm{N} / \mathrm{m}^{2}\right)$

$\tau_{\mathrm{p}}$ peak shear strength $\left(\mathrm{N} / \mathrm{m}^{2}\right)$

$\tau_{\mathrm{r}}$ residual shear strength $\left(\mathrm{N} / \mathrm{m}^{2}\right)$

$\tau_{\delta} \quad$ shear strength at displacement $\delta\left(\mathrm{N} / \mathrm{m}^{2}\right)$

\section{REFERENCES}

Akpinar, M. V. \& Benson, C. H. (2005). Effect of temperature on shear strength of two geomembrane-geotextile interfaces. Geotextiles and Geomembranes, 23, No. 5, 443-453.

Alexiew, D., Kirschner, R. \& Berkhout, H. (1995). On the slope stability of landfill capping seals using GCLs. Geosynthetic Clay Liners, Koerner, R. M., Gartung, E. \& Zanzinger, H., Editors, Balkema, Rotterdam, the Netherlands, pp. 151-158.

Allen, J. M. \& Fox, P. J. (2007). Pyramid-tooth gripping surface for GCL shear testing. Geosynthetics '07, North American Geosynthetics Society, Washington, DC, (CD-ROM).

Anderson, R., Rayhani, M. T. \& Rowe, R. K. (2012). Laboratory investigation of GCL hydration from clayey sand subsoil. Geotextiles and Geomembranes, 31, 31-38.

Arab, M., Kavazanjian, E. Jr, Fox, P. J. \& Matasovic, N. (2012). Plane behavior of geosynthetic barrier layers subject to cyclic loading. Second International Conference on Performance-Based Design in Earthquake Geotechnical Engineering, Taormina, Italy.

Arab, M. G., Kavazanjian, E. Jr, Fox, P. J., Sura, J. M. \& Nye, C. J. (2013). Strain softening constitutive model for the internal shear behavior of a geosynthetic clay liner. R. D. Holtz Symposium, Sound Geotechnical Research to Practice, Stuedlein, A. W. \& Christopher, B. R., Editors, ASCE, Reston, VA, USA, pp. 291-306, GSP No. 230.

Ashmawy, A., Darwish, E., Sotelo, N. \& Muhammad, N. (2002). Hydraulic performance of untreated and polymer-treated bentonite in inorganic landfill leachates. Clays and Clay Minerals, 50, No. 5, $546-552$.

ASTM D 4546 Standard Test Methods for One-Dimensional Swell or Settlement Potential of Cohesive Soils. ASTM International, West Conshohocken, PA, USA.

ASTM D 5321 Standard Test Method for Determining the Coefficient of Soil and Geosynthetic or Geosynthetic and Geosynthetic Friction by the Direct Shear Method. ASTM International, West Conshohocken, PA, USA.

ASTM D 6243 Standard Test Method for Determining the Internal and Interface Shear Resistance of Geosynthetic Clay Liner by the Direct Shear Method. ASTM International, West Conshohocken, PA, USA.

ASTM D 6496 Standard Test Method for Determining Average Bonding Peel Strength Between the Top and Bottom Layers of NeedlePunched Geosynthetic Clay Liners. ASTM International, West Conshohocken, PA, USA.

Athanassopoulos, C. \& Yuan, Z. (2011). Correlation between needlepunch-reinforced geosynthetic clay liner peel strength and internal shear strength. Geo-Frontiers 2011: Advances in Geotechnical 
Engineering, Han, J. \& Alzamora, D. E., Editors, ASCE, Reston, VA, USA, GSP No. 211, pp. 1922-1930.

Athanassopoulos, C., Fox, P. J. \& Ross, J. D. (2010). Cyclic shear test of a geosynthetic clay liner for a secondary containment application. Geosynthetics International, 17, No. 2, 107-111.

Athanassopoulos, C., Fox, P. J. \& Thielmann, S. S. (2012). Interface shear strength testing of geomembrane/GCL composite liner systems under ultra-high normal stresses. 5th European Geosynthetics Congress, Valencia, Spain (CD-ROM).

Azad, F. M., Rowe, R. K., El-Zein, A. \& Airey, D. W. (2011). Laboratory investigation of thermally induced desiccation of GCLs in double composite liner systems. Geotextiles and Geomembranes, 29, No. 6, 534-543.

Azad, F. M., El-Zein, A., Rowe, R. K. \& Airey, D. W. (2012). Modelling of thermally induced desiccation of geosynthetic clay liners in double composite liner systems. Geotextiles and Geomembranes, 34, 28-38.

Bacas, B. M., Konietzky, H., Berini, J. C. \& Sagaseta, C. (2011). A new constitutive model for textured geomembrane/geotextile interfaces. Geotextiles and Geomembranes, 29, No. 1, 137-148.

Bacas, B. M., Blanco-Fernandez, E. \& Cañizal, J. (2013). Comparison of the adhesion and shear tensile strength of needle-punched GCLs. Geotextiles and Geomembranes, 41, No. 1, 17-25.

Benson, C. H. \& Meer, S. R. (2009). Relative abundance of monovalent and divalent cations and the impact of desiccation on geosynthetic clay liners. Journal of Geotechnical and Geoenvironmental Engineering, 135, No. 3, 349-358.

Benson, C. H., Thorstad, P. A., Jo, H.-Y. \& Rock, S. A. (2007). Hydraulic performance of geosynthetic clay liners in a landfill final cover. Journal of Geotechnical and Geoenvironmental Engineering, 133, No. 7, 814-827.

Benson, C., Chen, J. \& Edil, T. (2014). Hydraulic Conductivity of Geosynthetic Clay Liners to Coal Combustion Product Leachates, Office of Sustainability, University of Wisconsin, Madison, WI, USA, Sustainability Report No. OS-13-07.

Berard, J. F. (1997). Evaluation of needle punched geosynthetic clay liners internal friction. Proceedings of Geosynthetics '97, IFAI, Long Beach, California, USA, Vol. 1, pp. 351-362.

Bergado, D. T., Ramana, G. V., Sia, H. I. \& Varun (2006). Evaluation of interface shear strength of composite liner system and stability analysis for a landfill lining system in Thailand. Geotextiles and Geomembranes, 24, No. 6, 371-393.

Bishop, A. W., Green, G. E., Garga, V. K., Andersen, A. \& Brown, J. D. (1971). A new ring shear apparatus and its application to the measurement of residual strength. Geotechnique, 21, No. 4, 273-328.

Boardman, B. T. \& Daniel, D. E. (1996). Hydraulic conductivity of desiccated geosynthetic clay liners. Journal of Geotechnical Engineering, 122, No. 3, 204-208.

Bouazza, A., Nahlawi, H. \& Aylward, M. (2011). In situ temperature monitoring in an organic-waste landfill cell. Journal of Geotechnical and Geoenvironmental Engineering, 137, No. 12, 1286-1289.

Bove, J. A. (1990). Direct shear friction testing for geosynthetics in waste containment. Geosynthetic Testing for Waste Containment Applications, Koerner, R. M., Editor, ASTM International, West Conshohocken, PA, USA, pp. 241-256STP 1081.

Breitenbach, A. J. \& Swan, R. H. Jr. (1999). Influence of high load deformations on geomembrane liner interface strengths. Proceedings of Geosynthetics '99, Boston, MA, USA, 28-30 April, Vol. 1, pp. $517-529$

Bressi, G., Zinesi, M., Montanelli, F. \& Rimoldi, P. (1995). The slope stability of GCL layers in geosynthetic lining system. Proceedings of the 5th International Symposium on Landfills, Cagliari, Italy, Vol. 1 , pp. 595-610.

Briancon, L., Girard, H. \& Poulin, D. (2002). Slope stability of lining systems - experimental modeling of friction at geosynthetic interfaces. Geotextiles and Geomembranes, 20, No. 3, 147-172.

Briancon, L., Girard, H. \& Gourc, J. P. (2011). A new procedure for measuring geosynthetic friction with an inclined plane. Geotextiles and Geomembranes, 29, No. 5, 472-482.

Bromhead, E. N. (1979). A simple ring shear apparatus. Ground Engineering, 12, No. 5, 40-44.
Byrne, R. J. (1994). Design issues with strain-softening interfaces in landfill liners. Proceedings of Waste Tech '94, Charleston, South Carolina, USA, pp. 1-26.

Chen, Y.-M., Lin, W.-A. \& Zhan, T. L. T. (2010). Investigation of mechanisms of bentonite extrusion from GCL and related effects on the shear strength of $\mathrm{GCL} / \mathrm{GM}$ interfaces. Geotextiles and Geomembranes, 28, No. 1, 63-71.

Chevrier, B., Cazaux, D., Didier, G., Gamet, M. \& Guyonnet, D. (2012). Influence of subgrade, temperature and confining pressure on GCL hydration. Geotextiles and Geomembranes, 33, 1-6.

Chiu, P. \& Fox, P. J. (2004). Internal and interface shear strengths of unreinforced and needle-punched geosynthetic clay liners. Geosynthetics International, 11, No. 3, 176-199.

Cowland, J. W. (1997). A design perspective on shear strength testing of geosynthetic clay liners. Testing and Acceptance Criteria for Geosynthetic Clay Liners, Well, L. W., Editor, ASTM International, West Conshohocken, PA, USA, pp. 229-239, STP 1308.

Daniel, D. E. (2013). Engineering characteristics of geosynthetic clay liners: Questions asked and answered over time. Proceedings of GRI-25, Long Beach, California, pp. 136-159.

Daniel, D. E., Shan, H.-Y. \& Anderson, J. D. (1993). Effects of partial wetting on the performance of the bentonite component of a geosynthetic clay liner. Proceedings of Geosynthetics '93, Vancouver, Canada, Industrial Fabrics Association International, Roseville, MI, USA, Vol. 3, pp. 1483-1496.

Daniel, D. E., Koerner, R. M., Bonaparte, R., Landreth, R. E., Carson, D. A. \& Scranton, H. B. (1998). Slope stability of geosynthetic clay liner test plots. Journal of Geotechnical and Geoenvironmental Engineering, 124, No. 7, 628-637.

De, A. \& Zimmie, T. F. (1998). Estimation of dynamic interfacial properties of geosynthetics. Geosynthetics International, 5, No. 1-2, $17-39$.

De Battista, D. J. (1996). Research on the compressibility and hydraulic conductivity of geosynthetic clay liners. MS thesis, School of Civil Engineering, Purdue University, West Lafayette, IN, USA.

Di Emidio, G., Van Impe, W. \& Flores, V. (2011). Advanced in geosynthetic clay liners: Polymer enhanced clays. GeoFrontiers 2011: Advances in Geotechnical Engineering, ASCE, Reston, VA, USA, pp. 1931-1940.

Dixon, N., Zamara, K., Jones, D. R. V. \& Fowmes, G. (2012). Waste/ lining system interaction: Implications for landfill design and performance. Geotechnical Engineering Journal of the SEAGS \& AGSSEA, 43, No. 3, 1-10.

Duncan, J. M. \& Chang, C.-Y. (1970). Nonlinear analysis of stress and strain in soils. Journal of the Soil Mechanics and Foundations Division, 96, No. SM5, 1629-1653.

Eichenauer, T. \& Reither, P. (2002). Comparison of different shear tests for GCLs and the use of these data in design. Clay Geosynthetic Barriers, Zanzinger, H., Koerner, R. M. \& Gartung, E., Editors, Swets \& Zeitlinger, Lisse, the Netherlands, pp. 119-125.

Eid, H. T. (2011). Shear strength of geosynthetic composite systems for design of landfill liner and cover slopes. Geotextiles and Geomembranes, 29, No. 3, 335-344.

Eid, H. T. \& Stark, T. D. (1997). Shear behavior of an unreinforced geosynthetic clay liner. Geosynthetics International, 4, No. 6, 645659 .

Eid, H. T., Stark, T. D. \& Doerfler, C. K. (1999). Effect of shear displacement rate on internal shear strength of a reinforced geosynthetic clay liner. Geosynthetics International, 6, No. 3, 219239.

Eid, H. T., Stark, T. D., Evans, W. D. \& Sherry, P. (2000). Municipal solid waste landfill slope failure I: Foundation and waste properties. Journal of Geotechnical and Geoenvironmental Engineering, 126, No. 5, 397-407.

Eith, A. W., Boschuk, J. \& Koerner, R. M. (1991). Prefabricated bentonite clay liners. Geotextiles and Geomembranes, 10, No. 5-6, 575-599.

Erickson, R. B. \& Thiel, R. (2002). Design and application of the geomembrane supported GCL in one-product and encapsulated composite liner systems. Proceedings of International Symposium on Clay Geosynthetic Barrier, Nuremberg, Germany, pp. 31-40.

Esterhuizen, J. J. B., Filz, G. M. \& Duncan, J. M. (2001). Constitutive 
behavior of geosynthetic interfaces. Journal of Geotechnical and Geoenvironmental Engineering, 127, No. 10, 834-840.

Evans, W. D., Stark, T. D., Wilson, V. L. \& Gonda, J. P. (1998). Design considerations for geosynthetic clay liners. Proceedings of the 20th International Madison Waste Conference: Municipal and Industrial Waste, University of Wisconsin, Madison, WI, USA, pp. 203-218.

Feki, N., Garcin, P., Faure, Y. H., Gourc, J. P. \& Berroir, G. (1997). Shear strength of geosynthetic clay liner systems. Proceedings of Geosynthetics '97, IFAI, Long Beach, California, USA, Vol. 2, pp. 899-912.

Filz, G. M., Esterhuizen, J. J. B. \& Duncan, J. M. (2001). Progressive failure of liner waste impoundments. Journal of Geotechnical and Geoenvironmental Engineering, 127, No. 10, 841-848.

Fox, P. J. (1998). Research on geosynthetic clay liners at Purdue University. Geotechnical News, 16, No. 1, 35-40.

Fox, P. J. (2006). Discussion of 'Analysis of a large database of GCL internal shear strength results' by Zornberg, J. G., McCartney, J. S. \& Swan, R. H., Jr. Journal of Geotechnical and Geoenvironmental Engineering, 132, No. 10, 1373-1375.

Fox, P. J. \& Athanassopoulos, C. (2012). Shear strength of geosynthetic clay liners: Part I - Strength measurement. Geosynthetics, 30, No. $5,46-51$.

Fox, P. J. \& Kim, R. H. (2008). Effect of progressive failure on measured shear strength of geomembrane/GCL interface. Journal of Geotechnical and Geoenvironmental Engineering, 134, No. 4, 459469.

Fox, P. J. \& Ross, J. D. (2011). Relationship between GCL internal and GMX/GCL interface shear strengths. Journal of Geotechnical and Geoenvironmental Engineering, 137, No. 8, 743-753.

Fox, P. J. \& Stark, T. D. (2004). State-of-the-art report: GCL shear strength and its measurement. Geosynthetics International, 11, No. 3, 141-175.

Fox, P. J., Sura, J. M. \& Nye, C. (2015). Dynamic shear strength of a needle-punched GCL for monotonic loading. Journal of Geotechnical and Geoenvironmental Engineering. [doi: 10.1061/(ASCE)GT. 1943-5606.0001304].

Fox, P. J., De Battista, D. J. \& Chen, S. H. (1996). Bearing capacity of geosynthetic clay liners for cover soils of varying particle size. Geosynthetics International, 3, No. 4, 447-461.

Fox, P. J., Rowland, M. G., Scheithe, J. R., Davis, K. L., Supple, M. R. \& Crow, C. C. (1997). Design and evaluation of a large direct shear machine for geosynthetic clay liners. Geotechnical Testing Journal, 20, No. 3, 279-288.

Fox, P. J., Rowland, M. G. \& Scheithe, J. R. (1998a). Internal shear strength of three geosynthetic clay liners. Journal of Geotechnical and Geoenvironmental Engineering, 124, No. 10, 933-944.

Fox, P. J., Triplett, E. J., Kim, R. H. \& Olsta, J. T. (1998b). Field study of installation damage for geosynthetic clay liners. Geosynthetics International, 5, No. 5, 491-520.

Fox, P. J., De Battista, D. J. \& Mast, D. G. (2000). Hydraulic performance of geosynthetic clay liners under gravel cover soils. Geotextiles and Geomembranes, 18, No. 2-4, 179-201.

Fox, P. J., Olsta, J. T. \& Chiu, P. (2002). Internal and interface shear strengths of needle-punched geosynthetic clay liners. Proceedings of the 7th International Conference on Geosynthetics, Nice, France, Vol. 2, pp. 667-670.

Fox, P. J., Stark, T. D. \& Swan, R. H. Jr (2004). Laboratory measurement of GCL shear strength. Advances in Geosynthetic Clay Liner Technology: 2nd Symposium, Mackey, R. E. \& von Maubeuge, K., Editors, ASTM International, West Conshohocken, PA, USA, pp. 92-109, STP 1456.

Fox, P. J., Nye, C. J., Morrison, T. C., Hunter, J. G. \& Olsta, J. T. (2006). Large dynamic direct shear machine for geosynthetic clay liners. Geotechnical Testing Journal, 29, No. 5, 392-400.

Fox, P. J., Ross, J. D., Sura, J. M. \& Thiel, R. S. (2011). Geomembrane damage due to static and cyclic shearing over compacted gravelly sand. Geosynthetics International, 18, No. 5, 272-279.

Fox, P. J., Thielmann, S. S., Stern, A. N. \& Athanassopoulos, C. (2014). Interface shear damage to HDPE geomembrane. I: Gravelly compacted clay liner. Journal of Geotechnical and Geoenvironmental Engineering, 140, No. 8, 04014039-1-04014039-14.
Frobel, R. K. (1996). Geosynthetic clay liners, Part four: Interface and internal shear strength determination. Geotechnical Fabrics Report, 14, No. 8, 20-23.

Fuller, J. M. (1995). Landfill cap designs using geosynthetic clay liners. Geosynthetic Clay Liners, Koerner, R. M., Gartung, E. \& Zanzinger, H., Editors, Balkema, Rotterdam, the Netherlands, pp. 129-140.

Garcin, P., Faure, Y. H., Gourc, J. P. \& Purwanto, E. (1995). Behavior of geosynthetic clay liner (GCL): Laboratory tests. Proceedings of the 5th International Symposium on Landfills, Cagliari, Italy, Vol. 1, pp. 347-358.

Gilbert, R. B. (2001). Peak vs. residual strength for waste containment systems. Proceedings of GRI 15th Annual Geosynthetics Conference, Houston, Texas, USA, pp. 29-39.

Gilbert, R. B. \& Byrne, R. J. (1996). Strain softening behavior of waste containment system interfaces. Geosynthetics International, 3, No. 2, 181-203.

Gilbert, R. B., Fernandez, F. \& Horsfield, D. W. (1996a). Shear strength of reinforced geosynthetic clay liner. Journal of Geotechnical Engineering, 122, No. 4, 259-266.

Gilbert, R. B., Long, J. H. \& Moses, B. E. (1996b). Analytical model of progressive slope failure in waste containment systems. International Journal for Numerical and Analytical Methods in Geomechanics, 20, No. 1, 35-56.

Gilbert, R. B., Scranton, H. B. \& Daniel, D. E. (1997). Shear strength testing for geosynthetic clay liners. Testing and Acceptance Criteria for Geosynthetic Clay Liners, Well, L. W., Editor, ASTM International, West Conshohocken, PA, USA, pp. 121-135, STP 1308.

Gilbert, R. B., Wright, S. G., Shields, M. K. \& Obermeyer, J. E. (2004). Lower-bound shear strength for geosynthetic clay liners in base liners. Geosynthetics International, 11, No. 3, 200-211.

Giroud, J. P. \& Daniel, D. E. (2004). Liquid migration in an encapsulated bentonite layer due to geomembrane defects. Geosynthetics International, 11, No. 4, 311-329.

Giroud, J. P., Darrasse, J. \& Bachus, R. C. (1993). Hyperbolic expression for soil-geosynthetic or geosynthetic-geosynthetic interface shear strength. Geotextiles and Geomembranes, 12, No. 3, 275-286.

Giroud, J. P., Thiel, R. S. \& Kavazanjian, E. (2004). Hydrated area of bentonite layer encapsulated between two geomembranes. Geosynthetics International, 11, No. 4, 330-354.

Gourc, J. P., Lalarakotoson, S., Muller-Rochholz, H. \& Bronstein, Z. (1996). Friction measurement by direct shearing or tilting process development of a European standard. Proceedings of EuroGeo 1, Maastricht, the Netherlands, pp. 1039-1046.

Hanson, J. L., Yesiller, N. \& Oettle, N. K. (2010). Spatial and temporal temperature distributions in municipal solid waste landfills. Journal of Environmental Engineering, 136, No. 8, 804-814.

Heerten, G., Saathoff, F., Scheu, C. \& von Maubeuge, K. P. (1995). On the long-term shear behavior of geosynthetic clay liners (GCLs) in capping sealing systems. Geosynthetic Clay Liners, Koerner, R. M., Gartung, E. \& Zanzinger, H., Editors, Balkema, Rotterdam, the Netherlands, pp. 141-150.

Hewitt, R. D., Soydemir, C., Stulgis, R. P. \& Coombs, M. T. (1997). Effect of normal stress during hydration and shear on the shear strength of GCL/textured geomembrane interfaces. Testing and Acceptance Criteria for Geosynthetic Clay Liners, Well, L. W., Editor, ASTM International, West Conshohocken, PA, USA, pp. 55-70, STP 1308.

Hillman, R. P. \& Stark, T. D. (2001). Shear strength characteristics of PVC geomembrane-geosynthetic interfaces. Geosynthetics International, 8, No. 2, 135-162.

Hsuan, Y. G. \& Koerner, R. M. (2002). Durability and lifetime of polymer fibers with respect to reinforced geosynthetic clay barriers; i. e. reinforced GCLs. Clay Geosynthetic Barriers, Zanzinger, H., Koerner, R. M. \& Gartung, E., Editors, Swets \& Zeitlinger, Lisse, the Netherlands, pp. 73-86.

Jafari, N. H., Stark, T. D. \& Rowe, K. (2014). Service life of HDPE geomembranes subjected to elevated temperatures. Journal of Hazardous, Toxic, and Radioactive Waste, 18, No. 1, 16-26.

Jones, D. R. \& Dixon, N. (1998). Shear strength properties of geomembrane/geotextile interfaces. Geotextiles and Geomembranes, 16, No. 1, 45-71. 
Jones, D. R. V. \& Dixon, N. (2005). Landfill lining stability and integrity: The role of waste settlement. Geotextiles and Geomembranes, 23, No. 1, 27-53.

Kavazanjian, E. Jr, Hushmand, B. \& Martin, G. R. (1991). Frictional base isolation using a layered soil-synthetic liner system. Proceedings of 3rd U.S. Conference on Lifeline Earthquake Engineering, Technical Council on Lifeline Earthquake Engineering, ASCE, Reston, VA, USA, pp. 1140-1151.

Kavazanjian, E. Jr, Arab, G. M. \& Matasovic, N. (2011). Seismic analysis of heap leach pad liner systems. Proceedings of 5th International Conference on Earthquake Geotechnical Engineering, Santiago, Chile, Paper No. SEIKA (CD-ROM).

Kim, J., Riemer, M. \& Bray, J. D. (2005). Dynamic properties of geosynthetic interfaces. Geotechnical Testing Journal, 28, No. 3, 1-9.

Koerner, R. M. (1998). Designing with Geosynthetics, 4th edition, Prentice Hall, Upper Saddle River, NJ, USA.

Koerner, R. M. (2006). Discussion of 'analysis of a large database of GCL internal shear strength results' by Zornberg, J. G., McCartney, J. S. \& Swan, R. H. Jr. Journal of Geotechnical and Geoenvironmental Engineering, 132, No. 10, 1373.

Koerner, R. M. (2012). Designing with Geosynthetics, 6th Edition, Vol. 2, Xlibris Corporation, Bloomington, IN, USA.

Koerner, R. M. \& Daniel, D. E. (1993). Technical equivalency assessment of GCLs to CCLs. Geosynthetic Liner Systems: Innovations, Concerns, and Designs, Koerner, R. M. \& Wilson-Fahmy, R. F., Editors, IFAI, Nashville, TN, USA, pp. 265-285.

Koerner, R. M. \& Narejo, D. (1995). Bearing capacity of hydrated geosynthetic clay liners. Journal of Geotechnical Engineering, 121, No. 1, 82-85.

Koerner, R. M. \& Soong, T.-Y. (1998). Analysis and design of veneer cover soils. Proceedings of the 6th International Conference on Geosynthetics, Atlanta, GA, USA, Vol. 1, pp. 1-23.

Koerner, R. M., Martin, J. P. \& Koerner, G. R. (1986). Shear strength parameters between geomembranes and cohesive soils. Geotextiles and Geomembranes, 4, No. 1, 21-30.

Koerner, G. R., Bowders, J. J. \& Scranton, H. B. (1997). Instrumentation for monitoring field performance of the Cincinnati GCL test plots. Geotextiles and Geomembranes, 15, No. 4-6, 341-365.

Koerner, R. M., Soong, T.-Y. \& Gontar, A. (1998). Selected aspects of GCL shear strength testing. Proceedings of the Geo-Bento '98, Insatec Publishing, Paris, France, pp. 97-110.

Koerner, R. M., Soong, T.-Y., Koerner, G. R. \& Gontar, A. (2001). Creep testing and data extrapolation of reinforced GCLs. Geotextiles and Geomembranes, 19, No. 7, 413-425.

Kolstad, D. C., Benson, C. H. \& Edil, T. B. (2004). Hydraulic conductivity and swell of nonprehydrated geosynthetic clay liners permeated with multispecies inorganic solutions. Journal of Geotechnical and Geoenvironmental Engineering, 130, No. 12, 1236-1249.

Lai, J., Daniel, D. E. \& Wright, S. G. (1998). Effects of cyclic loading on internal shear strength of unreinforced geosynthetic clay liner. Journal of Geotechnical and Geoenvironmental Engineering, 124, No. 1, 45-52.

Lalarakotoson, S., Villard, P. \& Gourc, J. P. (1999). Shear strength characterization of geosynthetic interfaces on inclined planes. Geotechnical Testing Journal, 22, No. 4, 284-291.

Li, M. \& Imaizumi, S. (2006). Finite element study on direct shear tests for multi-layered geosynthetic liners. Geosynthetics International, 13, No. 4, 145-160.

Lin, H., Shi, J., Qian, X. \& Zhang, L. (2014). An improved simple shear apparatus for GCL internal and interface stress-displacement measurements. Environmental Earth Sciences, 71, No. 8, 37613771.

Lo Grasso, S. A., Massimino, M. R. \& Maugeri, M. (2002). Dynamic analysis of geosynthetic interfaces by shaking table tests. Proceedings of the 7th International Conference on Geosynthetics, Nice, France, Delmas, P. \& Gourc, J. P., Editors, Balkema, Rotterdam, the Netherlands, Vol. 4, pp. 1335-1338.

Long, J. H., Gilbert, R. B. \& Daly, J. J. (1995). Effect of waste settlement on sloped lining systems. Proceedings, Geosynthetics '95, IFAI, Nashville, TN, USA, Vol. 2, pp. 729-744.
Lucas, S. N. (2002). Manufacturing of and the performance of an integrallyformed, polypropylene coated geosynthetic clay barrier. Clay Geosynthetic Barriers, Zanzinger, H., Koerner, R. M. \& Gartung, E., Editors, Swets \& Zeitlinger, Lisse, the Netherlands, pp. 227-232.

Luellen, J. R., Dove, J. E. \& Swan, R. H. Jr. (1999). Seismic engineering for interfaces in a landfill-containment system. Geotechnical Fabrics Report, 17, No. 1, 24-29.

Marr, W. A. (2001). Interface and internal shear testing procedures to obtain peak and residual values. Proceedings of GRI 15th Annual Geosynthetics Conference, Houston, TX, USA, pp. 1-28.

Marr, W. A. \& Christopher, B. (2003). Recommended design strength for needlepunched geosynthetic clay liner products. Geotechnical Fabrics Report, 21, No. 8, 18-23.

Martin, J. W., Stark, T. D., Thalhamer, T., Gerbasi-Graf, G. T. \& Gortner, R. E. (2013). Detection of aluminum waste reactions and associated waste fires. Journal of Hazardous, Toxic, and Radioactive Waste, 17, No. 3, 164-174.

Matasovic, N., Kavazanjian, E. \& Jr Giroud, J. P. (1998). Newmark seismic deformation analysis for geosynthetic covers. Geosynthetics International, 5, No. 1-2, 237-264.

McCartney, J. S., Zornberg, J. G., Swan, R. H. Jr. \& Gilbert, R. B. (2004a). Reliability-based stability analysis considering GCL shear strength variability. Geosynthetics International, 11, No. 3, 212-232.

McCartney, J. S., Zornberg, J. G. \& Swan, R. H. Jr. (2004b). Effect of specimen conditioning on geosynthetic clay liner shear strength. Proceedings of GeoAsia 2004, 3rd Asian Regional Conference on Geosynthetics, Seoul, South Korea, pp. 635-643.

McCartney, J. S., Zornberg, J. G. \& Swan, R. H. (2005). Effect of geomembrane texturing on GCL-geomembrane interface shear strength. Waste Containment and Remediation, ASCE, Reston, VA, USA, Geotechnical Special Publication No. 142 (CD-ROM).

McCartney, J. S., Zornberg, J. G. \& Swan, R. H. Jr. (2009). Analysis of a large database of GCL-geomembrane interface shear strength results. Journal of Geotechnical and Geoenvironmental Engineering, 135, No. 2, 209-223.

McKelvey, III. J. A. (1994). Consideration of equipment loadings in geosynthetic lined slope designs. Proceedings of Computer Methods and Advances in Geomechanics, Morgantown, WV, USA, Siriwardane, H. J. \& Zaman, M. M., Editors, Balkema, Rotterdam, the Netherlands, Vol. 2, pp. 1371-1377.

Meer, S. R. \& Benson, C. H. (2007). Hydraulic conductivity of geosynthetic clay liners exhumed from landfill final covers. Journal of Geotechnical and Geoenvironmental Engineering, 133, No. 5, $550-563$.

Mesri, G. \& Olson, R. E. (1970). Shear strength of montmorillonite. Geotechnique, 20, No. 3, 261-270.

Müller-Vonmoos, M. \& Løken, T. (1989). The shearing behavior of clays. Applied Clay Science, 4, No. 2, 125-141.

Müller, W., Buettgenbach, B., Jakob, I. \& Mann, H. (2003). Comparison of the oxidative resistance of various polyolefin geotextiles. Geotextiles and Geomembranes, 21, No. 5, 289-315.

Müller, W., Jakob, I., Seeger, S. \& Tatzky-Gerth, R. (2008). Long-term shear strength of geosynthetic clay liners. Geotextiles and Geomembranes, 26, No. 2, 130-144.

Narejo, D. B. (2003). A simple tilt table device to measure index friction angle of geosynthetics. Geotextiles and Geomembranes, 21, No. 1, 49-57.

Nye, C. J. \& Fox, P. J. (2007). Dynamic shear behavior of a needlepunched geosynthetic clay liner. Journal of Geotechnical and Geoenvironmental Engineering, 133, No. 8, 973-983.

Olsta, J. T. \& Swan, R. H. Jr. (2001). Internal shear strength of a geosynthetic clay liner at high normal loads. Proceeding of Tailings and Mine Wastes '01, Fort Collins, CO, USA, pp. 197-200.

Park, I. J., Seo, M. W., Park, J. B., Kwon, S. Y. \& Lee, J. S. (2004). Estimation of the dynamic properties for geosynthetic interfaces. Proceedings of 13th World Conference on Earthquake Engineering, Vancouver, BC, Canada, Paper No. 3210.

Parra, D., Soto, C. \& Valdivia, R. (2010). Soil liner-geomembrane interface shear strength using rigid substrata or overliner. Proceedings of 9th International Conference on Geosynthetics, Guaruja, Brazil (CD-ROM). 
Pavlik, K. L. (1997). Corps of Engineers geosynthetic clay liner interface test program. Proceedings of Geosynthetics '97, IFAI, Long Beach, CA, USA, Vol. 2, pp. 877-884.

Pitanga, H. N., Gourc, J.-P. \& Vilar, O. M. (2009). Interface shear strength of geosynthetics: Evaluation and analysis of inclined plane tests. Geotextiles and Geomembranes, 27, No. 6, 435-446.

Qian, X., Koerner, R. M. \& Gray, D. H. (2002). Geotechnical Aspects of Landfill Design and Construction, Prentice Hall, Upper Saddle River, NJ, USA.

Rayhani, M. T., Rowe, R. K., Brachman, R. W. I., Take, W. A. \& Siemens, G. (2011). Factors affecting GCL hydration under isothermal conditions. Geotextiles and Geomembranes, 29, No. 6, $525-533$.

Reddy, K. R., Kosgi, S. \& Motan, E. S. (1996). Interface shear behavior of landfill composite liner systems: A finite element analysis. Geosynthetics International, 3, No. 2, 247-275.

Richardson, G. N. (1997). GCL internal shear strength requirements. Geotechnical Fabrics Report, 15, No. 2, 20-25.

Ross, J. D. \& Fox, P. J. (2015). Dynamic shear strength of GMX/GCL composite liner for monotonic loading. Journal of Geotechnical and Geoenvironmental Engineering. [doi: 10.1061/(ASCE)GT.1943-5606. 0001198].

Ross, J., Fox, P. J. \& Olsta, J. T. (2011). Dynamic shear response of a geomembrane/ geosynthetic clay liner interface. Geo-Frontiers 2011: Advances in Geotechnical Engineering, Han, J. \& Alzamora, D. E., Editors, ASCE, Reston, VA, USA, Geotechnical Special Publication No. 211, pp. 2010-2020.

Rouncivell, W. E. \& Scheele, F. (2008). External and internal shear strength characteristics of a geosynthetic clay liner. Proceedings of 1st Pan American Geosynthetics Conference, IFAI, Cancun, Mexico, pp. $137-145$

Rowe, R. K. (2005). Long-term performance of contaminant barrier systems. Geotechnique, 55, No. 9, 631-678.

Rowe, R. K. \& Verge, A. (2013). Prediction of geosynthetic clay liner desiccation in low stress applications. Geosynthetics International, 20, No. 5, 301-315.

Sabatini, P. J., Griffin, L. M., Bonaparte, R., Espinoza, R. D. \& Giroud, J. P. (2002). Reliability of state of practice for selection of shear strength parameters for waste containment system stability analyses. Geotextiles and Geomembranes, 20, No. 4, 241-262.

Scalia, J. \& Benson, C. H. (2011). Hydraulic conductivity of geosynthetic clay liners exhumed from landfill final covers with composite barriers. Journal of Geotechnical and Geoenvironmental Engineering, 137, No. 1, 1-13.

Scalia, J., Benson, C. H., Bohnhoff, G. L., Edil, T. B. \& Shackelford, C. D. (2014). Long-term hydraulic conductivity of a bentonite-polymer composite permeated with aggressive inorganic solutions. Journal of Geotechnical and Geoenvironmental Engineering, 140, No. 3, 04013025-1-04013025-13.

Schmitt, K. E., Bowders, J. J., Gilbert, R. B. \& Daniel, D. E. (1997). Enhanced shear strength of sodium bentonite using frictional additives. Proceedings of International Containment Technology Conference, St. Petersburg, FL, USA, pp. 355-361.

Seeger, S., Müller, W. \& Mohr, K. (2002). Long term tensile testing of polyolefin fibers in geotextiles. Proceedings of 7 th International Conference on Geosynthetics, Nice, France, Vol. 4, pp. 1459-1462.

Shackelford, C., Benson, C., Katsumi, T., Edil, T. \& Lin, L. (2000). Evaluating the hydraulic conductivity of GCLs permeated with nonstandard liquids. Geotextiles and Geomembranes, 18, No. 2-4, 133161.

Shan, H.-Y. \& Chen, R.-H. (2003). Effect of gravel subgrade on hydraulic performance of geosynthetic clay liner. Geotextiles and Geomembranes, 21, No. 6, 339-354.

Shan, H.-Y. \& Daniel, D. E. (1991). Results of laboratory tests on a geotextile/bentonite liner material. Proceedings of Geosynthetics 91', IFAI, Atlanta, GA, USA, Vol. 2, pp. 517-535.

Sia, A. H. I. \& Dixon, N. (2012). Numerical modeling of landfill lining system - waste interaction: Implications of parameter variability. Geosynthetics International, 19, No. 5, 393-408.

Siebken, J. R., Swan, R. H. Jr. \& Yuan, Z. (1997). Short-term and creep shear characteristics of a needlepunched thermally locked geosynthetic clay liner. Testing and Acceptance Criteria for Geosynthetic Clay Liners, Well, L. W., Editor, ASTM International, West Conshohocken, PA, USA, pp. 89-102, STP 1308.

Siemens, G., Take, W. A., Rowe, R. K. \& Brachman, R. W. I. (2012). Numerical investigation of transient hydration of unsaturated geosynthetic clay liners. Geosynthetics International, 19, No. 3, 232-251.

Smith, M. E. \& Criley, K. (1995). Interface shear strength is not for the uninitiated. Geotechnical Fabrics Report, 13, No. 3, 28-31.

Southen, J. M. \& Rowe, R. K. (2005a). Modelling of thermally induced desiccation of geosynthetic clay liners. Geotextiles and Geomembranes, 23, No. 5, 425-442.

Southen, J. M. \& Rowe, R. K. (2005b). Laboratory investigation of geosynthetic clay liner desiccation in a composite liner subjected to thermal gradients. Journal of Geotechnical and Geoenvironmental Engineering, 131, No. 7, 925-935.

Stark, T. D. (1997). Effect of swell pressure on GCL cover stability. Testing and Acceptance Criteria for Geosynthetic Clay Liners, Well, L. W., Editor, ASTM International, West Conshohocken, PA, USA, pp. 30-44, STP 1308.

Stark, T. D. (1998). Bentonite migration in geosynthetic clay liners. Proceedings of 6th International Conference on Geosynthetics, IFAI, Atlanta, GA, USA, Vol. 1, pp. 315-320.

Stark, T. D. \& Choi, H. (2004). Peak versus residual interface strengths for landfill liner and cover design. Geosynthetics International, 11, No. 6, 491-498.

Stark, T. D. \& Eid, H. T. (1996). Shear behavior of reinforced geosynthetic clay liners. Geosynthetics International, 3, No. 6, 771786.

Stark, T. D. \& Poeppel, A. R. (1994). Landfill liner interface strengths from torsional-ring-shear tests. Journal of Geotechnical Engineering, 120, No. 3, 597-615.

Stark, T. D. \& Poeppel, A. R. (1995). Closure to 'Landfill liner interface strengths from torsional ring shear tests'. Journal of Geotechnical Engineering, 121, No. 6, 509-510.

Stark, T. D., Williamson, T. A. \& Eid, H. T. (1996). HDPE geomembrane/geotextile interface shear strength. Journal of Geotechnical Engineering, 122, No. 3, 197-203.

Stark, T. D., Arellano, D., Evans, W. D., Wilson, V. L. \& Gonda, J. P. (1998). Unreinforced geosynthetic clay liner case history. Geosynthetics International, 5, No. 5, 521-544.

Stark, T. D., Eid, H. T., Evans, W. D. \& Sherry, P. (2000). Municipal solid waste landfill slope failure II: stability analyses. Journal of Geotechnical and Geoenvironmental Engineering, 126, No. 5, 408419.

Stark, T. D., Choi, H. \& Akhtarshad, R. (2004). Occurrence and effect of bentonite migration in geosynthetic clay liners. Geosynthetics International, 11, No. 4, 296-310.

Stark, T. D., Martin, J. W., Gerbasi, G. T., Thalhamer, T. \& Gortner, R. E. (2012). Aluminum waste reaction indicators in a municipal solid waste landfill. Journal of Geotechnical and Geoenvironmental Engineering, 138, No. 3, 252-261.

Stolz, G., Gallo, R., Poulain, D. \& Touze-Foltz, N. (2012). Testing procedure with an inclined plane device to assess the residual friction characteristics at geosynthetic interfaces. Proceedings of 5th European Geosynthetics Congress, Valencia, Spain (CD-ROM).

Tanays, E., Le Tellier, I., Bernhard, C. \& Gourc, J. P. (1994). Behaviour of lining systems on waste landfill slopes: An experimental approach. Proceedings of 5th International Conference on Geotextiles, Geomembranes, and Related Products, Singapore (CDROM).

Thiel, R., Daniel, D. E., Erickson, R. B., Kavazanjian, E. Jr. \& Giroud, J. P. (2001). The GSE GundSeal GCL Design Manual., GSE Lining Technologies, Inc, Houston, TX, USA.

Thiel, R., Giroud, J. P., Erickson, R., Criley, K. \& Bryk, J. (2006). Laboratory measurements of GCL shrinkage under cyclic changes in temperature and hydration conditions. Proceedings of 8th International Conference on Geosynthetics, Yokohama, Japan, Vol. 1 , pp. 157-162.

Thielmann, S. S., Fox, P. J. \& Athanassopoulos, C. (2013). Interface shear testing of GCL liner systems for very high normal stress 
conditions. Stability and Performance of Slopes and Embankments III, ASCE, Reston, VA, USA, Geotechnical Special Publication No. 231, pp. 63-71.

Thies, M., Gerloff, C., Müller, W. \& Seeger, S. (2002). Long-term shear testing of geosynthetic clay liners. Clay Geosynthetic Barriers, Zanzinger, H., Koerner, R. M. \& Gartung, E., Editors, Swets \& Zeitlinger, Lisse, the Netherlands, pp. 97-104.

Thomas, R. W. (2002). Thermal oxidation of a polypropylene geotextile used in a geosynthetic clay liner. Clay Geosynthetic Barriers, Zanzinger, H., Koerner, R. M. \& Gartung, E., Editors, Swets \& Zeitlinger, Lisse, the Netherlands, pp. 87-96.

Trauger, R. \& Darlington, J. (2000). Next-generation geosynthetic clay liners for improved durability and performance. TR-220, Colloid Environmental Technologies Company, Arlington Heights, IL, USA, pp. 2-14.

Trauger, R. J., Swan, R. H. \& Yuan, Z. (1997). Long-term shear strength behavior of a needlepunched geosynthetic clay liner. Testing and Acceptance Criteria for Geosynthetic Clay Liners, Well, L. W., Editor, ASTM International, West Conshohocken, PA, USA, STP 1308, pp. 103-120.

Triplett, E. J. \& Fox, P. J. (2001). Shear strength of HDPE geomembrane/ geosynthetic clay liner interfaces. Journal of Geotechnical and Geoenvironmental Engineering, 127, No. 6, 543-552.

USEPA (1995). Code of Federal Regulations, 40 CFR Parts 190 to 250, Revised July 1, 1995, U. S. Environmental Protection Agency, Washington, DC, USA.

von Maubeuge, K. P. \& Eberle, M. A. (1998). Can geosynthetic clay liners be used on slopes to achieve long-term stability. Proceedings of 3rd International Congress on Environmental Geotechnics, Lisbon, Portugal, Vol. 1, pp. 375-380.

von Maubeuge, K. P. \& Ehrenberg, H. (2000). Comparison of peel bond and shear tensile test methods for needlepunched geosynthetic clay liners. Geotextiles and Geomembranes, 18, No. 2-4, 203-214.

von Maubeuge, K. P. \& Lucas, S. N. (2002). Peel and shear test comparison and geosynthetic clay liner shear strength correlation. Clay Geosynthetic Barriers, Zanzinger, H., Koerner, R. M. \& Gartung, E., Editors, Swets \& Zeitlinger, Lisse, the Netherlands, pp. 105-110.

Vukelic, A., Szavits-Nossan, A. \& Kvasnicka, P. (2008). The influence of bentonite extrusion on shear strength of GCL/geomembrane interface. Geotextiles and Geomembranes, 26, No. 1, 82-90.
Yazdani, R., Campbell, J. L. \& Koerner, G. R. (1995). Long-term in-situ measurements of a high density polyethylene geomembrane in a municipal solid waste landfill. Proceedings of Geosynthetics '95, IFAI, Nashville, TN, USA, Vol. 3, pp. 893-905.

Yegian, M. K. \& Lahlaf, A. M. (1992). Dynamic interface shear strength properties of geomembranes and geotextiles. Journal of Geotechnical and Geoenvironmental Engineering, 118, No. 5, 760-779.

Zanzinger, H. \& Alexiew, N. (2000). Prediction of long term shear strength of geosynthetic clay liners with shear creep tests. Proceedings of 2nd European Geosynthetic Conference, Patron Editore, Bologna, Italy, Vol. 2, pp. 567-571.

Zanzinger, H. \& Alexiew, N. (2002). Long-term internal shear testing on clay geosynthetic barriers. Clay Geosynthetic Barriers, Zanzinger, H., Koerner, R. M. \& Gartung, E., Editors, Swets \& Zeitlinger, Lisse, the Netherlands, pp. 111-117.

Zanzinger, H. \& Saathoff, F. (2010). Shear creep rupture behavior of a stitch-bonded clay geosynthetic barrier. Proceedings of $3 \mathrm{rd}$ International Symposium on Geosynthetic Clay Liners, Würzburg, Germany, pp. 219-229.

Zanzinger, H. \& Saathoff, F. (2012). Long-term internal shear strength of a reinforced GCL based on shear creep rupture tests. Geotextiles and Geomembranes, 33, 43-50.

Zelic, B. K., Znidarcic, D. \& Kovacic, D. (2002). Shear strength testing on a GCL. Proceedings of 7 th International Conference on Geosynthetics, Nice, France, Vol. 4, pp. 1329-1334.

Zornberg, J. G. \& McCartney, J. S. (2009). Chapter 8: Internal and interface shear strength of GCLs. Geosynthetic Clay Liners for Waste Containment, Bouazza, A. \& Bowders, J. J., Editors, CRC Press, Taylor \& Francis Group, Boca Raton, FL, USA, pp. 143168.

Zornberg, J. G., McCartney, J. S. \& Swan, R. H. Jr. (2005). Analysis of a large database of GCL internal shear strength results. Journal of Geotechnical and Geoenvironmental Engineering, 131, No. 3, 367380 .

Zornberg, J. G., McCartney, J. S. \& Swan, R. H. Jr. (2006). Closure to 'Analysis of a large database of GCL internal shear strength results' by Zornberg, J. G., McCartney, J. S. \& Swan, R, H. Jr. Journal of Geotechnical and Geoenvironmental Engineering, 132, No. 10, 1376-1379.

The Editor welcomes discussion on all papers published in Geosynthetics International. Please email your contribution to discussion@geosynthetics-international.com by 15 August 2015. 